IVONETE ÁVILA

\title{
Estudo TERMOGRAVIMÉTRICO DA ABSORÇÃo DE DIÓXIDO dE ENXOFRE POR CALCÁRIO
}

Dissertação apresentada à Escola de Engenharia de São Carlos da Universidade de São Paulo, como parte dos requisitos para a obtenção do título de Mestre em Engenharia Mecânica.

Orientador: Prof. Dr. Fernando Eduardo Milioli 


\section{Dedico}

Aos meus pais Affonso (in memoriam) e Zelinda que com luta, dedicação e amor, me prepararam para a vida.

Às minhas filhas Maísa e Diana que me motivam a acreditar em um futuro melhor

Ao meu amado marido Carlos pelo amor, compreensão, incentivo e apoio incondicional em todos os momentos. 


\section{AGRADEÇO:}

Ao Prof. Dr. Fernando Eduardo Milioli pela orientação, incentivo, confiança e valiosas sugestões além da grande amizade.

Em especial à Dra. Paula Manoel Crnkovic, amiga e co-orientadora deste trabalho, minha grande admiração e respeito por sua capacidade e entusiasmo nas investigações científicas e motivação do grupo.

Aos professores do NETeF, Antônio Moreira, Geraldo Lombardi, Josmar D. Pagliuso, Paulo Seleghim Júnior e Sérgio R. Fontes, pelos ensinamentos e ética profissional.

Aos técnicos do laboratório Hélio J. D. Trebbi, José F. Torres, Pedro Donisete Luchesi, Roberto A. Lourenço e Theodomiro Luchesi, pelo suporte nos problemas experimentais e, Jorge N. dos Santos e Roberto C. Pratavieira, pelo apoio e atenção nos problemas computacionais.

Aos colaboradores da secretaria do NETeF e secretaria da pósgraduação do departamento de engenharia mecânica.

Aos colegas do departamento NETeF pelos momentos compartilhados, que fez com o tempo passasse de forma mais prazerosa durante o desenvolvimento deste trabalho, em especial aos amigos: Cecília, Christian, Deuzuita, Érika, Juliana, Julio, Keyll e Manoel.

Ao CNPq pelo suporte financeiro. 
"A cinética é a maneira da natureza evitar que aconteça tudo de uma única vez".

S.E. LeBlanc 


\section{SUMÁRIO}

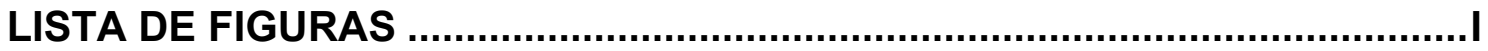

LISTA DE TABELAS

LISTA DE APÊNDICES....................................................................... IV

LISTA DE SÍMBOLOS ......................................................................... V

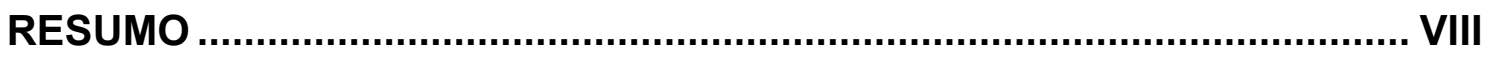

ABSTRACT

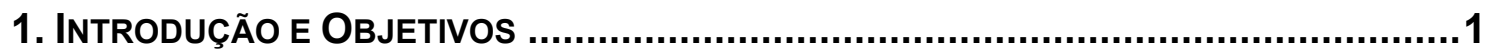

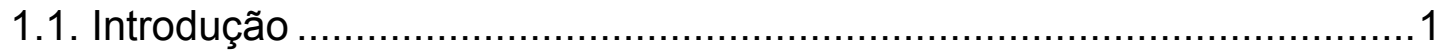

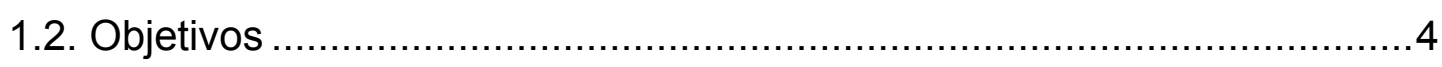

2. ESTADO DA ARTE

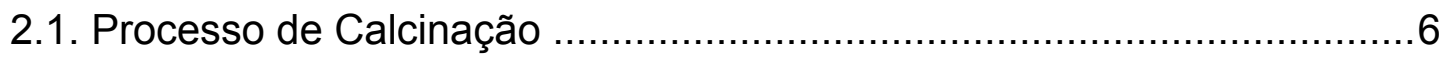

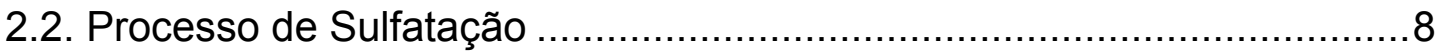

2.3. Cinética Química do Processo de Sulfatação de Calcários ...................12

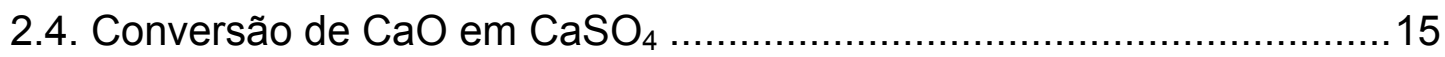

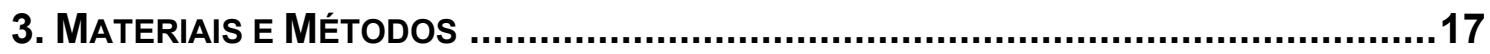

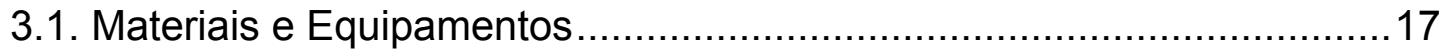

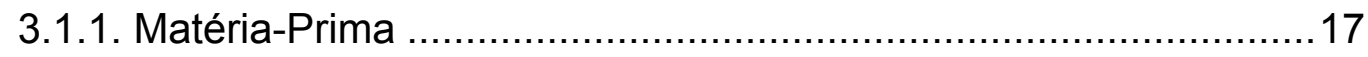

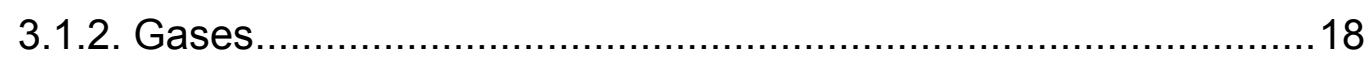

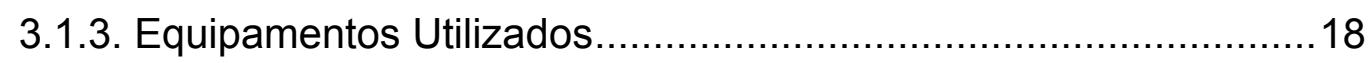

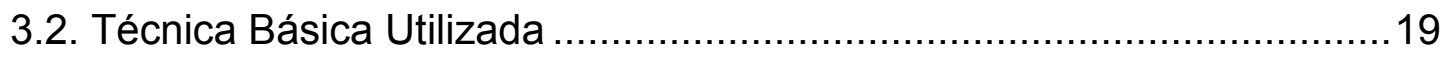

3.2.1. Procedimento de Operação da Balança Termogravimétrica........21

3.2.2. Procedimento nas Condições Experimentais Adotadas no Estudo

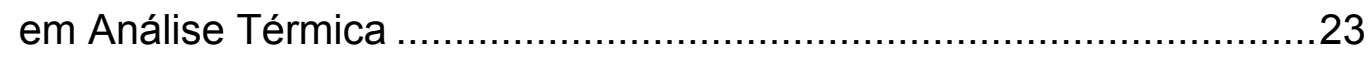

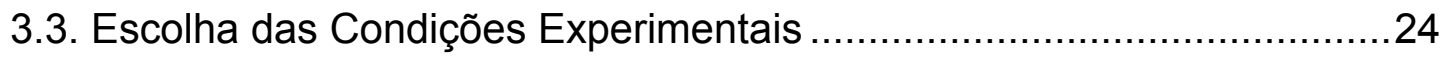

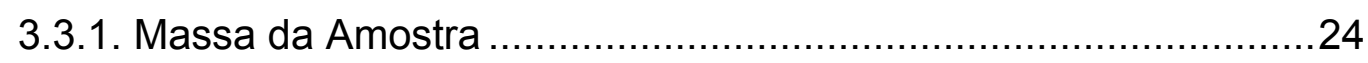

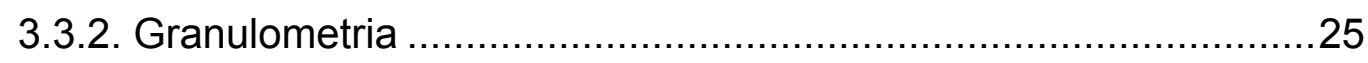

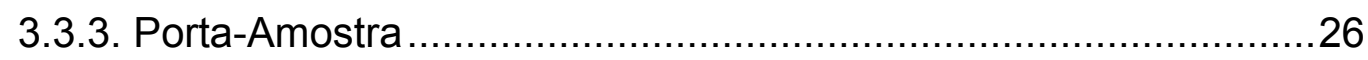

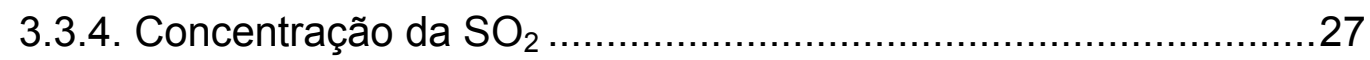


3.4. Obtenção dos Parâmetros Cinéticos ............................................27

3.5. Cálculo da Efetividade ............................................................ 34

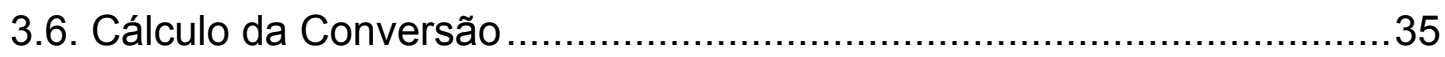

3.7. Avaliação Estatística dos Resultados ............................................ 37

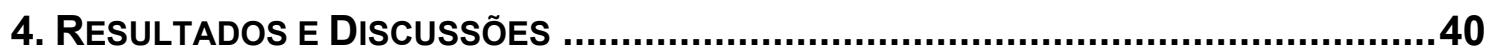

4.1. Estudo Cinético-Químico da Reação de Sulfatação ............................40

4.2. Efetividade da Reação de Sulfatação .................................................46

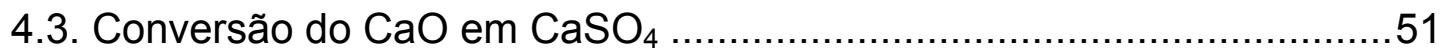

4.4. Avaliação Estatística dos Resultados ............................................56

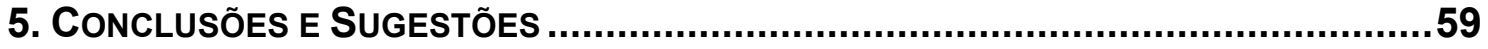

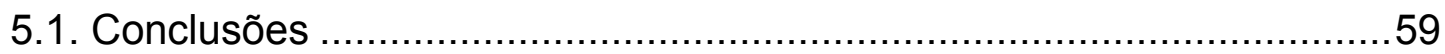

5.2. Sugestões para Trabalhos Futuros ............................................61

REFERÊNCIAS BIBLIOGRÁFICAS ......................................................63

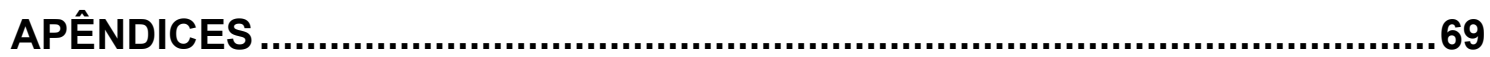


Figura 1: Balança Termogravimétrica Shimadzu $51 \mathrm{H}$

Figura 2: Sistema Termogravimétrico com aquisição de dados (CRNKOVIC, 2003). 22

Figura 3: Curva TG obtida em um ensaio a $900{ }^{\circ} \mathrm{C}$ em atmosfera dinâmica de nitrogênio.

Figura 4: Porta amostra de alumina. 26

Figura 5: Dados obtidos nas curvas TG e DTG para o cálculo da massa de cálcio e magnésio disponíveis para a reação e de sua taxa. 34

Figura 6: Conjunto de Curvas TG de 4 testes aplicados a $900{ }^{\circ} \mathrm{C}$ em atmosfera de nitrogênio.

Figura 7: Conjunto de Curvas DTG das curvas TG da Figura 6 de 4 testes aplicados a $900{ }^{\circ} \mathrm{C}$ em atmosfera de nitrogênio.

Figura 8: Valores médios de $\ln \left[-\left(\frac{1}{m} \frac{d m}{d t}\right)_{\max } \mid\right.$ versus $1 / \mathrm{T}$ para os ensaios isotérmicos nas temperaturas de 750 à $950{ }^{\circ} \mathrm{C}$ em atmosfera dinâmica de ar. As barras indicam o desvio padrão em relação à média.

Figura 9: Valores médios de $\ln \left\lfloor-\left(\frac{1}{m} \frac{d m}{d t}\right)_{\max }\right\rfloor$ versus $1 / \mathrm{T}$ para os ensaios isotérmicos nas temperaturas de 650 a $850{ }^{\circ} \mathrm{C}$ em atmosfera dinâmica de ar. As barras indicam o desvio padrão em relação à média.

Figura 10: Valores médios de $\ln \left[-\left(\frac{1}{m} \frac{d m}{d t}\right)_{\max }\right\rfloor$ versus 1/T para os ensaios isotérmicos nas temperaturas de 750 à $950{ }^{\circ} \mathrm{C}$ em atmosfera dinâmica de nitrogênio. As barras indicam o desvio padrão em relação à média. .45

Figura 11: Efetividade versus tempo de sulfatação em atmosfera dinâmica de ar nas temperaturas estudadas. O tempo de $100 \mathrm{~s}$ equivale ao tempo de $k_{\max }=\left\lfloor-\left(\frac{1}{m} \frac{d m}{d t}\right)_{\max }\right\rfloor \ldots$ 
Figura 12: Efetividade versus tempo de sulfatação em atmosfera dinâmica de nitrogênio nas temperaturas estudadas. O tempo de $100 \mathrm{~s}$ equivale ao tempo de $k_{\max }=\left[-\left(\frac{1}{m} \frac{d m}{d t}\right)_{\max }\right\rfloor$.....

Figura 13: Efetividade média da absorção de enxofre pelo calcário em atmosferas dinâmicas de ar e de nitrogênio, em função da temperatura. .50

Figura 14: Valores médios da variação de massa na sulfatação do calcário em função do tempo em atmosfera de ar, nas condições isotérmicas de $750,800,850,900$ e $950{ }^{\circ} \mathrm{C}$

Figura 15: Valores médios da variação de massa na sulfatação do calcário em função do tempo em atmosfera de nitrogênio, nas condições isotérmicas de $750,800,850,900$ e $950{ }^{\circ} \mathrm{C}$.

Figura 16: Curvas TG da calcinação do calcário $\mathrm{Cl}$ previamente calcinado e hidratado, seguida de sulfatação nas temperaturas de 700, 800 e $900{ }^{\circ} \mathrm{C}$. Condições: razão de aquecimento: $30{ }^{\circ} \mathrm{C} \min ^{-1}$. A numeração indica: (1) perda de água (2) desidroxilação e (3) perda de $\mathrm{CO}_{2 \cdot}$ (CRNKOVIC, 2003). .53

Figura 17: Conversão percentual da absorção de enxofre pelo $\mathrm{CaO}$ em atmosfera dinâmica de ar e de nitrogênio em função da temperatura. As barras indicam o desvio padrão em relação à média. 55 
Tabela 1:Reação de Ca-S em função da temperatura ("+" representa "maior que") - Anthony e Granatstein (2001)..................................... 8

Tabela 2: Composição química elementar (\% massa/massa) do calcário $\mathrm{Cl}$ (CRNKOVIC, 2003).

Tabela 3: Valores de ganho de massa na sulfatação para diferentes massas de amostra de calcário calcítico (CRNKOVIC, 2003).

Tabela 4: Frações mássicas e massa molecular dos componentes reacionais 33

Tabela 5: Área abaixo da curva de efetividade e efetividade média na sulfatação do calcário, em atmosfera de ar nas temperaturas estudadas

Tabela 6: Área abaixo da curva de efetividade e efetividade média na sulfatação do calcário, em atmosfera de nitrogênio nas temperaturas estudadas

Tabela 7: Conversão média percentual da absorção de Enxofre pelo calcário $\mathrm{CaO}$ em atmosferas de ar e nitrogênio .54

Tabela 8: Análise estatística dos valores de $\ln \left(k_{\max }\right)$ obtidos no estudo cinéticoquimico na absorção de enxofre por calcário em atmosfera de ar e de nitrogênio. .57

Tabela 9: Análise estatística dos resultados de conversão obtidos em atmosferas de ar e de nitrogênio 
Apêndice 1: Curvas TG e DTG de todas as temperaturas ensaiadas em atmosfera de ar .70

Apêndice 2: Curvas TG e DTG de todas as temperaturas ensaiadas em atmosfera de nitrogênio .77

Apêndice 3: Resumo dos dados e equações utilizadas para os cálculos em atmosfera de Ar Sintético

Apêndice 4: Resumo dos dados e equações utilizadas para os cálculos em atmosfera de Nitrogênio. 83

Apêndice 5: Planilha de Cálculo dos Dados Cinéticos em atmosfera de ar......84 Apêndice 6: Planilha de Cálculo dos Dados Cinéticos em atmosfera de nitrogênio 85

Apêndice 7: Planilha de Cálculo da Conversão em atmosfera de ar ..... 86

Apêndice 8: Planilha de Cálculo da Conversão em atmosfera de nitrogênio....87

Apêndice 9: Planilha de Cálculo da Efetividade para 1 experimento a $950{ }^{\circ} \mathrm{C}$ em atmosfera de Ar Sintético. .88

Apêndice 10: Planilha de Cálculo da Efetividade para 1 experimento a $950{ }^{\circ} \mathrm{C}$ em atmosfera de nitrogênio 


\section{SímBolos GeRAIS:}

A $\quad$ - fator pré-exponencial ou fator de freqüência

$a, b \quad$ - ordem da reação global em relação a cada um dos gases reagentes

CV - coeficiente de variação

$C_{\mathrm{SO}_{2}}$ - Concentração de $\mathrm{SO}_{2}$ na atmosfera da balança

$\mathrm{C}_{\mathrm{O}_{2}}$ - concentração de $\mathrm{SO}_{2}$ na atmosfera da balança

$\frac{d m}{d t} \quad$ - taxa de reação de Ca e Mg disponíveis na amostra de calcário

$\left[\mathrm{kg} \cdot \mathrm{s}^{-1}\right]$

$\frac{d M}{d t} \quad$ - taxa de reação da amostra de calcário

$E_{a} \quad-\quad$ energia de ativação

$k \quad$ - coeficiente de taxa de reação

$k_{\text {Max }} \quad$ - coeficiente de taxa de reação máximo

$m \quad$ - massa de cálcio e magnésio disponíveis para a reação

M - Massa da amostra

[kg]

$M_{A} \quad$ - Massa inicial da amostra (calcário natural)

$M_{c} \quad$ - massa do calcário calcinado

$M_{F} \quad$ - massa final após sulfatação completa

$M_{s} \quad$ - massa do calcário sulfatado

[kg]

$N \quad$ - quantidade de repetições

$\mathrm{n}_{\mathrm{SO}_{2}} \quad$ - quantidade molar de $\mathrm{SO}_{2}$

$n_{C a} \quad$ - quantidade molar de Cálcio $\quad$ [mol]

$n_{e} \quad$ - quantidade de moles da espécie química que entra no processo 


\begin{tabular}{|c|c|c|c|}
\hline$n_{M g}$ & - & quantidade molar de Magnésio & [mol] \\
\hline$n_{s}$ & - & quantidade de moles da espécie química que sai do processo & [mol] \\
\hline$R$ & - & constante universal dos gases & {$\left[\mathrm{kJ} \cdot \mathrm{mol}^{-1} \cdot \mathrm{K}\right]$} \\
\hline$T$ & - & temperatura absoluta & {$[\mathrm{K}]$} \\
\hline$t_{\infty}$ & - & tempo final de sulfatação (500 s após tempo zero) & [s] \\
\hline$t_{0}$ & - & tempo zero (100 s antes do pico máximo da curva DTG) & {$[\mathrm{s}]$} \\
\hline$t_{r}$ & - & tempo de residência & [s] \\
\hline$W_{C a}$ & - & massa molar de cálcio & {$\left[\mathrm{kg} \cdot \mathrm{kmol}^{-1}\right]$} \\
\hline$W_{C a}$ & - & massa molar de cálcio & {$\left[\mathrm{kg} \cdot \mathrm{kmol}^{-1}\right]$} \\
\hline$W_{M g}$ & - & massa molar de magnésio & {$\left[\mathrm{kg} \cdot \mathrm{kmol}^{-1}\right]$} \\
\hline$W_{M g}$ & - & massa molar de magnésio & {$\left[\mathrm{kg} \cdot \mathrm{kmol}^{-1}\right]$} \\
\hline$W_{\mathrm{SO}_{2}}$ & - & massa molar de $\mathrm{SO}_{2}$ & {$\left[\mathrm{~kg} \cdot \mathrm{kmol}^{-1}\right]$} \\
\hline$W_{\mathrm{O}_{2}}$ & - & massa molar do $\mathrm{O}_{2}$ & {$\left[\mathrm{~kg} \cdot \mathrm{kmol}^{-1}\right]$} \\
\hline$x$ & - & Conversão de $\mathrm{CaO}$ em $\mathrm{CaSO}_{4}$ & [\%] \\
\hline$x_{i}$ & - & valores obtidos em cada repetição dos ensaios & \\
\hline $\bar{x}$ & - & média aritmética & \\
\hline$Y_{C a}$ & - & fração em massa de cálcio no calcário natural & [adm.] \\
\hline$Y_{C a}$ & - & fração molar de cálcio & [adm.] \\
\hline$Y_{M g}$ & - & fração em massa de magnésio no calcário natural & [adm.] \\
\hline$Y_{M g}$ & - & fração molar de magnésio & [adm.] \\
\hline
\end{tabular}




\section{Símbolos Gregos}

\begin{tabular}{|c|c|c|}
\hline$\eta$ & - fator de efetividade & [adm.] \\
\hline$\sigma$ & - desvio padrão & \\
\hline$\Delta H$ & - entalpia de Formação & {$\left[\mathrm{kJ} \cdot \mathrm{g}^{-1} \cdot \mathrm{mol}^{-1}\right]$} \\
\hline$\Delta M$ & - variação de massa do calcário calcinado & [kg] \\
\hline dia & - efetividade média & {$\left[\mathrm{s}^{-1}\right]$} \\
\hline
\end{tabular}


ÁVILA, Ivonete (2005). Estudo Termogravimétrico da Absorção de Dióxido de Enxofre por Calcário. 97p. Dissertação (Mestrado). Escola de Engenharia de São Carlos, Universidade de São Paulo, São Carlos.

Neste trabalho determina-se, através da termogravimetria, o efeito da temperatura e atmosfera sobre a conversão, a cinética e a efetividade da absorção de $\mathrm{SO}_{2}$ por calcário. Aplica-se temperaturas e tamanho de particulado típicos do processo de combustão de carvão em leito fluidizado. Foram realizados ensaios isotérmicos em diferentes temperaturas (entre 650 e $950{ }^{\circ} \mathrm{C}$ ), na pressão atmosférica local ( $697 \mathrm{mmHg}$ ), em atmosferas dinâmicas de ar e de nitrogênio. Os resultados de sulfatação foram avaliados empregando-se a cinética de Arrhenius. A ordem de grandeza dos valores de energia de ativação obtidos $\left(4,446 \mathrm{~kJ} \mathrm{~mol}^{-1} \mathrm{em}\right.$ ar e 3,748 $\mathrm{kJ} \mathrm{mol}^{-1} \mathrm{em}$ nitrogênio) sugere que o processo reativo seja controlado por difusão de Knudsen. A temperatura ótima de conversão resultou entre 800 e $850{ }^{\circ} \mathrm{C}$ em ar, e muito próxima de $900{ }^{\circ} \mathrm{C}$ em nitrogênio. Definiu-se efetividade como a relação entre o coeficiente de taxa de reação instantâneo e o seu valor máximo, indicando o decaimento temporal da reatividade da amostra com o progresso da sulfatação. Determinou-se a efetividade média para todas as temperaturas no intervalo de tempo em que a sulfatação se desenvolveu, sempre em torno de 200 s nos vários ensaios. Os maiores valores de efetividade média foram a $800{ }^{\circ} \mathrm{C}$ em atmosfera de ar $(0,2854)$, e a $900{ }^{\circ} \mathrm{C}$ em atmosfera de nitrogênio $(0,3142)$.

Palavras-Chave: Termogravimetria, sulfatação, calcário, dióxido de enxofre, cinética química. 
ÁVILA, Ivonete (2005). Thermogravimetric Study of Sulfur Dioxide Absorption by Limestone. 97p. M.Sc. Dissertation. Escola de Engenharia de São Carlos, Universidade de São Paulo, São Carlos.

In this work thermogravimetry is applied to determine the effect of temperature and atmosphere on conversion, kinetics and effectiveness of $\mathrm{SO}_{2}$ absorption by limestone. Ranges of temperature and particle size were applied that are typical of the fluidized bed coal combustion process. Isothermal experiments were performed for different temperatures (between 650 and $950{ }^{\circ} \mathrm{C}$ ), at local atmospheric pressure $(\sim 697 \mathrm{mmHg})$, in dynamic atmospheres of air and nitrogen. The results of sulfation were evaluated using Arrhenius' kinetics. The order of magnitude of the resulting activation energies $\left(4.446 \mathrm{~kJ} \mathrm{~mol}^{-1}\right.$ in air and $3.748 \mathrm{~kJ} \mathrm{~mol}^{-1}$ in nitrogen) suggest the reaction to be controlled by Knudsen diffusion. Optimum conversion resulted between 800 and $850{ }^{\circ} \mathrm{C}$ in ar, and around $900{ }^{\circ} \mathrm{C}$ in nitrogen. Effectiveness was defined as the ratio between the instantaneous reaction rate coefficient and its maximum value, indicating the time decay of reactivity as sulfation advances. The average effectiveness was determined for all the temperatures considering the whole sulfation time interval, which was always around 200 seconds. The highest values of average effectiveness were found at $800{ }^{\circ} \mathrm{C}$ in air atmosphere $(0,2854)$, and $900{ }^{\circ} \mathrm{C}$ in nitrogen atmosphere $(0,3142)$.

Keywords: thermogravimetry, sulfation, limestone, sulfur dioxide, chemical kinetcs. 


\section{Capítulo 1}

\section{INTRODUÇÃO E OBJETIVOS}

\subsection{INTRODUÇÃO}

Óxidos de Enxofre $\left(\mathrm{SO}_{\mathrm{x}}\right)$, de um modo geral, são substâncias responsáveis por significativa poluição atmosférica. Atividades antropogênicas e naturais produzem os $\mathrm{SO}_{\mathrm{x}}$. Tais emissões contribuem para aumentar a acidez na atmosfera, sendo o dióxido de enxofre $\left(\mathrm{SO}_{2}\right)$ um dos principais causadores da chuva ácida. Embora o efeito ácido seja neutralizado no contato com substâncias alcalinas presentes na água e no solo, este equilíbrio é rompido principalmente em regiões industrializadas devido a grande emissão de $\mathrm{SO}_{2}$.

A queima de combustíveis fósseis com elevados teores de enxofre para produção de energia é reconhecida como a principal fonte de emissão de $\mathrm{SO}_{2}$ na atmosfera (LI e SADAKATA, 1999). Entre os combustíveis poluidores de utilização em larga escala destacam-se os carvões minerais e os óleos pesados derivados do petróleo.

O carvão mineral constitui-se em importante fonte de energia não renovável do Brasil e apresenta-se como alternativa viável para suprir as crescentes demandas no setor energético brasileiro. As reservas disponíveis conhecidas estão estimadas em 32 milhões de toneladas, e são suficientes para séculos de exploração termoelétrica em larga escala.

Os problemas freqüentemente associados à queima dos carvões minerais referem-se principalmente à poluição ambiental. $O$ carvão nacional está na categoria de "Carvão Betuminoso de Alto Volátil C, não Coqueificável" 
da classificação ASTM. Possui altos teores de cinzas, que variam de 40 a $60 \%$ e altos teores de enxofre (de 1 a $6 \%$ ).

Absorventes calcários são largamente empregados para remoção de óxidos de enxofre de gases da combustão. No processo de combustão em leito fluidizado, por exemplo, é injetado na própria câmara de combustão promovendo remoção de $\mathrm{SO}_{x}$ "in loco", no mesmo ambiente em que é formado (VAN HOUTE e DELMON, 1979). Quando expostos às temperaturas elevadas os calcários calcinam emitindo $\mathrm{CO}_{2}$ e formando óxido de cálcio $(\mathrm{CaO})$. O $\mathrm{CaO}$ resultante é altamente poroso e caracterizado por grande área superficial interna em comparação com o calcário original. Exposto a gases contendo $\mathrm{SO}_{2}$, o $\mathrm{CaO}$ sulfata produzindo principalmente sulfato de cálcio $\left(\mathrm{CaSO}_{4}\right)$. Com a evolução do processo reativo os poros das partículas de calcário calcinado são progressivamente bloqueados pelo produto $\mathrm{CaSO}_{4}$ e a área superficial interna é reduzida e/ou torna-se inacessível. A efetividade de reação é então progressivamente reduzida ao longo do processo (BRUCE et al., 1989; BORGWARDT e HARVEY, 1972; DENNIS e HAYHURST, 1990).

Técnicas de análise térmica são amplamente utilizadas em estudos de processos reativos heterogêneos de materiais complexos tais como absorção gás-sólido. As técnicas de análise térmica mais empregadas têm sido a termogravimétrica (TG), a térmica diferencial (DTA) e a calorimétrica de varredura (DSC e DSC pressurizada ou PDSC). Os ensaios TG mostram variações de massa de amostras em função do tempo e da temperatura durante um processo reativo. Taxas de variação de massa das amostras (denominadas curvas DTG) são determinadas para melhor identificação de regiões com diferentes taxas de reação. Picos DTG indicam pontos de máxima taxa de reação. Os ensaios DTA e DSC permitem detectar e quantificar as transações de energia nos processos reativos.

Parâmetros cinéticos de processos reativos podem ser obtidos a partir de resultados de ensaios de análise térmica. Para tal, necessita-se definir modelos descritivos destes processos. Há grande discussão na literatura relativa a qual modelo cinético é mais adequado para diferentes processos 
reativos de materiais complexos (BURNHAM e BRAUN, 1987).

Os métodos cinéticos tradicionais para reações gasosas de primeira e segunda ordem não aparentam ser adequados para estes processos. Em conseqüência, procedimentos alternativos, denominados análises cinéticas globais, têm sido propostos para lidar com a cinética reativa de materiais complexos.

Em processos reativos gás-sólido, por exemplo, os resultados cinéticos incorporam difusão gasosa intrapartícula, difusão de Knudsen (quando o diâmetro dos poros é menor que o livre caminho médio entre moléculas do gás) e difusão iônica. Assim, são comuns na literatura definições como energia cinética aparente e ordem de reação aparente.

Dois procedimentos têm sido seguidos para a determinação de parâmetros cinéticos a partir de dados de análise térmica (OZAWA, 1965). Em um deles integra-se equações de taxa global de reação em função da temperatura, gerando relações que, com a inclusão de dados empíricos termo-analíticos, permitem a determinação dos parâmetros cinéticos. O outro procedimento, mais comum, consiste em transformar as equações de taxa global de reação para formas lineares, e então obter parâmetros cinéticos por regressão linear.

O coeficiente de taxa de reação $(k)$, é freqüentemente modelado pela expressão de Arrhenius, desenvolvida a partir da teoria cinética de gases,

$$
k(T)=A \exp \left(-\frac{E_{a}}{R T}\right)
$$

sendo $A$, o fator de freqüência ou pré-exponencial, representando a freqüência de colisões efetivas entre moléculas, e $E_{a}$ a energia de ativação, definida como a energia necessária para mover os reagentes através da barreira energética de forma que a reação possa ocorrer.

' BRAUN, R. L. e BURNHAM, A. K. Energy \& Fuels, 1(1987)153-161. (apud BURNHAM e BRAUN, 1999). 
Choques molecular efetivos e com energia igual ou superior a de ativação produzem complexos ativados, estruturas moleculares instáveis que dão origem aos produtos. A equação de Arrhenius tem apenas justificação qualitativa quando aplicada a processos reativos complexos (BURNHAM e BRAUN, 1999). Contudo, o atual estado do conhecimento em cinética de reações complexas ainda não se produziu alternativa claramente melhor, e a expressão de Arrhenius mantém-se largamente utilizada.

Em estudos cinético-químicos via técnicas de análise térmica pode-se aplicar procedimentos isotérmicos e não isotérmicos. Há uma considerável literatura argumentando a favor de cada um dos procedimentos tendo em vista diferentes processos reativos de diferentes materiais (PRASAD et al., 1992). Os ensaios isotérmicos são desejáveis para estudos de sistemas de combustão onde combustível e outros reagentes são rapidamente aquecidos e os processos reativos ocorrem, na sua maior parte, em condições aproximadamente isotérmicas. Esse é o caso, por exemplo, dos processos de combustão e absorção de $\mathrm{SO}_{2}$ por calcários em reatores de leito fluidizado.

Este trabalho insere-se no contexto do programa de pesquisas em energia e poluição do Núcleo de Engenharia Térmica e Fluidos (NETeF), da Escola de Engenharia de São Carlos (EESC) da Universidade de São Paulo (USP). Uma das metas deste programa é contribuir para o uso dos carvões minerais brasileiros na geração termoelétrica, desenvolvendo tecnologia adequada à redução de emissões poluentes. Neste trabalho aplica-se técnicas termogravimétricas para o estudo do processo de absorção de $\mathrm{SO}_{2}$ por calcários.

\subsection{Objetivos}

Neste trabalho estuda-se a influência da temperatura e atmosfera no processo de absorção do dióxido de enxofre por calcário. Aplica-se termogravimetria considerando-se condições típicas do processo de combustão em leito fluidizado. Espera-se contribuir para a geração de informações que sirvam como subsídios para a melhor compreensão e otimização de projeto de 
sistemas de dessulfuração, e para o desenvolvimento de modelos de simulação.

Os objetivos específicos deste trabalho são:

- Estabelecer parâmetros cinético-químicos (fator pré-exponencial e energia de ativação aparente), conversão e efetividade transiente de reação na sulfatação de calcários, empregando termogravimetria.

- Avaliar efeitos da temperatura e da atmosfera reativa sobre os parâmetros cinéticos, conversão e efetividade transiente de reação. 


\section{Capítulo 2}

\section{ESTADO DA ARTE}

\subsection{Processo de Calcinação}

$\mathrm{Na}$ decomposição térmica ou calcinação de calcários produz-se principalmente $\mathrm{CaO}$ e MgO. Pettijohn (1957) classifica os calcários em função do teor de $\mathrm{MgO}$ presente após calcinação: calcítico (0 a 1,1\%); magnesiano (1,1 a 2,1\%); e dolomítico (2,1 a 10,8\%).

Com base na forma cristalina de $\mathrm{CaCO}_{3}$, os calcários podem ser classificados como calcítico (romboédrica) e aragonite (ortorrômbica). Este último é meta-estável na presença da água e lentamente se recristaliza para o calcítico. A maioria dos calcários se apresenta na forma do calcítico, que é tipicamente o sorvente utilizado em reatores de leito fluidizado (ANTHONY e GRANATSTEIN, 2001).

Outro sorvente a base de $\mathrm{Ca}$ e $\mathrm{Mg}$ é a dolomita, que quando quimicamente puro tem a fórmula molecular $\mathrm{CaMg}\left(\mathrm{CO}_{3}\right)_{2}$. Sua forma cristalina é romboédrica. A razão molar Ca:Mg na dolomita normalmente é de 1 a 1,2. Muitos calcários possuem dolomita na sua composição (ANTHONY e GRANATSTEIN, 2001).

O calcário natural possui estrutura interna compacta e densa com baixa porosidade, podendo esta variar com a idade geológica. Em geral calcários de idade geológica mais antiga possuem uma estrutura física interna mais compacta quando comparados aos de idade geológica mais nova, que possuem estrutura mais porosa (DAM-JOHANSEN e OSTERGAARD, 1991). 
Quando submetido a altas temperaturas o calcário natural absorve energia para calcinar, formando o $\mathrm{CaO}$ com a liberação de $\mathrm{CO}_{2}$ de sua estrutura interna. A reação é mostrada na equação [2].

$$
\mathrm{CaCO}_{3}(\mathrm{~s}) \rightarrow \mathrm{CaO}(\mathrm{s})+\mathrm{CO}_{2}(\mathrm{~g}) \quad \Delta \mathrm{H}=+182,1 \mathrm{~kJ} \mathrm{~g}^{-1} \mathrm{~mol}^{-1}
$$

O volume molar do calcário natural $\left(\mathrm{CaCO}_{3}\right)$ é aproximadamente $36,9 \mathrm{~cm}^{3} \mathrm{~mol}^{-1}$, e após calcinação $(\mathrm{CaO})$ seu volume molar é aproximadamente $16,9 \mathrm{~cm}^{3} \mathrm{~mol}^{-1}$ (DAM-JOHANSEN e OSTERGAARD, 1991). O aumento da porosidade do calcário após calcinação é devido à diferença entre o volume molar do absorvente natural e o volume molar de $\mathrm{CaO}$ formado. Como o tamanho de partícula do calcário permanece praticamente o mesmo, a porosidade aumenta com a calcinação (HARTMAN e COUGHLIN, 1976; SIMONS et al., 1987).

Crnkovic (2003) analisou por microscopia eletrônica e porosimetria a estrutura física de partículas de um calcário calcítico, natural e calcinado. A autora observou que o calcário calcinado apresenta-se com maior porosidade e área superficial BET comparado ao calcário natural.

Dam-Johansen e Ostergaard (1991) investigaram a relação entre a compactação de calcários com seu tempo de calcinação. Notaram que calcários mais compactos são caracterizados por longos tempos de calcinação, indicando que este processo é controlado pelo transporte intrapartícula de $\mathrm{CO}_{2}$.

Mai e Edgar (1989) estudaram a evolução da área superficial do hidróxido de cálcio durante o processo de calcinação e de sinterização nas temperaturas de 1011 e $1151{ }^{\circ} \mathrm{C}$. Observam que a sinterização que se desenvolve em paralelo com a calcinação afeta consideravelmente a estrutura porosa dos calcários, reduzindo sua área superficial específica.

Borgwardt (1985) investigou o efeito da temperatura (entre 516 e $1000{ }^{\circ} \mathrm{C}$ ) na conversão de $\mathrm{CaCO}_{3}$ em $\mathrm{CaO}$ em balança termogravimétrica. Os resultados mostraram que a maior conversão em função do tempo de calcinação, ocorreu na temperatura de $1000{ }^{\circ} \mathrm{C}$ e não observou influência do 
tamanho de partícula. O autor concluiu que a conversão e a taxa de sinterização aumentam com o aumento da temperatura.

Davini et al. (1991) estudaram o efeito da temperatura e do tempo de reação no decréscimo da área $\mathrm{BET}$ de partículas de $\mathrm{CaO}$ devido à sinterização. O $\mathrm{CaO}$ foi obtido via decomposição térmica de $\mathrm{Ca}(\mathrm{OH})_{2}$ e de $\mathrm{CaCO}_{3}$. Observaram diminuição da área superficial BET com 0 aumento da temperatura de calcinação para o $\mathrm{CaO}$ proveniente de ambos, $\mathrm{Ca}(\mathrm{OH})_{2}$ e $\mathrm{CaCO}_{3}$. Para o primeiro, a redução de área variou entre $20 \mathrm{~m}^{2} \mathrm{~g}^{-1}$ a $800{ }^{\circ} \mathrm{C} \mathrm{e}$ $1 \mathrm{~m}^{2} \mathrm{~g}^{-1}$ a $1200{ }^{\circ} \mathrm{C}$. Para o $\mathrm{CaO}$ originado do $\mathrm{CaCO}_{3}$ a perda de área superficial variou entre $10 \mathrm{~m}^{2} \mathrm{~g}^{-1}$ a $800{ }^{\circ} \mathrm{C}$ e $1 \mathrm{~m}^{2} \mathrm{~g}^{-1}$ a $1200{ }^{\circ} \mathrm{C}$.

Muitos modelos para explicar o mecanismo da calcinação são encontrados na literatura (BORGWARDT, 1985; DENNIS e HAYHURST, 1987). De um modo geral, assume-se que as partículas de $\mathrm{CaCO}_{3}$ reagem de acordo com o modelo "shrinking-core" ou "unreacted-core". Através dos modelos propostos busca-se determinar a taxa de conversão de $\mathrm{CaCO}_{3}$ em CaO e o tempo para calcinação completa.

\subsection{Processo de Sulfatação}

Dependendo da temperatura e pressão parcial do $\mathrm{SO}_{2}$, diferentes espécies químicas podem ser produzidas pela reação de $\mathrm{SO}_{2}$ com $\mathrm{CaO}$. A Tabela 1 apresenta resultados de diferentes autores em diferentes condições (ANTHONY e GRANATSTEIN, 2001).

Tabela 1:Reação de Ca-S em função da temperatura ("+" representa "maior que") - Anthony e Granatstein (2001)

\begin{tabular}{||c|c|c||}
\hline $\begin{array}{c}\text { Faixa de Temperatura } \\
\left({ }^{\circ} \mathrm{C}\right)\end{array}$ & $\begin{array}{c}\text { Condições } \\
\text { Oxidantes }\end{array}$ & $\begin{array}{c}\text { Condição } \\
\text { Redutoras }\end{array}$ \\
\hline$<450$ & $\mathrm{CaSO}_{3}$ & \\
\hline$<650-700$ & $\begin{array}{c}\mathrm{CaSO}_{3}, \\
\mathrm{CaSO}_{4}\end{array}$ & $\begin{array}{c}\mathrm{CaSO}_{3}, \mathrm{CaSO}_{4} \\
\mathrm{CaS}\end{array}$ \\
\hline $700+$ & $\mathrm{CaSO}_{4}$ & \\
\hline $830+$ & & $\mathrm{CaS}, \mathrm{CaSO}_{4}$ \\
\hline
\end{tabular}

O conhecimento do mecanismo de reação pode fornecer informações 
preciosas acerca do comportamento do processo reativo. Entretanto, o mecanismo da sulfatação de calcários calcinados é ainda assunto de muitas controvérsias.

Há um consenso geral, que a reação global de sulfatação seja representada por:

$$
\mathrm{CaO}(\mathrm{s})+\mathrm{SO}_{2}(\mathrm{~g})+1 / 2 \mathrm{O}_{2}(\mathrm{~g}) \rightarrow \mathrm{CaSO}_{4}(\mathrm{~s})
$$

Entre as rotas de reação possíveis, as mais difundidas na literatura são:

$$
\begin{aligned}
& \mathrm{CaO}(\mathrm{s})+\mathrm{SO}_{2}(\mathrm{~g}) \rightarrow \mathrm{CaSO}_{3}(\mathrm{~s}) \\
& \mathrm{CaSO}_{3}(\mathrm{~s})+1 / 2 \mathrm{O}_{2}(\mathrm{~g}) \rightarrow \mathrm{CaSO}_{4}(\mathrm{~s}) \\
& \mathrm{SO}_{2}(\mathrm{~g})+1 / 2 \mathrm{O}_{2}(\mathrm{~g}) \rightarrow \mathrm{SO}_{3}(\mathrm{~g}) \\
& \mathrm{CaO}(\mathrm{s})+\mathrm{SO}_{3}(\mathrm{~g}) \rightarrow \mathrm{CaSO}_{4}(\mathrm{~s}) \\
& 4 \mathrm{CaO}(\mathrm{s})+4 \mathrm{SO}_{2}(\mathrm{~g}) \rightarrow 4 \mathrm{CaSO}_{3}(\mathrm{~s}) \\
& 4 \mathrm{CaSO}_{3}(\mathrm{~s}) \rightarrow 3 \mathrm{CaSO}_{4}(\mathrm{~s})+\mathrm{CaS}(\mathrm{s})
\end{aligned}
$$

Como observado por Dennis e Hayhurst (1990), as rotas [4] e [5] foram propostas por Moss (1975). A rota [6] foi proposta por Low et al. (1971).

Como observado em Anthony e Granatstein (2001), Moss sugeriu que as reações da rota [4] são importantes a baixas temperaturas onde $\mathrm{CaSO}_{3}$ é estável, enquanto as reações da rota [5] são dominantes a altas temperaturas $\left(>850{ }^{\circ} \mathrm{C}\right.$ ), devido a instabilidade do $\mathrm{CaSO}_{3}$.

Durante a conversão para $\mathrm{CaSO}_{4}$ os poros das partículas de $\mathrm{CaO}$ são preenchidos com produtos $\left(\mathrm{CaSO}_{4}, \mathrm{CaSO}_{3}, \mathrm{CaS}\right)$, e se tornam saturados. Mesmo em comparação com o calcário natural não calcinado, a estrutura física da partícula sulfatada torna-se mais compacta devido à diferença entre os volumes molares do $\mathrm{CaSO}_{4}\left(\sim 46 \mathrm{~cm}^{3} \mathrm{~mol}^{-1}\right)$ e do $\mathrm{CaCO}_{3}\left(\sim 36,9 \mathrm{~cm}^{3} \mathrm{~mol}^{-1}\right)$ (DAM-JOHANSEN e OSTERGAARD, 1991)..

Com a sulfatação as passagens para o gás reagente através do absorvente são bloqueadas. O bloqueio ocorre preferencialmente nas camadas mais externas das partículas, de tal modo que o seu núcleo torna-se 
praticamente inacessível (MATTISSON e LYNGFELT, 1998; DAM-JOHANSEN e OSTERGAARD, 1991; FUERTES et al., 1994; HSIA et al., 1993). Na medida em que o $\mathrm{CaSO}_{4}$ é formado, o calcário torna-se progressivamente desativado, a taxa da sulfatação decresce, e torna-se virtualmente impossível alcançar conversão completa do CaO para $\mathrm{CaSO}_{4}$ (MATTISSON e LYNGFELT, 1998).

A busca pelo fator limitante no mecanismo da reação de absorção de $\mathrm{SO}_{2}$ pelo $\mathrm{CaO}$, tem sido investigado por vários autores.

Dennis e Hayhurst (1990) investigaram o mecanismo da reação de sulfatação considerando efeitos das concentrações de $\mathrm{SO}_{2}, \mathrm{SO}_{3}, \mathrm{H}_{2} \mathrm{O}$ e $\mathrm{O}_{2}$ no ambiente. Os resultados obtidos sugerem que o $\mathrm{SO}_{2}$ em relação ao $\mathrm{SO}_{3}$ se difunde muito mais rapidamente pela camada do produto. Os autores concluíram que é a concentração de $\mathrm{O}_{2}$, e não a concentração de $\mathrm{SO}_{3}$, que é responsável pela limitação da reação. Estas observações foram feitas com base nas rotas [4] e [5].

Lindo (2003) investigou o efeito da concentração de $\mathrm{SO}_{2}$ nas reações de calcinação e sulfatação de calcários em reator de leito fluidizado. $O$ autor observou que a calcinação mostrou-se mais rápida e mais efetiva em maiores concentrações de $\mathrm{SO}_{2}$. Supostamente, nas concentrações de $\mathrm{SO}_{2}$ mais elevadas, o bloqueio de poros se intensifica nas camadas mais externas das partículas, formando "cascas" sulfatadas mais finas. Estas seriam rompidas pela passagem de $\mathrm{CO}_{2}$ para fora da partícula, provendo rota de acesso para a penetração do $\mathrm{SO}_{2}$.

Em vista das características do processo de sulfatação, parâmetros e propriedades físicas dos calcários assumem grande relevância no estabelecimento das taxas de reação. Efeitos destes parâmetros e propriedades são amplamente explorados na literatura.

Carello e Vilela (1993) investigaram via TG a absorção de $\mathrm{SO}_{2}$ por 5 tipos de calcários brasileiros da região sul (3 dolomíticos, 1 magnesiano e 1 calcítico). Observaram baixa influência da composição química do calcário no processo de remoção do $\mathrm{SO}_{2}$, e os teores de $\mathrm{MgO}$ presentes não contribuíram significativamente nas taxas de sulfatação. 
Adánez et al. (1996) estudaram a sulfatação de 5 diferentes calcários. Investigaram a evolução do tamanho e distribuição dos poros do sorvente e sua influência na capacidade de sulfatação. Observaram que sorventes calcinados com tamanho de poros acima de $100 \AA$ mostraram-se mais reativos e com maior capacidade de sulfatação. Estes ainda mantiveram poros com tamanhos < $80 \AA$ durante todo o processo nas condições de operação. Os sorventes com poros abaixo de $80 \AA$ se tornaram bloqueados durantes a sulfatação. Neste caso foram mais sensíveis às diferentes variáveis operacionais que afetam o processo de sulfatação, tais como a concentração de $\mathrm{SO}_{2}$ e a temperatura.

Dam-Johansen e Ostegaard (1991) determinaram a capacidade de absorção de $\mathrm{SO}_{2}$ de 23 diferentes calcários em reatores de leito fluidizado. Quanto à idade geológica, os calcários foram classificados como jovens, intermediários e velhos. Análises de microscopia eletrônica de varredura mostraram que calcários mais antigos apresentam estrutura física mais compacta. Concluíram que os calcários mais jovens (menos compactados) são bem mais reativos que os calcários mais antigos (mais compactados).

Yrjas et al. (1995) estudaram a sulfatação de 11 calcários calcíticos e 6 dolomíticos em analisador termogravimétrico. Os resultados mostraram que os calcários calcíticos, mais jovens (60 a 100 milhões de anos), alcançaram níveis de conversão mais altos em relação aos mais velhos (500 milhões de anos), independentemente da composição química. Os calcários calcíticos foram mais efetivos a $850{ }^{\circ} \mathrm{C}$, enquanto os dolomíticos mostraram-se mais efetivos a $950{ }^{\circ} \mathrm{C}$. Os autores concluíram que a reatividade dos calcários é função de suas propriedades físicas iniciais.

Silva (2001) investigou o efeito da granulometria do calcário na absorção de $\mathrm{SO}_{2}$ em batelada em reator de leito fluidizado borbulhante. O autor utilizou granulometria estreita de 2 tipos de calcário com diâmetro médio de 390, 462, 545, 650 e $770 \mu \mathrm{m}$. Observou que o coeficiente global de taxa de reação e a conversão aumentaram com a redução do diâmetro.

De um modo geral, os parâmetros e propriedades mais relevantes que afetam o processo de sulfatação de calcários são: porosidade, tamanho e 
distribuição de poros, área superficial interna (BORGWARDT e BRUCE, 1986; ADÁNEZ et al., 1993; LI e SADAKATA, 1999), idade geológica, tamanho e densidade das partículas (YRJAS et al., 1995). Um outro aspecto importante a considerar é a presença de componentes químicos nos calcários que possam agir como catalisadores ou envenenadores na sulfatação (DAM-JOHANSEN e OSTEGAARD, 1991).

\subsection{Cinética Química do Processo de Sulfatação de Calcários}

Supostamente, na sulfatação de calcários, $\mathrm{SO}_{2}$ e $\mathrm{O}_{2}$ ou $\mathrm{SO}_{3}$ penetram na partícula e através da camada de produto por difusão gasosa ou por difusão no estado sólido, encontrando $\mathrm{CaO}$ na interface entre $\mathrm{CaO}$ e $\mathrm{CaSO}_{4}$ onde ocorre a sulfatação. Outra possibilidade é que o $\mathrm{CaO}$ migre para fora do poro através da camada de produto por difusão iônica, encontrando $\mathrm{SO}_{2}$ e $\mathrm{O}_{2}$ ou $\mathrm{SO}_{3}$ na superfície exterior da camada de produto de $\mathrm{CaSO}_{4}$ onde a reação ocorre (HSIA et al., 1993; CHENG et al., 2003).

A identificação do mecanismo e do fator limitante das taxas de reação entre $\mathrm{CaO}$ e $\mathrm{SO}_{2}$ tem sido objeto de muitas pesquisas.

No início da década de 70 , foram feitos os primeiros trabalhos demonstrando a influência da estrutura interna dos poros das partículas de $\mathrm{CaO}$ na reação com $\mathrm{SO}_{2}$. Com isso passou-se a considerar aspectos físicos intrínsecos, e não apenas efeitos superficiais externos como até então considerados (BORGWARDT e BRUCE, 1986). Em um dos primeiros trabalhos, Pigford e Sliger (1973) observaram que partículas de calcário de 96 $\mu \mathrm{m}$ impunham significativa resistência à difusão a $980{ }^{\circ} \mathrm{C}$. Concluíram que a difusão de $\mathrm{SO}_{2}$ através das camadas do produto $\mathrm{CaSO}_{4}$ era o fator limitante da sulfatação.

Borgwardt e Harvey (1972) definiram um fator de efetividade para avaliar o efeito da porosidade sobre a efetividade na sulfatação de calcários calcinados. Definiram fator de efetividade como a razão entre a taxa de reação observada e o seu valor se todo o volume da partícula participasse igualmente da reação. Determinaram o fator de efetividade inicial (no inicio da absorção) 
para vários calcários. Para a maioria dos calcários o fator de efetividade inicial resultou entre 0,17 e 1 para partículas de $250 \mu \mathrm{m}$. Assim, dependendo do tipo de calcário, partículas grandes podem manter-se altamente efetivas ou tornar-se bastante não efetivas. Por outro lado, partículas menores podem manter considerável efetividade independente do tipo de calcário. Os autores observaram uma forte relação de dependência entre o fator de efetividade e a estrutura dos poros (volume, área e forma). Concluíram que a efetividade é dependente do preenchimento de camadas externas pelo produto $\mathrm{CaSO}_{4}$, tornando o $\mathrm{CaO}$ das camadas mais internas inacessível, e do bloqueio da entrada dos poros com conseqüente perda de área superficial.

James e Hughes (1976) ${ }^{\mathrm{ii}}$ apud Van Houte e Delmon (1979), realizaram experimentos de sulfatação de calcários em temperaturas entre 800 e $1050{ }^{\circ} \mathrm{C}$. Não observaram efeito significativo de resistências difusivas intrínsecas. Concluíram que a cinética química controla a taxa global de reação, predominando sobre a difusão em poros. A taxa de reação seguiu uma relação linear de Arrhenius com energia de ativação de $130 \pm 13 \mathrm{~kJ} \mathrm{~mol}^{-1}$.

lisa e Hupa (1992) estudaram a sulfatação em analisador termogravimétrico de um calcário de diâmetro médio entre 125 e $280 \mu \mathrm{m}$, e de carbonato de cálcio com distribuição de diâmetros entre 1 e $5 \mu \mathrm{m}$. Entre 650 e $800{ }^{\circ} \mathrm{C}$, a energia de ativação para o calcário resultou $133 \mathrm{~kJ} \mathrm{~mol}^{-1}$. Para o carbonato de cálcio resultou $75 \mathrm{~kJ} \mathrm{~mol}^{-1}$ entre 875 e $950{ }^{\circ} \mathrm{C}$. Concluíram que para as partículas maiores, a sulfatação é limitada pela difusão através da camada do produto, enquanto para as partículas menores, a sulfatação é controlada pela cinética da reação química.

Snow et al. (1988) e Hajaligol et al. (1988) realizaram estudos termogravimétricos de sulfatação em atmosferas com concentração de $\mathrm{CO}_{2}$ variável, incluindo casos de concentrações altas o suficiente para inibir a calcinação do $\mathrm{CaCO}_{3}$ (a sulfatação nesses casos é denominada direta). Ambos observaram a sulfatação direta mais efetiva que aquela precedida de calcinação. Atribuíram esse efeito ao desenvolvimento de porosidade na

\footnotetext{
ii James e Hughes (1976), paper presented at $2^{\text {nd }}$. Int. Conf. on Conf. of Gaseous Sulphur and Nitrogen Compound Emission, Salford (1979), apud Van Houte e Delmon (1979).
} 
camada do produto $\mathrm{CaSO}_{4}$, que ocorreria na sulfatação direta (devido ao fluxo de $\mathrm{CO}_{2}$ produzido durante a calcinação e favorecendo caminhos através das camadas de $\mathrm{CaSO}_{4}$ ). Concluíram que a sulfatação direta do $\mathrm{CaCO}_{3}$ é inicialmente controlada por cinética química, e que, após esta etapa inicial, a reação torna-se controlada por difusão através da camada do produto $\mathrm{CaSO}_{4}$. Hajaligol et al. (1988) observaram que a difusividade através da camada de $\mathrm{CaSO}_{4}$ varia com a conversão. Para conversão acima de 50 \%, reportaram energia de ativação na sulfatação direta de $146 \mathrm{~kJ} \mathrm{~mol}^{-1}$. Snow et al. (1988) reportaram $64 \mathrm{~kJ} \mathrm{~mol}^{-1}$ para sulfatação direta, e $205 \mathrm{~kJ} \mathrm{~mol}^{-1}$ para sulfatação com calcinação prévia.

Van Houte e Delmon (1979) investigaram a sulfatação direta em temperaturas baixas para evitar a calcinação. Para temperaturas em torno de $550{ }^{\circ} \mathrm{C}$ e conversões baixas, reportaram energia de ativação de $210 \mathrm{~kJ} \mathrm{~mol}^{-1}$; para conversão de $60 \%$ reportaram $110 \mathrm{~kJ} \mathrm{~mol}^{-1}$.

Tullin et al. (1993) investigaram a sulfatação direta de carbonato de cálcio em analisador termogravimétrico, em temperaturas entre 500 e $850{ }^{\circ} \mathrm{C}$. Para 30, 50 e $80 \%$ de $\mathrm{CO}_{2}$ na atmosfera reativa encontraram energias de ativação de, respectivamente, $95 \pm 14,77 \pm 20$ e $70 \pm 21 \mathrm{~kJ} \mathrm{~mol}^{-1}$. Estes valores foram determinados para conversões mais elevadas, e indicam que nessas condições o controle de reação se dá por difusão através do produto sólido.

Crnkovic (2003) realizou estudos termogravimétricos (TG) de sulfatação com diferentes tipos de calcário de diferentes procedências: (Calcítico $(\mathrm{Cl})$, Magnesiano (MI) e Dolomítico (DI) de Itaú de Minas-MG; Dolomítico (DP) de Ipeúna-SP; e Calcítico (CSJ) de São José da Lapa-MG). Utilizou amostras com faixas granulométricas estreitas entre 390 e $779 \mu \mathrm{m}$, em temperaturas de processo entre 600 e $900{ }^{\circ} \mathrm{C}$. Realizou experimentos de calcinação seguida de sulfatação. Crnkovic observa que a forma molecular $\mathrm{CaMg}\left(\mathrm{CO}_{3}\right)_{2}$ predominante no calcário mais jovem (DP) possivelmente permite a geração de estrutura porosa mais favorável à sulfatação em relação a forma molecular $\mathrm{CaCO}_{3}$ predominante no calcário mais velho $(\mathrm{Cl})$. Para ambos os calcários, a calcinação seguida de sulfatação, entre 825 e $900{ }^{\circ} \mathrm{C}$, mostrou máxima 
reatividade em torno de $850{ }^{\circ} \mathrm{C}$. A autora sugere que a queda de reatividade em temperaturas superiores pode ser explicada pela eliminação de porosidade e área superficial devido à sinterização de grãos de $\mathrm{CaO}$ e/ou dissociação do $\mathrm{CaSO}_{4}$ com re-emissão de $\mathrm{SO}_{2}$. Na sulfatação do calcário DP pré-calcinado de $650 \mu \mathrm{m}$ de diâmetro médio, em atmosfera de $\mathrm{SO}_{2}$, a energia de ativação aparente na condição de máxima taxa de reação resultou entre $5,3 \mathrm{~kJ} \mathrm{~mol}^{-1}$ (na faixa de $600-700{ }^{\circ} \mathrm{C}$ ), $11,6 \mathrm{~kJ} \mathrm{~mol}^{-1}$ (na faixa de $700-850{ }^{\circ} \mathrm{C}$ ) e $8,8 \mathrm{~kJ} \mathrm{~mol}^{-1}$ (na faixa de $\left.600-850^{\circ} \mathrm{C}\right)$.

Segundo Fuertes et al. (1994), diferentes autores (BHATIA e PERMUTTER, 1981; PIGFORD e SLIGER, 1973; GOPALAKRISHANAN e SEEHRA, 1990 iii) concordam que os altos valores reportados na literatura para energia de ativação na sulfatação de calcário calcinado (entre 121 e $167 \mathrm{~kJ} \mathrm{~mol}^{-1}$ ) não são satisfatoriamente explicados tendo em vista controle difusivo de reação. Nesse caso resultariam energias de ativação em torno de $12 \mathrm{~kJ} \mathrm{~mol}^{-1}$ para controle por difusão molecular, e $4 \mathrm{~kJ} \mathrm{~mol}^{-1}$ para controle por difusão de Knudsen.

\subsection{Conversão de CaO em $\mathrm{CaSO}_{4}$}

Dennis e Hayhurst (1990) determinaram a conversão e o coeficiente de taxa de reação na absorção de $\mathrm{SO}_{2}$ por calcário em leito fluidizado aquecido eletricamente, na presença de quantidades variáveis de $\mathrm{O}_{2}$ e $\mathrm{N}_{2}$. Os resultados mostraram que a conversão aumentou com o decréscimo da fração molar de $\mathrm{O}_{2}$. O coeficiente de taxa de reação diminui mais rapidamente no tempo com o aumento da fração de $\mathrm{O}_{2}$. Entretanto, os autores concluíram que a adição de uma pequena quantidade de $\mathrm{O}_{2}$ acelera a taxa de sulfatação no tempo sem que ocorra uma diminuição significativa na conversão.

LIPING et al. (2001) investigaram o efeito dos gases de reação, em ensaios não isotérmicos no intervalo de 250 a $1080{ }^{\circ} \mathrm{C}$, na captura do enxofre pelo calcário durante a combustão de carvão em leito fixo. Os ensaios foram

\footnotetext{
iii GOPALAKRISHANAN, R.; SEEHRA, M.S. (1990). Kinetics of the high-temperature reaction of $\mathrm{SO}_{2}$ with $\mathrm{CaO}$ using gas-phase Fourier transform infrared spectroscopy. Energy Fuels. 4: 226-230. (apud Fuertes et al., 1994).
} 
feitos em 3 atmosferas: $\mathrm{O}_{2}, \mathrm{O}_{2} / \mathrm{N}_{2}(1 / 1)$ e $\mathrm{N}_{2}$. Os resultados obtidos indicaram que a maior absorção de enxofre pelo calcário deu-se em atmosfera contendo $\mathrm{O}_{2}$ e a menor em atmosfera de $\mathrm{N}_{2}$.

Moss (1975) estudou o efeito da temperatura na eficiência de absorção de $\mathrm{SO}_{2}$ por partículas de calcário calcinado em leito fluidizado, com granulometria de 100 a $200 \mu \mathrm{m}$, fluidizado com gases da queima de óleo combustível com $4 \%$ de enxofre. Observou máxima conversão a $865{ }^{\circ} \mathrm{C}$.

Costa (2000) estudou o efeito da temperatura sobre a conversão e o coeficiente global de taxa de reação na absorção de $\mathrm{SO}_{2}$ por calcário em reator de leito fluidizado em escala de bancada. O autor utilizou o mesmo calcário estudado no presente trabalho em duas granulometria (545 e $650 \mu \mathrm{m}$ ). O resultado do coeficiente global de taxa de reação para o calcário com granulometria de $650 \mu \mathrm{m}$ indicou uma temperatura ótima de $881{ }^{\circ} \mathrm{C}$ para máxima absorção do $\mathrm{SO}_{2}$. 


\section{Capítulo 3}

\section{MATERIAIS E MÉTODOS}

Este trabalho é uma continuidade das pesquisas desenvolvidas no NETeF aplicando a termogravimetria no estudo da absorção de dióxido de enxofre por calcário.

Devido a isso as condições experimentais são baseadas em trabalhados anteriores. Uma ênfase maior é dada ao trabalho de Crnkovic (2003).

\subsection{MATERIAIS E EQUIPAMENTOS}

\subsubsection{MATÉRIA-PRIMA}

A matéria-prima utilizada neste trabalho é o calcário de Itaú de Minas, classificado como calcítico, i.e., contendo 0 a $1,1 \%$ de $\mathrm{MgO}$ no calcário calcinado, segundo Pettijohn (1997).

Seguindo a nomenclatura utilizada em trabalhos anteriores desenvolvidos no NETeF (COSTA, 2000; SILVA, 2001; SILVA, 2003; CRNKOVIC, 2003; MICHELS Jr. 2004), o calcário calcítico de Itaú de Minas, é denominado de calcário $\mathrm{Cl}$.

A composição química elementar do calcário $\mathrm{Cl}$ foi determinada por espectrometria de emissão atômica (ICP-AES). As condições de operação do equipamento e preparação de amostras para análise química em ICP-AES estão descritas em detalhes em Crnkovic (2003). Os resultados da composição 
química do calcário Cl são apresentados na Tabela 2.

Tabela 2: Composição química elementar (\% massa/massa) do calcário $\mathrm{Cl}$ (CRNKOVIC, 2003).

\begin{tabular}{||c|c|c|c|c|c|c|c||}
\hline \multirow{2}{*}{ Calcário } & \multicolumn{6}{|c||}{ Composição Química (fração em massa) } \\
\cline { 2 - 8 } & $\mathrm{Ca}$ & $\mathrm{Mg}$ & $\mathrm{Fe}$ & $\mathrm{Al}$ & $\mathrm{Sr}$ & $\mathrm{K}$ & $\mathrm{Mn}$ \\
\hline Calcítico de Itaú de Minas $(\mathrm{Cl})$ & 35,34 & 0,35 & 2,45 & 0,25 & 0,14 & 0,09 & 0,52 \\
\hline
\end{tabular}

O calcário $\mathrm{Cl}$ foi coletado diretamente da mina, por meio de seleção de pedras em diferentes pontos. As pedras foram britadas utilizando-se moinho de martelos e posteriormente peneiradas em um conjunto de peneiras vibratórias de laboratório. Este procedimento foi feito no NETeF.

\subsubsection{GASES}

Os gases de processo nas análises termogravimétricas foram obtidos de cilindros de gases especiais da White Martins padrão-primário:

- Gás Inerte sob alta pressão - Nitrogênio $\left(\mathrm{N}_{2}\right)$;

- Ar sintético sob alta pressão - $(20 \pm 0,5) \%$ de $\mathrm{O}_{2}$ e $(80 \pm 0,5 \%)$ de $\mathrm{N}_{2}$;

- Dióxido de Enxofre liquefeito sob pressão $\left(\mathrm{SO}_{2}\right), 100$ \% (v/v).

\subsubsection{EqUIPAMENTOS UTILIZADOS}

Os equipamentos e instrumentos utilizados neste trabalho são:

\section{Medidor/Controlador de Fluxo}

Medidor/Controlador de fluxo AALBORG modelo G19618C, específico para $\mathrm{SO}_{2}$ para vazões de até $200 \mathrm{~mL} \mathrm{~min}^{-1}$.

\section{Peneirador Vibrador}

Peneirador Vibrador com peneiras das série Tyler, marca SOLOTEST. 


\section{Balança Analítica}

Balança analítica METTLER TOLEDO - modelo AG 245.

\section{Sistema de Aquisição de Dados}

Computador COMPAQ K6II $450 \mathrm{mHz}$ com memória de 160 MB e interface TA-50WSI.

\section{Balança Termogravimétrica}

Analisador Termogravimétrico SHIMADZU - modelo TGA-51 (Figura 1).
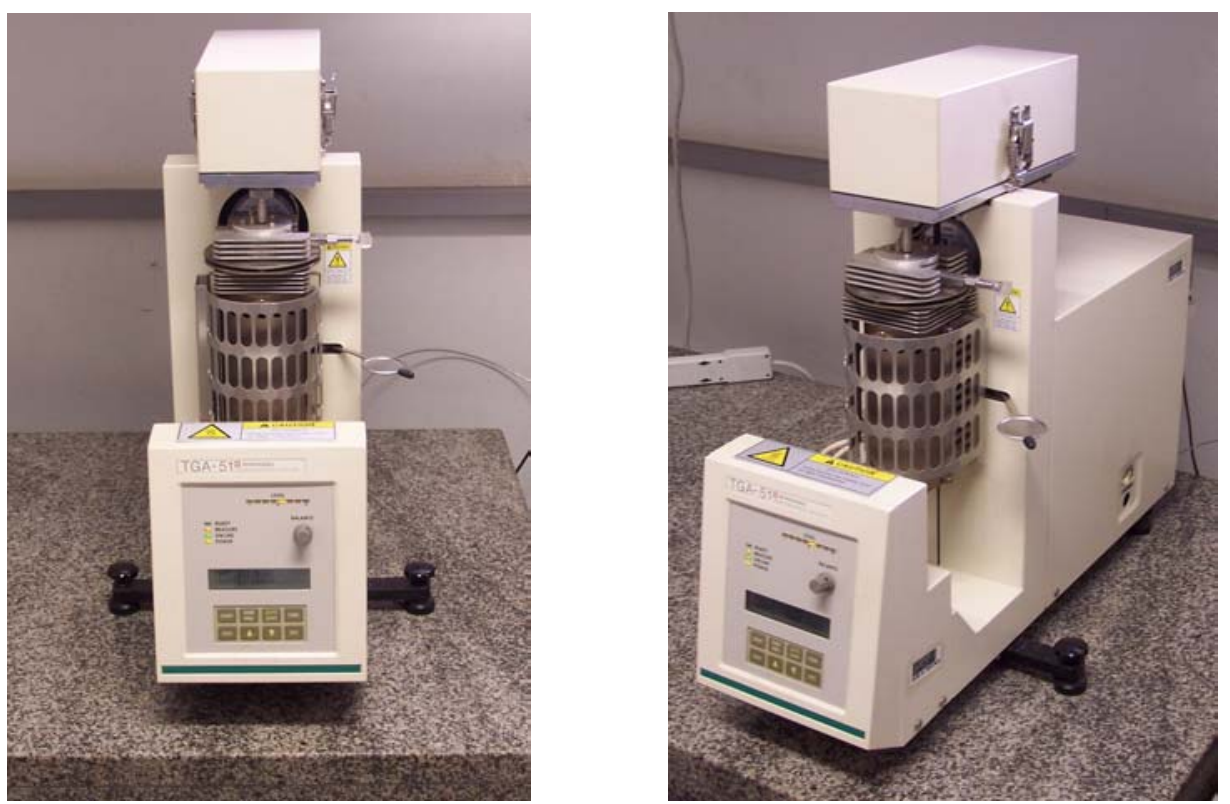

Figura 1: Balança Termogravimétrica Shimadzu 51H.

\subsection{TÉCNICA BÁSICA UTILIZADA}

A técnica básica utilizada neste trabalho é a termogravimetria, uma das técnicas de análise térmica.

Mackenzie (1979) define análise térmica como um grupo de técnicas nas quais uma propriedade física de uma substância e/ou seus produtos de reação é medida em função da temperatura enquanto a substância é submetida a uma programação controlada de temperatura. 
Esta definição foi aceita pela Confederação Internacional de Análise Térmica (ICTA) em 1992. No Brasil, a ABRATEC (Associação Brasileira de Análise Térmica e Calorimetria) é responsável pela tradução dos termos técnicos em acordo com as instruções dadas pela ICTA.

Os métodos de análise térmica fornecem resultados na forma de curvas, nas quais contêm informações a respeito da variação do parâmetro medido.

A termogravimetria (TG) é definida como: a técnica na qual a massa de uma substância é medida em função da temperatura, enquanto a substância é submetida a uma programação controlada de temperatura (IONASHIRO e GIOLITO, 1980 e 1988). A termogravimetria derivada (DTG) fornece a derivada primeira da curva termogravimétrica em função do tempo ou da temperatura. Os resultados da TG e DTG são apresentados nas curvas TG e curvas DTG respectivamente.

Para aplicar a técnica TG é necessário introduzir a amostra no portaamostras, também chamado de cadinho. O tipo de material e o tamanho do cadinho dependem da temperatura máxima desejada e da natureza, quantidade e reatividade da amostra. Normalmente utiliza-se cadinho de platina, alumina, alumínio, quartzo, vidro e grafite. Dependendo do estudo, o cadinho deve permitir (ou não) bom contato entre a amostra e a atmosfera do forno, facilitando (ou não) a perda rápida de produtos voláteis da reação.

Os fatores que afetam as curvas TG são as variáveis instrumentais e da amostra, sendo afetada também pelo operador. As variáveis instrumentais são: razão de aquecimento do forno, atmosfera do forno, geometria do suporte da amostra e do forno, sensibilidade do mecanismo de registro, tipo e composição química do porta-amostra.

As variáveis da amostra que afetam as curvas TG são: gases desprendidos da amostra, quantidade de amostra, tamanho e geometria das partículas, empacotamento, condutividade térmica, capacidade calorífica e natureza da amostra.

Os fatores que podem gerar erros em curvas de TG são: flutuações do mecanismo de equilíbrio, efeitos eletrostáticos em mecanismos de equilíbrio e 
de indução no forno, reação entre o cadinho e a amostra, erros de convecção, efeito de turbulência decorrente do fluxo gasoso, medida de massa da balança, medida da temperatura por meio dos termopares, etc. Estes erros podem ser minimizados, ou até mesmo eliminados, quando se desconta da curva TG obtida no experimento, uma outra curva TG gerada sem a amostra, utilizando as mesmas condições experimentais (nomeada "branco").

Há na literatura livros na área de análise térmica, abordando estes tópicos aqui descritos. Entre eles cita-se Wendlandt (1985) e Brown (1988).

\subsubsection{Procedimento de Operação da Balança Termogravimétrica}

As condições de operação de um equipamento termoanálitico devem garantir a estabilidade do equipamento e a repetitividade dos resultados.

O procedimento com a seqüência operacional na rotina dos experimentos para o estudo da reação do calcário $\operatorname{com} \mathrm{SO}_{2}$ balança $\mathrm{TG}$, é descrito abaixo.

1. Ligar o computador e acessar o "software TA-60WS Collection Monitor" para fazer a aquisição de dados;

2. Ligar a balança termogravimétrica;

3. Abrir o regulador de vazão do cilindro do gás de arraste (que fluirá através da balança TG seguindo para o forno) e ajustar a vazão da atmosfera da balança;

4. Abrir o forno da balança termogravimétrica;

5. Colocar o cadinho vazio no suporte da balança termogravimétrica;

6. Tarar a balança termogravimétrica;

7. Abrir o forno e retirar o cadinho vazio;

8. Tarar a balança analítica com o cadinho; pesar a massa aproximada;

9. Colocar o cadinho com a amostra no suporte da balança e fechar o forno; 
10.Programar a condição experimental desejada no "software TA-60WS Collection Monitor".

11.Dar o "Start" no "software TA-60WS Collection Monitor";

12.Aguardar a temperatura desejada ser atingida, e o sistema se estabilizar por $5 \mathrm{~min}$.

13.Ligar o medidor/controlador de vazão (Aalborg), ajustado previamente para a vazão desejada;

14. Abrir a válvula do regulador de vazão do cilindro de $\mathrm{SO}_{2}$;

15. Esperar o programa se completar para obter as curvas TG e DTG;

16. Desligar o medidor/controlador de vazão (Aalborg);

17. Desligar a válvula do regulador de vazão do cilindro de $\mathrm{SO}_{2}$;

18. Aguardar o sistema se resfriar;

19.Desligar o regulador de vazão do cilindro do gás de arraste;

20.Desligar a balança termogravimétrica;

21.Desligar o computador.

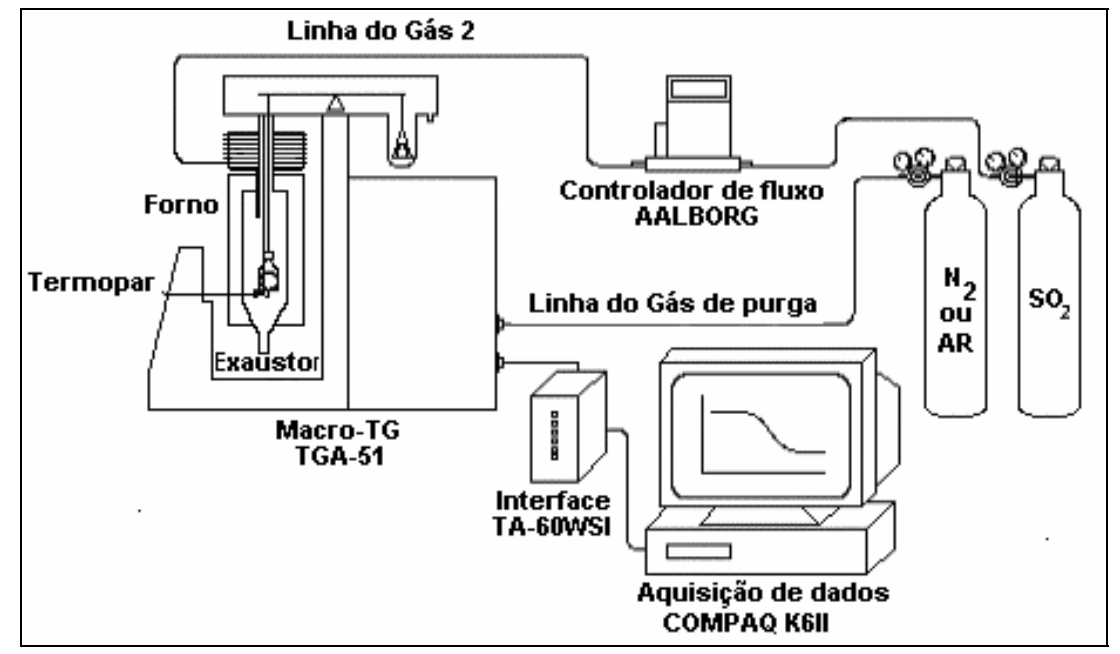

Figura 2: Sistema Termogravimétrico com aquisição de dados (CRNKOVIC, 2003). 
A Figura 2 mostra o esquema do módulo termogravimétrico, sistema de aquisição de dados e trajeto dos gases até o forno da balança TG. A vazão do gás de purga foi controlada por um rotâmetro interno da balança com fundo de escala de $100 \mathrm{~mL} \mathrm{~min}^{-1}$.

\subsubsection{Procedimento nas Condições Experimentais AdotadAs no Estudo em}

\section{ANÁLISE TÉRMICA}

Inicialmente foi feita a calcinação do calcário natural em balança termogravimétrica. Para isto utilizou-se atmosfera dinâmica de ar e de nitrogênio (ambas com vazão de $80 \mathrm{~mL} \mathrm{~min}^{-1}$ ) e razão de aquecimento de $30{ }^{\circ} \mathrm{C} \mathrm{min}^{-1}$ até a temperatura desejada.

Após a calcinação, o calcário calcinado foi submetido à sulfatação e, nesta etapa, os ensaios foram isotérmicos.

Ao se atingir a temperatura desejada, aplicou-se uma condição isotérmica de 20 minutos e, após os 5 primeiros minutos de estabilização, foi injetado $\mathrm{SO}_{2}(100 \% \mathrm{v} / \mathrm{v})$ com vazão de $20 \mathrm{~mL} \mathrm{~min}^{-1}$.

Foram consideradas 5 temperaturas diferentes $(750,800,850,900$ e $950{ }^{\circ} \mathrm{C}$ ) e para cada ensaio foram feitas 4 repetições.

Nos ensaios isotérmicos em temperaturas abaixo de $850{ }^{\circ} \mathrm{C}$, foi necessário fazer a calcinação da amostra até $850{ }^{\circ} \mathrm{C}$. Nestes experimentos fezse o aquecimento com taxa de $30{ }^{\circ} \mathrm{C} \min ^{-1}$ até $850{ }^{\circ} \mathrm{C}$, esperou-se $\mathrm{O}$ equipamento se estabilizar por 5 minutos e iniciou-se o resfriamento com taxa de $30{ }^{\circ} \mathrm{C} \mathrm{min}^{-1}$ até a temperatura desejada. Em seguida procedeu-se conforme descrito no item 13 do procedimento de operação da balança TG.

A Figura 3 ilustra curvas obtidas na termogravimetria de calcinação seguida de sulfatação para um dos ensaios realizados. São mostrados perfis TG $(\Delta M)$, DTG $(d M / d t)$ e da taxa de aquecimento $(\Delta T)$. As indicações de [1] até [2] sobre a curva TG mostram a perda de massa relacionada à conversão do calcário natural em $\mathrm{CaO}$. Após a calcinação completa é injetado $\mathrm{SO}_{2}$ na atmosfera do forno, e a sulfatação se desenvolve formando $\mathrm{CaSO}_{4}$ [3]. $\mathrm{Na}$ curva DTG indica-se também o ponto de máxima taxa de sulfatação [4]. Para o 
propósito deste estudo, a análise dos dados é feita a partir da calcinação total da amostra até a sulfatação completa (área em cinza).

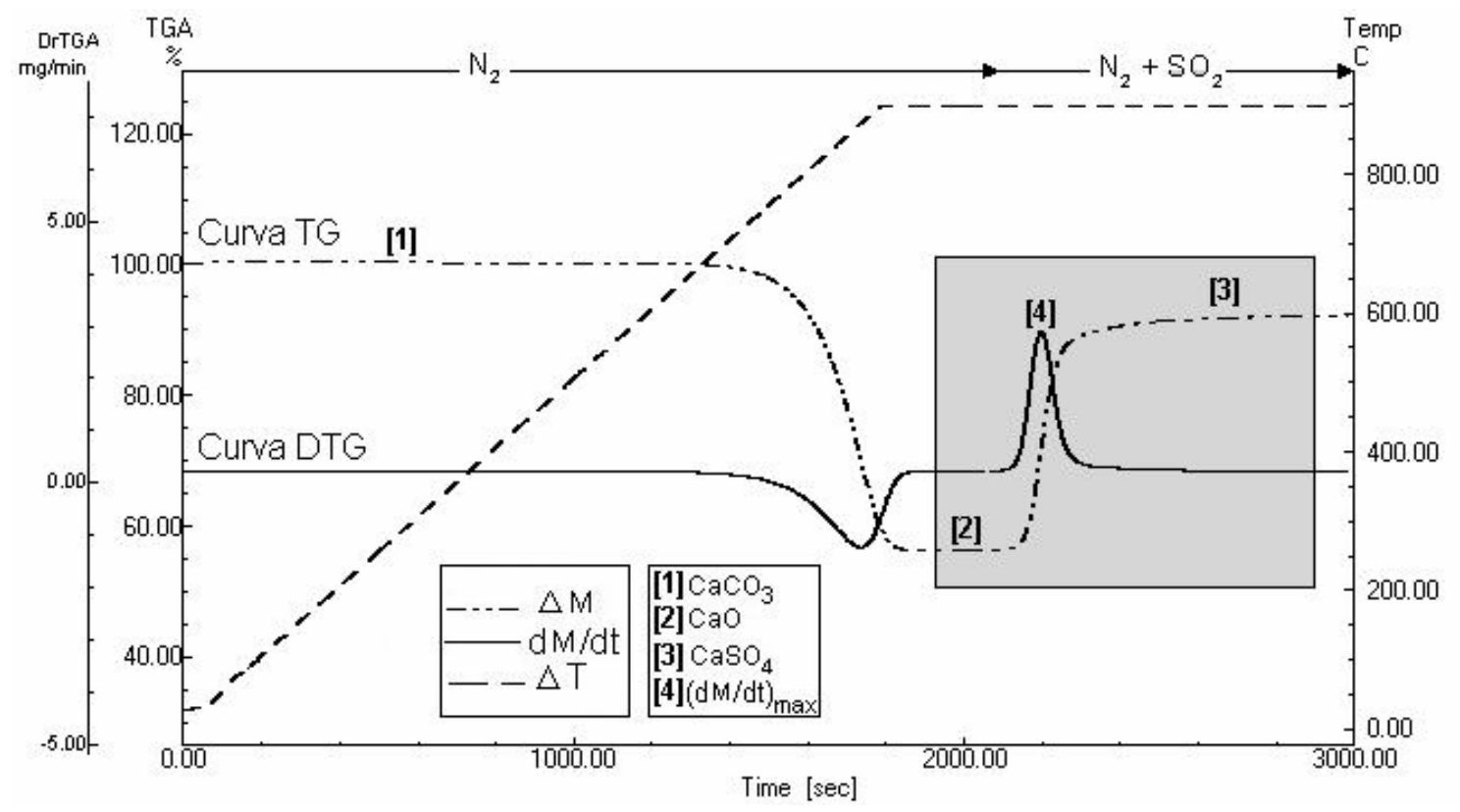

Figura 3: Curva TG obtida em um ensaio a $900{ }^{\circ} \mathrm{C}$ em atmosfera dinâmica de nitrogênio.

\subsection{ESCOLHA DAS CONDIÇÕES EXPERIMENTAIS}

\subsubsection{MASSA DA AMOSTRA}

Para o propósito deste trabalho, optou-se pela massa de $10 \mathrm{mg}$, pois esta quantidade garante que toda a amostra fique espalhada pelo suporte em uma monocamada, minimizando a resistência da transferência de massa.

Crnkovic (2003) estudou o ganho de massa de um calcário calcítico calcinado na etapa de sulfatação para 4 quantidades diferentes de amostra. Os resultados são reproduzidos na Tabela 3.

A autora observou que o ganho percentual de massa diminuiu com o aumento da quantidade de amostra possivelmente devido à dificuldade de acesso do $\mathrm{SO}_{2}$ aos grãos de material localizados mais no interior da amostra. 
Tabela 3: Valores de ganho de massa na sulfatação para diferentes massas de amostra de calcário calcítico (CRNKOVIC, 2003).

\begin{tabular}{||c|c|c|c|c||}
\hline \multirow{2}{*}{} & \multicolumn{4}{|c|}{ Experimentos TG - Massa da Amostra (mg) } \\
\cline { 2 - 5 } & 10 & 20 & 30 & 40 \\
\hline $\begin{array}{c}\text { Ganho de massa na } \\
\text { sulfatação (\% massa) }\end{array}$ & 84,4 & 83,0 & 81,9 & 80,0 \\
\hline
\end{tabular}

\subsubsection{GRANULOMETRIA}

Neste estudo da sulfatação optou-se pela granulometria média de $545 \mu \mathrm{m}$, tamanho de partícula típico, utilizado nos reatores de leito fluidizado do NETeF.

A granulometria média do calcário foi obtida por meio de seleção entre duas peneiras sucessivas da série ASTM, de modo a compor a faixa mais estreita possível e minimizar o efeito da distribuição granulométrica. Neste caso a granulometria de $545 \mu \mathrm{m}$ resultou da passagem pela peneira de $590 \mu \mathrm{m}$ e retenção na peneira de $500 \mu \mathrm{m}$.

Silva (2003) avaliou o efeito da distribuição granulométrica para dois tipos de calcário (calcítico e dolomítico) na absorção de $\mathrm{SO}_{2}$ em reator de leito fluidizado. O autor descreve que de um modo geral, a diminuição da granulometria do calcário proporciona aumento na absorção de $\mathrm{SO}_{2}$. Atribuiu esse comportamento a maior área específica, e à calcinação mais rápida e supostamente mais completa apresentada pelas partículas com granulometrias menores.

Segundo Kato et al. (1994) apud Silva (2003) o uso de partículas muito pequenas em leito fluidizado é limitado pela elutriação do material devido a sua baixa velocidade terminal e pelo fato de partículas muito pequenas terem a tendência de se aglomerarem.

${ }^{i v}$ KATO, K. et al (1994). Effective dry desulfurization by a powder-particle fluidized bed. Journal of Chemical Engineering of Japan, vol 27 no 3 pp 276-278. 


\subsubsection{PORTA-AMOSTRA}

O porta-amostra, ou cadinho, usado neste estudo foi escolhido para suportar temperaturas de até $950{ }^{\circ} \mathrm{C}$. Materiais como platina e alumina correspondem a esta necessidade. Outro requisito a ser considerado é o cadinho não interferir na reação de sulfatação.

Crnkovic (2003) avaliou a influência do suporte da amostra na reação de sulfatação e observou que nas mesmas condições experimentais, os resultados mostraram ganhos médios de massa de 82,9 e 72,6\% com suporte de platina e de alumina respectivamente, após um tempo de 40 minutos de exposição ao $\mathrm{SO}_{2}$. Comprovou assim a observação de Wieczorec-Ciurowa (1992) de que a platina exerce um efeito catalítico na reação de sulfatação.

Com base nestas observações, escolhe-se neste estudo cadinho de alumina, com 5,8 mm de diâmetro e 2,6 mm de altura (Figura 4), por suportar altas temperaturas e apresentar menor efeito sobre a reação de sulfatação quando comparado ao cadinho de platina.

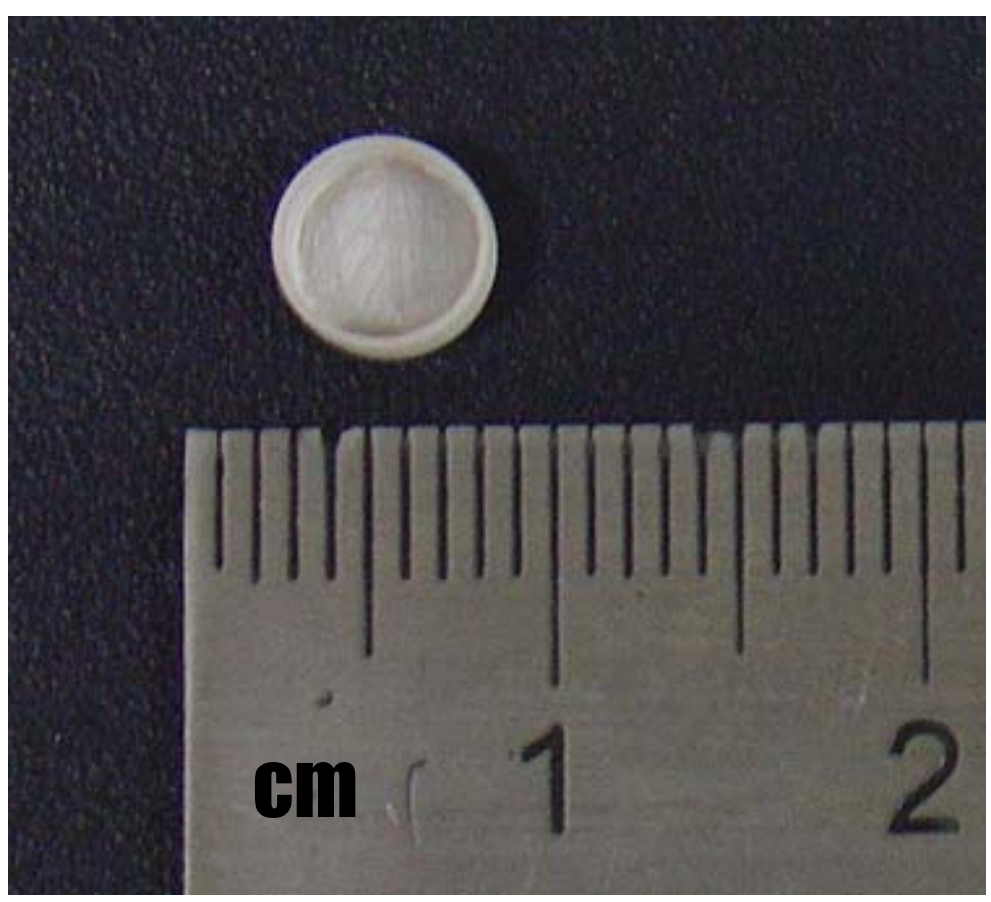

Figura 4: Porta amostra de alumina. 


\subsubsection{CONCENTRAÇÃO DA $\mathrm{SO}_{2}$}

Crnkovic (2003) avaliou o efeito da concentração de $\mathrm{SO}_{2}$ na sulfatação. Observou que houve um aumento de ganho de massa de $10 \%$ quando a fração de $\mathrm{SO}_{2}$ no gás reagente variou 10 para $20 \%$. Quando a variação da fração de $\mathrm{SO}_{2}$ foi 20 para $30 \%$, não ocorreu variação significativa no ganho de massa. Nestes ensaios foi aplicada vazão total de gás reagente de $100 \mathrm{~mL} \min ^{-1}\left(10,20\right.$ e $30 \mathrm{~mL} \mathrm{~min}^{-1}$ de $\mathrm{SO}_{2}$ e 90,80 e $70 \mathrm{~mL} \mathrm{~min}^{-1}$ de ar sintético).

A partir destas considerações optou-se pela vazão de $20 \mathrm{~mL} \mathrm{~min}{ }^{-1}$ de $\mathrm{SO}_{2}$ com vazão do gás de arraste de $80 \mathrm{~mL} \min ^{-1}$. A fração de $\mathrm{SO}_{2}$ no gás reagente ficou em $20 \%$ da atmosfera total na balança TG. Esta escolha garante que a taxa de reação seja independente da concentração de $\mathrm{SO}_{2}$, tornando-se de pseudo-ordem zero em relação a este gás, e os parâmetros avaliados sejam intrínsecos às partículas.

\subsection{Obtenção dos Parâmetros Cinéticos}

O efeito da temperatura na velocidade de reações foi identificado por Svante Arrhenius no fim do século XIX. Arrhenius plotou em um gráfico o logaritmo da constante de velocidade versus o inverso da temperatura absoluta, obtendo assim uma linha reta. Designou de $(\ln A)$ a interseção com a ordenada e (- $\left.E_{a} / R\right)$ a inclinação da reta (ATIKINS, 2001).

As duas constantes, $A$ (fator pré-exponencial) e $E_{a}$ (energia de ativação), são conhecidas como os parâmetros de Arrhenius da reação. $O$ fator pré-exponencial $(A)$ representa a freqüência de colisões efetivas entre moléculas. A energia de ativação $\left(E_{a}\right)$ é definida como a energia necessária para mover os reagentes através da barreira energética de forma que a reação possa ocorrer.

Em análise térmica as reações estudadas são reações quase sempre heterogêneas em temperaturas que são aumentadas continuamente de acordo com algum programa fixado (normalmente linear). A validade da aplicação da equação de Arrhenius para reações heterogêneas tem sido questionada, mas 
os parâmetros $E_{a}$ e $A$ são determinados, ainda que seja difícil sua interpretação teórica (BROWN, 1988).

No presente trabalho são obtidos os parâmetros de Arrhenius para a reação de absorção do $\mathrm{SO}_{2}$ pelo calcário, a partir de curvas termogravimétricas. O estudo é feito em condições isotérmicas em meio reativo heterogêneo. A escolha de estudar a cinética em condições isotérmicas deve-se ao fato da proximidade com as condições experimentais observadas em reatores de leito fluidizado na queima de carvão mineral.

O coeficiente de taxa (ou constante de velocidade) de reação ( $k$ ), é então modelado pela expressão de Arrhenius, desenvolvida a partir da teoria cinética de gases, ou seja:

$$
k(T)=A \exp \left(-\frac{E_{a}}{R T}\right)
$$

\section{Sendo:}

$k \quad$ - coeficiente de taxa de reação $\left[\mathrm{s}^{-1}\right]$

$T \quad$ - a temperatura absoluta $[\mathrm{K}]$

$A \quad$ - o fator pré-exponencial ou fator de freqüência $\left[\mathrm{s}^{-1}\right]$

$E_{a} \quad$ - a energia de ativação [J.mol $\left.{ }^{-1}\right]$

$R \quad$ - a constante universal dos gases $\left[8,314 \mathrm{~J} \cdot \mathrm{mol}^{-1} \cdot \mathrm{K}^{-1}\right]$

$\mathrm{Na}$ Equação [7] o termo exponencial, conhecido como fator ou distribuição de Boltzmann, especifica a fração das colisões com energia superior à energia de ativação. Multiplicado pela fração de colisões efetivas ou favoráveis, representada pelo fator pré-exponencial, define a freqüência de reação ou coeficiente de taxa.

A equação de Arrhenius tem apenas justificativa qualitativa quando aplicada a processos reativos complexos (BURNHAM e BRAUN, 1999). Contudo, o atual estado do conhecimento em cinética de reações complexas ainda não produziu alternativa claramente melhor. 
Para ocorrer absorção do $\mathrm{SO}_{2}$ pelo calcário é necessário a difusão do $\mathrm{SO}_{2}$ e $\mathrm{O}_{2}$ ou $\mathrm{SO}_{3}$ para dentro da partícula e a interação destes gases com a superfície reacional disponível.

Nos primeiros instantes de reação, os gases se difundem através dos poros das partículas do calcário e o processo controlador é a reação química com o $\mathrm{CaO}$ na superfície dos grãos. Uma vez formada a camada de $\mathrm{CaSO}_{4}$, a difusão através das camadas de $\mathrm{CaSO}_{4}$ se torna um fator limitante. Quando a camada de $\mathrm{CaSO}_{4}$ alcança uma determinada espessura, a difusão no estado sólido (iônica) se torna o fator limitante (BORGWARDT e BRUCE, 1987; SIMONS et al., 1987; SNOW et al. 1988, FUERTE et al., 1994; QIN, 1995 al., 1988; LAUSEN et al., 2000).

A taxa de reação de absorção pode ser dada por:

$$
-\frac{d m}{d t} \propto \mathrm{m}^{\mathrm{a}} \mathrm{C}_{\mathrm{SO}_{2}}^{\mathrm{b}} \mathrm{C}_{\mathrm{O}_{2}}^{\mathrm{c}} \text { ou }-\frac{d m}{d t} \propto \mathrm{m}^{\mathrm{a}} \mathrm{C}_{\mathrm{SO}_{3}}^{\mathrm{d}}
$$

Sendo:

$$
\begin{gathered}
m \text { - massa de cálcio e magnésio disponíveis para a reação [kg] } \\
C_{\mathrm{SO}_{2}}, C_{\mathrm{O}_{2}}, \mathrm{C}_{\mathrm{SO}_{3}}^{\mathrm{a}}-\quad \begin{array}{l}
\text { concentrações de gases na atmosfera da balança } \\
{\left[\mathrm{kmol} . \mathrm{m}^{-3}\right]}
\end{array}
\end{gathered}
$$

$a, b, c, d$ - ordem da reação global em relação a cada um dos gases reagentes

De acordo com a literatura, apenas o $\mathrm{CaO}$ dos calcários é absorvente de $\mathrm{SO}_{\mathrm{X}}$ nas temperaturas de interesse em processos de combustão (WEIDENANN et al., 1990; FUERTES et al., 1995). MgO não absorve SOX posto que o produto $\mathrm{MgSO}_{4}$ torna-se instável a altas temperaturas. Outro argumento é que a reação do $\mathrm{MgO}$ com $\mathrm{O} \mathrm{SO}_{2}$ é muito lenta e não ocorre sulfatação significativa (BORGWARDT e HARVEY, 1972). Contudo, alguns resultados obtidos no NETeF apontam uma possível atividade do $\mathrm{MgO}$ (PAGLIUSO et al., 2002). Há também na literatura evidência da ocorrência de $\mathrm{MgSO}_{4}$ como produto da reação (BORGWARDT, 1970). Neste trabalho MgO é 
tratado como absorvente.

Considera-se reação de primeira ordem em relação à massa da amostra e independente das concentrações de gases reagentes, isto é, assume-se pseudo-ordem zero em relação às concentrações dos gases reagentes. Não há informação na literatura de sulfatação de calcários que permita estabelecer a ordem de reação em relação à massa da amostra. Em geral assume-se ordem 1. Quanto aos gases reagentes, pratica-se concentrações altas o suficiente para que seus valores não afetem as taxas de reação (neste trabalho, 20\% para $\mathrm{SO}_{2}$ e $16 \%$ para $\mathrm{O}_{2}$ ). Assim, assume-se $a=1$ e $b=c=d=0$.

Então tem-se:

$$
-\frac{\mathrm{dm}}{\mathrm{dt}} \propto \mathrm{m}
$$

Introduzindo-se um coeficiente de taxa de reação $(k)$, da Equação [9] tem-se:

$$
-\frac{\mathrm{dm}}{\mathrm{dt}}=\mathrm{km}
$$

Assim, o coeficiente de taxa de reação resulta:

$$
\mathrm{k}=\left[-\frac{1}{\mathrm{~m}} \frac{\mathrm{dm}}{\mathrm{dt}}\right]
$$

Substituindo a equação [7] na [11] e aplicando o operador logarítimo natural, obtém-se:

$$
\ln \left[-\frac{1}{m} \frac{d m}{d t}\right]=\ln A-\frac{E_{a}}{R} \frac{1}{T}
$$

Os valores de $m, d m / d t$ e $T$ são obtidos experimentalmente a partir das curvas TG e DTG, com relação a amostra de calcário. A massa transiente $(m)$ 
corresponde ao cálcio e magnésio disponíveis para a reação, obtida do balanço de massa presumindo-se que $\mathrm{Ca}$ e $\mathrm{Mg}$ sejam consumidos à mesma taxa, ou seja:

$$
m=\left|\begin{array}{c}
\text { massa inicial } \\
\text { de }(\mathrm{Ca}+\mathrm{Mg})
\end{array}\right|-\left|\begin{array}{c}
\text { massa de }(\mathrm{Ca}+\mathrm{Mg}) \text { consumida pela } \\
\text { reação } \mathrm{com} \mathrm{SO}_{3}\left(\mathrm{ou} . \mathrm{SO}_{2}+1 / 2 \mathrm{O}_{2}\right)
\end{array}\right|
$$

(ii)

Os termos (i) e (ii) são dados por:

$$
\begin{aligned}
|\mathrm{i}| & =\left|\begin{array}{l}
\text { massa de } \mathrm{Ca}+\mathrm{Mg} \text { disponível no } \\
\text { calcário natural para reação }
\end{array}\right| \\
|\mathrm{ii}| & =\left|\begin{array}{l}
\text { massa de Ca reagido } \\
\text { do calcário calcinado }
\end{array}\right|+\left|\begin{array}{l}
\text { massa de Mg reagido } \\
\text { do calcário calcinado }
\end{array}\right|
\end{aligned}
$$

Ou seja,

$$
\begin{aligned}
|\mathrm{i}|= & M_{A}\left(Y_{C a}+Y_{M g}\right) \\
|\mathrm{ii}|= & \left(M_{s}-M_{c}\right) \cdot\left(\frac{W_{\mathrm{Ca}}}{W_{\mathrm{SO}_{2}}+1 / 2 W_{\mathrm{O}_{2}}}\right) \cdot\left(\frac{Y_{\mathrm{Ca}}}{Y_{\mathrm{Ca}}+Y_{M g}}\right) \\
& +\left(M_{s}-M_{c}\right) \cdot\left(\frac{W_{M g}}{W_{\mathrm{SO}_{2}}+1 / 2 W_{\mathrm{O}_{2}}}\right) \cdot\left(\frac{Y_{M g}}{Y_{\mathrm{Ca}}+Y_{M g}}\right)
\end{aligned}
$$

Sendo:

$M_{A}$ - massa da amostra (calcário natural) em TG [kg]

$Y_{C a}$ - fração em massa de cálcio no calcário natural [kg]

$Y_{M g}$ - fração em massa de magnésio no calcário natural [adim.]

$M_{s}$ - massa do calcário sulfatado [adim.]

$M_{c}$ - massa do calcário calcinado $[\mathrm{kg}]$ 
$W_{C a}-$ massa molar de cálcio $\left[\mathrm{kg} \cdot \mathrm{mol}^{-1}\right]$

$W_{M g}$ - massa molar de magnésio $\left[\mathrm{kg} \cdot \mathrm{mol}^{-1}\right]$

$W_{\mathrm{SO}_{2}}$ - massa molar de $\mathrm{SO}_{2}\left[\mathrm{~kg} \cdot \mathrm{mol}^{-1}\right]$

$W_{\mathrm{O}_{2}}$ - massa molar do $\mathrm{O}_{2}\left[\mathrm{~kg} \cdot \mathrm{mol}^{-1}\right]$

Substituindo [14] e [15] em [13] obtém-se $m$ :

$$
m=M_{A}\left(Y_{C a}+Y_{M g}\right)-\left\{\left(M_{s}-M_{c}\right) \cdot\left[\frac{\left(W_{C a} Y_{C a}+W_{M g} Y_{M g}\right)}{\left(W_{S_{2}}+1 / 2 W_{O_{2}}\right) \cdot\left(Y_{C a}+Y_{M g}\right)}\right]\right\} .
$$

Para a obtenção de dm/dt é necessário derivar a equação [16]. Nesta expressão apenas a massa que está sendo sulfatada $\left(M_{s}\right)$ está variando no tempo. Tem-se então:

$$
\frac{d m}{d t}=-\left[\frac{\left(W_{C a} Y_{C a}+W_{M g} Y_{M g}\right)}{\left(W_{\mathrm{SO}_{2}}+1 / 2 W_{\mathrm{O}_{2}}\right) \cdot\left(Y_{\mathrm{Ca}}+Y_{\mathrm{Mg}}\right)}\right] \frac{d M_{s} .}{d t} .
$$

A equação [16] foi desenvolvida para atmosfera de ar. Para o cálculo de $m$ em atmosfera inerte, como por exemplo, em atmosfera de nitrogênio, tem-se:

$$
\begin{aligned}
& m=M_{A}\left(Y_{C a}+Y_{M g}\right)-\left\{\left(M_{s}-M_{c}\right) \cdot\left[\frac{\left(W_{C a} Y_{C a}+W_{M g} Y_{M g}\right)}{W_{S_{2}}\left(Y_{C a}+Y_{M g}\right)}\right]\right\} . \\
& \frac{d m}{d t}=-\left[\frac{\left(W_{C a} Y_{C a}+W_{M g} Y_{M g}\right)}{W_{\mathrm{SO}_{2}} \cdot\left(Y_{C a}+Y_{M g}\right)}\right] \frac{d M_{s}}{d t} .
\end{aligned}
$$

Para a obtenção dos parâmetros cinéticos em atmosfera de $\mathrm{Ar}$ substitui-se as equações [16] e [17] na equação [12]: 


$$
\ln \left[-\frac{-\left[\frac{\left(W_{C a} Y_{C a}+W_{M g} Y_{M g}\right)}{\left(W_{S O_{2}}+1 / 2 W_{O_{2}}\right) \cdot\left(Y_{C a}+Y_{M g}\right)}\right]\left(\frac{d M_{s}}{d t}\right)}{M_{A}\left(Y_{C a}+Y_{M g}\right)-\left\{\left(M_{s}-M_{c}\right) \cdot\left[\frac{\left(W_{C a} Y_{C a}+W_{M g} Y_{M g}\right)}{\left(W_{S O_{2}}+1 / 2 W_{O_{2}}\right) \cdot\left(Y_{C a}+Y_{M g}\right)}\right]\right\}}\right]=\ln A-\frac{E_{a}}{R} \frac{1}{T}
$$

Para a obtenção dos parâmetros cinéticos em atmosfera de nitrogênio substitui-se as equações [18] e [19] na equação [12]:

$$
\ln \left[-\frac{-\left[\frac{\left(W_{C a} Y_{C a}+W_{M g} Y_{M g}\right)}{W_{S O_{2}} \cdot\left(Y_{C a}+Y_{M g}\right)}\right]\left(\frac{d M_{s}}{d t}\right)}{M_{A}\left(Y_{C a}+Y_{M g}\right)-\left\{\left(M_{s}-M_{c}\right) \cdot\left[\frac{\left(W_{C a} Y_{C a}+W_{M G} Y_{M g}\right)}{W_{S_{2}} \cdot\left(Y_{C a}+Y_{M g}\right)}\right]\right\}}\right]=\ln A-\frac{E_{a}}{R} \frac{1}{T}
$$

A partir dos dados empíricos calcula-se os valores do primeiro termo à esquerda da equação [20] ou [21] em cada temperatura estudada. Plota-se então este termo versus $1 / T(K)$. Por regressão linear obtém-se o coeficiente angular $\left(-E_{a} / R\right)$ e o coeficiente linear $(A)$ da reta.

As frações mássicas de $Y_{C a}$ e $Y_{M g}$ e massas moleculares do cálcio, magnésio, $\mathrm{SO}_{2}$ e $\mathrm{O}_{2}$ são apresentados na Tabela 4 .

Tabela 4: Frações mássicas e massa molecular dos componentes reacionais

\begin{tabular}{||c|c|c|c|c|c||}
\hline \hline \multicolumn{2}{|c|}{ Fração Molar } & \multicolumn{4}{c||}{ Massa Molecular ou Atômica } \\
\hline $\mathrm{Y}_{\mathrm{Ca}}$ & $\mathrm{Y}_{\mathrm{Mg}}$ & $\mathrm{W}_{\mathrm{Ca}}$ & $\mathrm{W}_{\mathrm{Mg}}$ & $\mathrm{W}_{\mathrm{SO} 2}$ & $\mathrm{~W}_{\mathrm{O} 2}$ \\
\hline 0,3534 & 0,0035 & 40,078 & 24,305 & 64,064 & 31,998 \\
\hline
\end{tabular}

Os valores de $M_{A}, M_{s}, M_{c}$ e $d M / d t$ são dados obtidos nas curvas TG e DTG, conforme mostrado na Figura 5. 


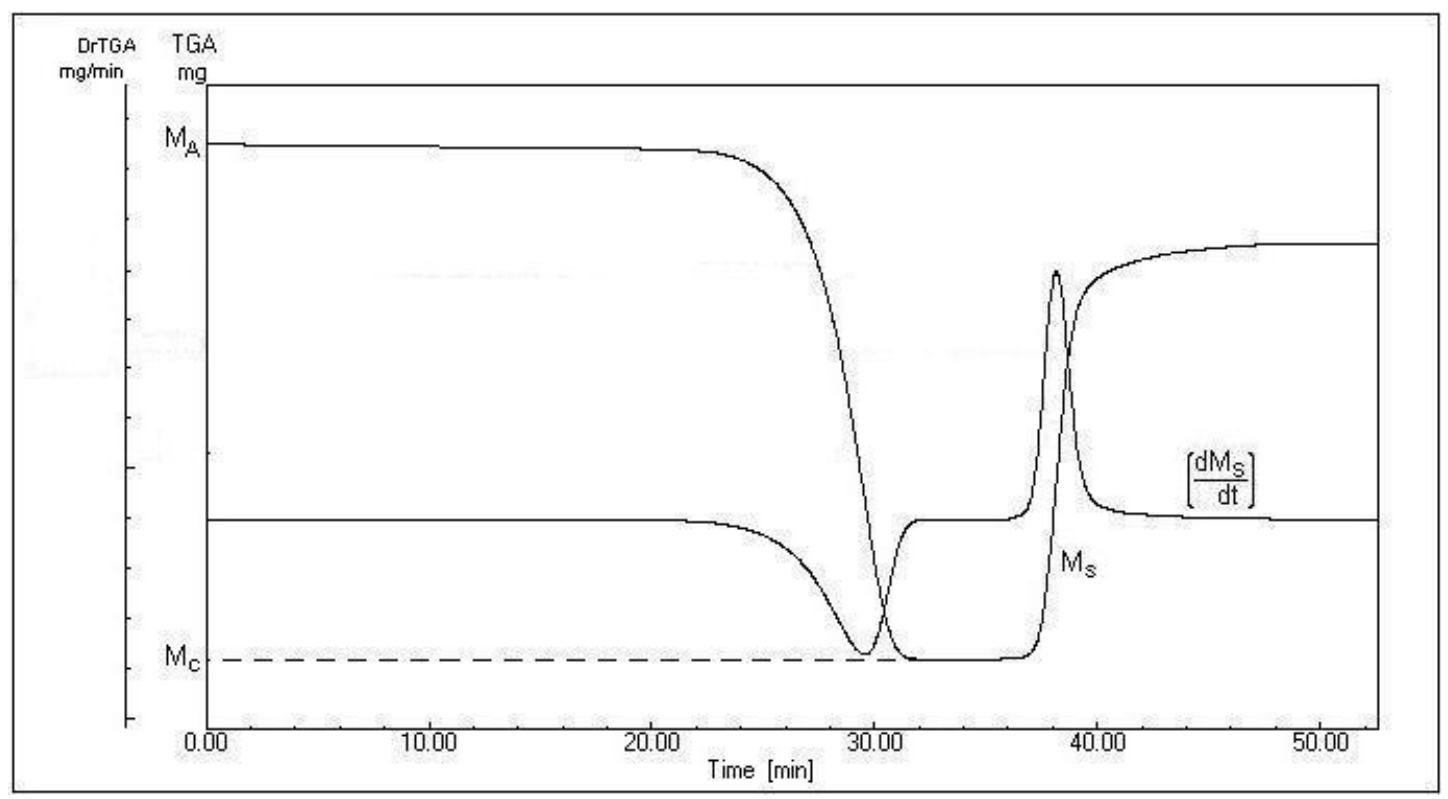

Figura 5: Dados obtidos nas curvas TG e DTG para o cálculo da massa de cálcio e magnésio disponíveis para a reação e de sua taxa.

\subsection{CÁlculo da Efetividade}

Em análises cinéticas de processos reativos gás-sólido geralmente determina-se efetividades de reação levando-se em conta áreas superficiais internas e externas de particulados reativos.

O fator de efetividade é normalmente utilizado para representar o grau que a reação ocorre dentro da estrutura interna do sólido. O máximo valor igual a 1 indica que a reação ocorre igualmente ao longo da estrutura interna de poros. Fator de efetividade baixo (<1) está associado com forte resistência de difusão nos poros $\mathrm{e}$ indica que a estrutura interna não participa significativamente da reação, i.e., que a reação ocorre principalmente na superfície externa de partículas individuais (BORGWARDT e HARVEY, 1972).

Uma definição comum é o denominado fator de efetividade interno, que relaciona a taxa de reação real àquela que resultaria se toda a superfície interna de uma partícula fosse exposta à concentração de gás presente na sua superfície externa. Se a concentração de gás considerada for aquela de uma fase fluida distante da superfície da partícula, a efetividade é dita global (FOGLER, 1999). 
No presente trabalho assume-se efetividade $(\eta)$ como a relação entre o coeficiente de taxa de reação e o seu valor máximo. Assim, a efetividade representa o decaimento da taxa de reação no tempo, e é dada por:

$$
\eta=\frac{k}{k_{\max }}=\frac{\left[-\frac{1}{m} \frac{d m}{d t}\right]}{\left[-\frac{1}{m} \frac{d m}{d t}\right]_{\max }}
$$

\subsection{CÁlculo da Conversão}

A conversão de um reagente i indica uma relação quantitativa entre o número de moles da espécie alimentada no processo e o número de moles desta mesma espécie que efetivamente reagem. A conversão pode ser apresentada na forma percentual :

$$
\text { Conversão }(\%)=\frac{\text { moles de i que reagem }}{\text { moles de i alimentados no processo }} \times 100
$$

Em um processo operando em regime estacionário, a quantidade de moles da espécie química i que reage é igual à diferença entre a quantidade de moles de i que entram no processo $\left(n_{e}\right)$ e a quantidade de moles de i que saem $\left(n_{s}\right)$. Desta forma, em regime estacionário:

$$
\text { Conversão }(\%)=\frac{\mathrm{n}_{\mathrm{e}}-\mathrm{n}_{\mathrm{s}}}{\mathrm{n}_{\mathrm{e}}} \times 100
$$

Para os ensaios de absorção de $\mathrm{SO}_{2}$ por calcário em balança termogravimétrica tem-se:

$$
X=\frac{n_{\mathrm{SO}_{2}}}{\mathrm{n}_{\mathrm{Ca}}+n_{\mathrm{Mg}}} \times 100
$$


Sendo:

$n_{\mathrm{SO}_{2}}$ - quantidade molar de $\mathrm{SO}_{2}$ absorvida

$n_{C a}, n_{M g}$ - quantidade molar de Ca e de $M g$ na amostra.

A variação de massa do calcário calcinado $(\Delta M)$ após a injeção de $\mathrm{SO}_{2}$ na balança termogravimétrica é:

$$
\Delta M=M_{\mathrm{SO}_{2}}+M_{\mathrm{O}_{2}}=n_{\mathrm{SO}_{2}} W_{\mathrm{SO}_{2}}+n_{\mathrm{O}_{2}} W_{\mathrm{O}_{2}}
$$

Dada a reação:

$\mathrm{CaO}(\mathrm{ou} \mathrm{MgO})+\mathrm{SO}_{2}+1 / 2 \mathrm{O}_{2} \rightarrow \mathrm{CaSO}_{4}(\mathrm{ou} \mathrm{MgSO} 4)$

tem-se que:

$$
\frac{\mathrm{n}_{\mathrm{SO}_{2}}}{\mathrm{n}_{\mathrm{O}_{2}}}=\frac{1}{1 / 2} \therefore \mathrm{n}_{\mathrm{O}_{2}}=1 / 2 \mathrm{n}_{\mathrm{SO}_{2}}
$$

Substituindo a equação [27] na equação [26]:

$$
\Delta M=n_{\mathrm{SO}_{2}}\left(W_{\mathrm{SO}_{2}}+1 / 2 W_{\mathrm{O}_{2}}\right) \quad \therefore n_{\mathrm{SO}_{2}}=\frac{\Delta M}{\left(W_{\mathrm{SO}_{2}}+1 / 2 W_{\mathrm{O}_{2}}\right)}
$$

O número de moles de cálcio $\left(\mathrm{n}_{\mathrm{Ca}}\right)$ e magnésio $\left(\mathrm{n}_{\mathrm{Mg}}\right)$ disponível na amostra é dado por:

$$
n_{C a}+n_{M g}=M_{A}\left(\frac{Y_{C a}}{W_{C a}}+\frac{Y_{M g}}{W_{M g}}\right)
$$

Substituindo as equações [28] e [29] na equação [25] obtém-se a 
equação para cálculo de conversão em atmosfera de ar:

$$
X=\frac{\frac{\Delta M_{S}}{W_{\mathrm{so}_{2}}+W_{1 / 2 \mathrm{O}_{2}}}}{M_{A}\left(\frac{Y_{C a}}{W_{C a}}+\frac{Y_{M g}}{W_{M g}}\right)} \times 100
$$

Em atmosfera de nitrogênio tem-se:

$$
X=\frac{\frac{\Delta M_{S}}{W_{\mathrm{so}_{2}}}}{M_{A}\left(\frac{Y_{C a}}{W_{C a}}+\frac{Y_{M g}}{W_{M g}}\right)} \times 100
$$

Os valores de $\Delta M_{S}$ e $M_{A}$ são dados empíricos obtidos na curva TG, conforme mostrado na Figura 5. $O$ cálculo de $\Delta M_{S}$ é dado pela equação:

$$
\Delta M_{S}=M_{F}-M_{C}
$$

Sendo $M_{F}$ a massa final após sulfatação completa da massa inicial $\left(M_{C}\right)$ do calcário calcinado.

\subsection{Avaliação Estatística dos Resultados}

Qualquer medida experimental está sujeita a erro, ou seja, haverá sempre uma diferença entre o valor verdadeiro e o valor medido (LEITE, 1996). Entretando não se pode comparar o valor medido com o valor verdadeiro se este não é conhecido.

Como estimativa do valor verdadeiro é usual utilizar a média aritmética das medidas (SHIMAKURA e RIBEIRO Jr., 2005). A média aritmética é dada por: 


$$
\bar{X}=\frac{\sum_{i=1}^{n} X_{i}}{N}
$$

Sendo:

$$
\bar{X} \text { - média aritmética }
$$

$X_{i}$ - valores obtidos em cada repetição dos ensaios

$N$ - quantidade de repetições.

De forma complementar deve-se também avaliar como se comporta a distribuição dos dados ao redor de sua média aritmética. Uma medida dessa dispersão é o desvio padrão (PARADINE e RIVETT, 1974; LEITE, 1996), dado por:

$$
\sigma=\sqrt{\frac{\sum_{i=1}^{n}\left(X_{1}-\bar{X}\right)^{2}}{N-1}}
$$

Sendo:

$\sigma$ - desvio padrão.

É conveniente comparar o espalhamento dos resultados em diferentes condições de valores médios. Para tal normaliza-se o desvio padrão em função da média aritmética das medidas, definindo um coeficiente de variação $(C V)$ (LEITE, 1996), dado por:

$$
C V=\frac{\sigma}{\bar{X}} \times 100
$$

Quanto menor o CV mais preciso é o resultado obtido no experimento. 
De acordo com Gomes (1973) os valores de CV são considerados baixos quando inferiores a $10 \%$, médios quando de 10 a $20 \%$, altos quando de 20 a $30 \%$, e muito altos quando superiores a $30 \%$. A classificação dada por Gomes (1973) é baseada em "ensaios agrícolas de campo".

Como critério de aceitação dos ensaios, será considerado como aceitável, valores de $\mathrm{CV}<25 \%$, deixando claro que este critério foi baseado na experimentação, sendo específico para este estudo. 


\section{Capítulo 4}

\section{RESULTADOS E Discussões}

Neste capítulo são apresentados os resultados obtidos e as discussões dos resultados.

Enfatiza-se que estes resultados são válidos para as condições estudadas no presente trabalho, descritas no item 3.3. Comparações com dados de literatura devem ser cuidadosas, levando-se em consideração diferenças nas condições experimentais praticadas.

\subsection{Estudo CinÉtico-Químico da Reação de Sulfatação}

Em estudos de reações heterogêneas fluido-sólidos, como no presente estudo, a energia de ativação é enormemente afetada por efeitos de transporte intrapartícula. Fatores como bloqueio de poros, sinterização e tamanho de partícula assumem importância crucial (JAMES e HUGHES, 1976; IISA e HUPA, 1992; CRNKOVIC, 2003). Nestes casos a energia de ativação é melhor denominada por Energia de Ativação Aparente.

Como descrito no item 3.2.2, foram feitos 4 ensaios termogravimétricos (replicatas) para cada temperatura escolhida $\left(750,800,850,900\right.$ e $\left.950{ }^{\circ} \mathrm{C}\right)$ em cada atmosfera estudada (ar sintético e nitrogênio). A Figura 6 apresenta um conjunto destes testes para a temperatura de $900{ }^{\circ} \mathrm{C}$ em atmosfera de nitrogênio, ilustrando a dispersão dos resultados. 


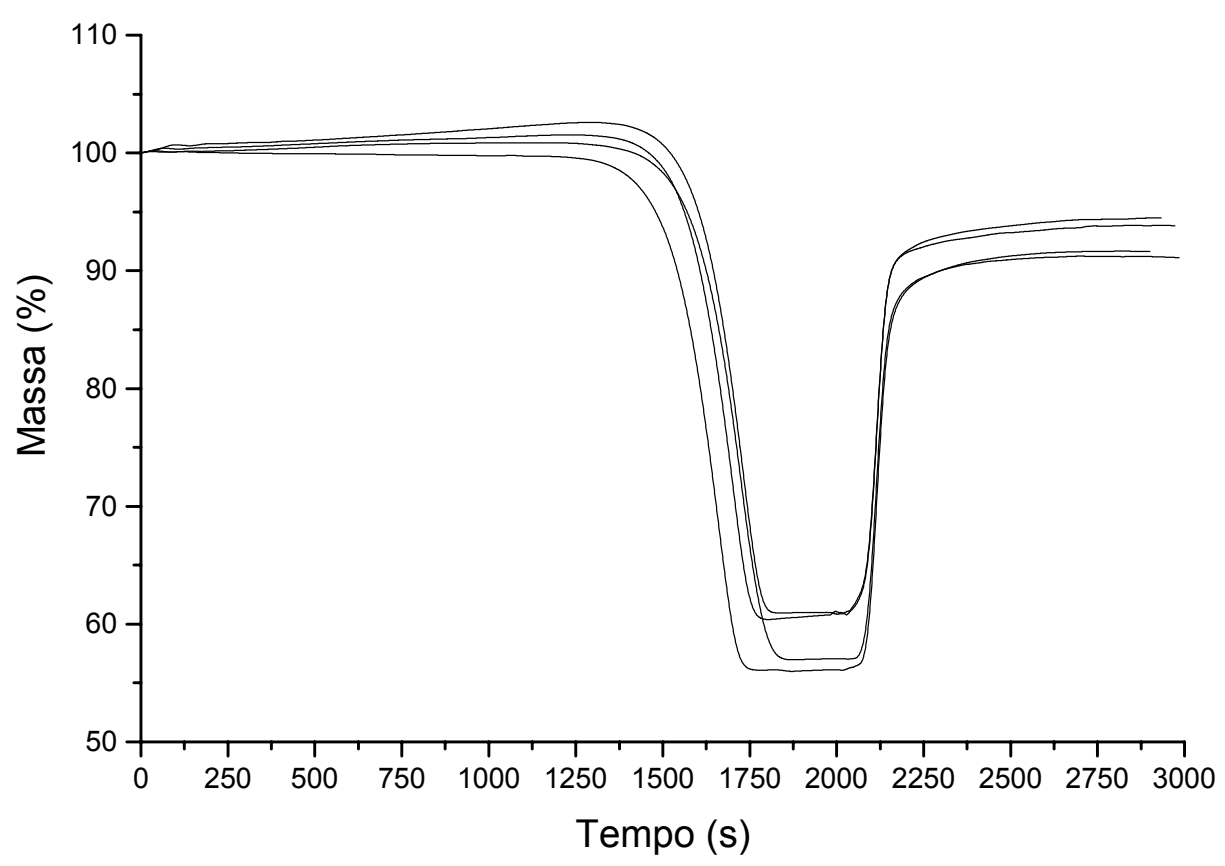

Figura 6: Conjunto de Curvas TG de 4 testes aplicados a $900^{\circ} \mathrm{C}$ em atmosfera de nitrogênio.

A Figura 7 mostra as curvas da derivada temporal (curvas DTG) das curvas TG apresentadas na Figura 6.

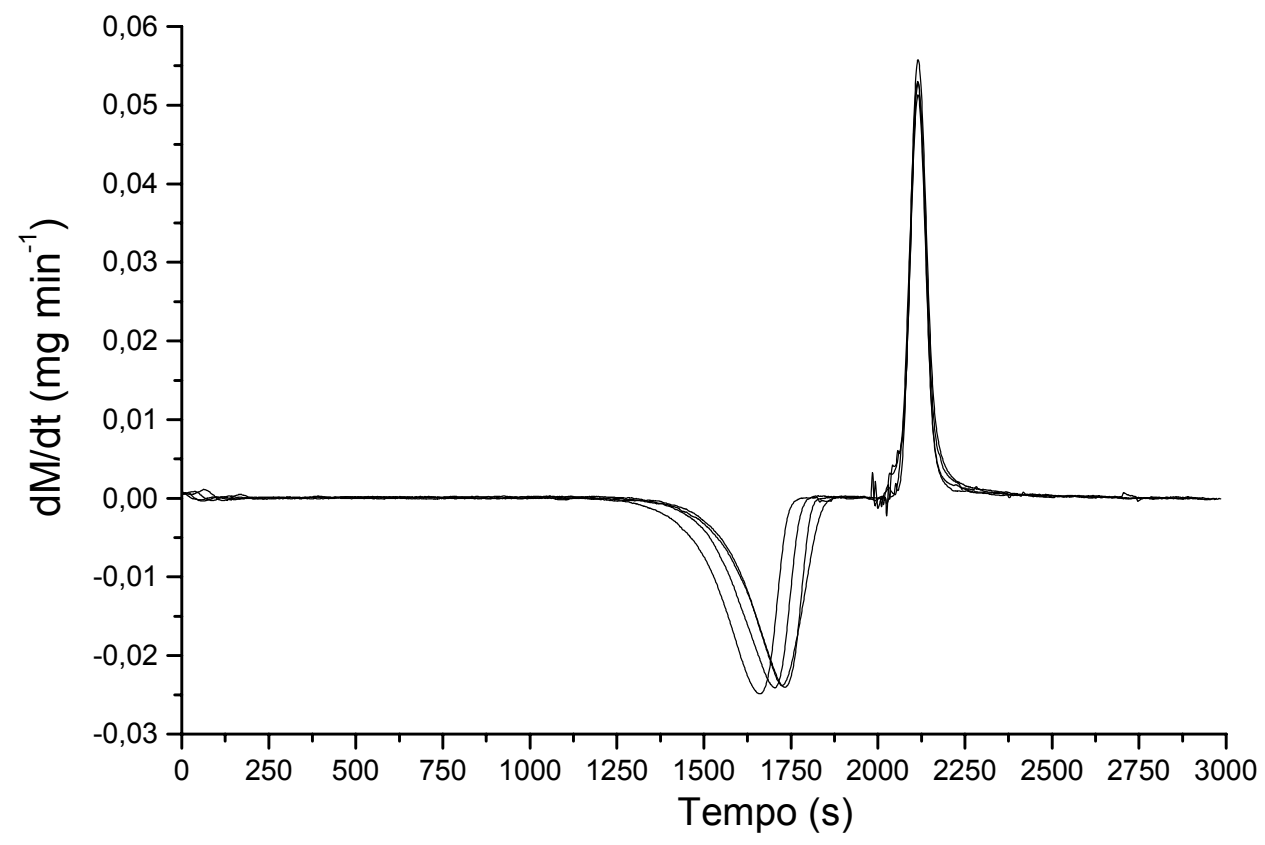

Figura 7: Conjunto de Curvas DTG das curvas TG da Figura 6 de 4 testes aplicados a $900{ }^{\circ} \mathrm{C}$ em atmosfera de nitrogênio. 
Observa-se boa concordância nas curvas DTG, especialmente na altura do pico máximo. Porém no estudo cinético, além de $\mathrm{dM} / \mathrm{dt}$ também são utilizados dados da curva TG $\left(M_{A}, M_{C}\right.$ e $\left.M_{S}\right)$, notando-se considerável dispersão nos resultados obtidos.

A determinação dos parâmetros cinéticos foi feita com base nas curvas TG e DTG para todas as temperaturas ensaiadas, apresentando comportamento semelhante aos mostrados na Figura 6 e Figura 7. As curvas TG e DTG para todas as temperaturas ensaiadas nas atmosferas de ar e nitrogênio, são apresentadas no Apêndice 1 e Apêndice 2 respectivamente.

Nota-se que em todas as curvas TG do Apêndice 1 e Apêndice 2 há uma perda de massa entre 1200 e $1800 \mathrm{~s}$, correspondente à perda de $\mathrm{CO}_{2}$. Entretanto, antes deste evento, em algumas curvas nota-se pequenos degraus correspondentes ao fenômeno da decrepitação (McINTOSHI et al., 1990; McCAULEY e JOHNSON, 1991). A decrepitação é um fenômeno termomecânico provocado por pequenas explosões dentro das partículas, devido à pressão de vapor da água no retículo cristalino. Quanto ocorre este fenômeno no ensaio TG, as explosões fazem com que algumas partículas sejam lançadas para fora do porta-amostra, ocorrendo os degraus observados nas curvas TG. É importante observar que a decrepitação não interfere nos resultados finais, pois para os cálculos utiliza-se como valor da massa inicial, a massa imediatamente antes do início do processo de calcinação.

Neste estudo os parâmetros cinéticos serão obtidos considerando-se 0 coeficiente de taxa de reação dado em função do seu valor temporal máximo $\left(k_{\max }\right)$. Neste caso os parâmetros de Arrhenius serão obtidos no ponto onde a taxa de reação é máxima, ou seja, no pico da curva DTG.

Pode-se então reescrever a equação [12] como:

$$
\ln \left[-\left(\frac{1}{m} \frac{d m}{d t}\right)_{\max }\right]=\ln A-\frac{E_{a}}{R} \frac{1}{T}
$$

Para a obtenção dos parâmetros cinéticos em atmosfera de ar a 
equação [20], passa a ser reescrita como:

$$
\ln \left[-\frac{-\left[\frac{\left(W_{\mathrm{Ca}} Y_{\mathrm{Ca}}+W_{M g} Y_{M g}\right)}{\left(W_{\mathrm{SO}_{2}}+1 / 2 W_{\mathrm{O}_{2}}\right) \cdot\left(Y_{\mathrm{Ca}}+Y_{M g}\right)}\right]\left(\frac{d M_{s}}{d t}\right)_{\max }}{M_{A}\left(Y_{\mathrm{Ca}}+Y_{M g}\right)-\left\{\left(M_{s}-M_{c}\right) \cdot\left[\frac{\left(W_{\mathrm{Ca}} Y_{\mathrm{Ca}}+W_{M g} Y_{M g}\right)}{\left(W_{\mathrm{SO}_{2}}+1 / 2 W_{\mathrm{O}_{2}}\right) \cdot\left(Y_{\mathrm{Ca}}+Y_{\mathrm{Mg}}\right)}\right]\right\}}\right]=\ln A-\frac{E_{a}}{R} \frac{1}{T}
$$

Para a obtenção dos parâmetros cinéticos em atmosfera de nitrogênio substitui-se as equações [18] e [19] na equação [12]:

$$
\ln \left[-\frac{-\left[\frac{\left(W_{C a} Y_{C a}+W_{M g} Y_{M g}\right)}{W_{\mathrm{SO}_{2}} \cdot\left(Y_{C a}+Y_{M g}\right)}\right]\left(\frac{d M_{s}}{d t}\right)_{\max }}{M_{A}\left(Y_{C a}+Y_{M g}\right)-\left\{\left(M_{s}-M_{c}\right) \cdot\left[\frac{\left(W_{C a} Y_{C a}+W_{M g} Y_{M g}\right)}{W_{\mathrm{SO}_{2}} \cdot\left(Y_{C a}+Y_{M g}\right)}\right]\right\}}\right]=\ln A-\frac{E_{a}}{R} \frac{1}{T}
$$

No estudo cinético-químico da reação de sulfatação procedeu-se conforme descrito no item 3.4. O resultado obtido em atmosfera de ar é apresentado na Figura 8.

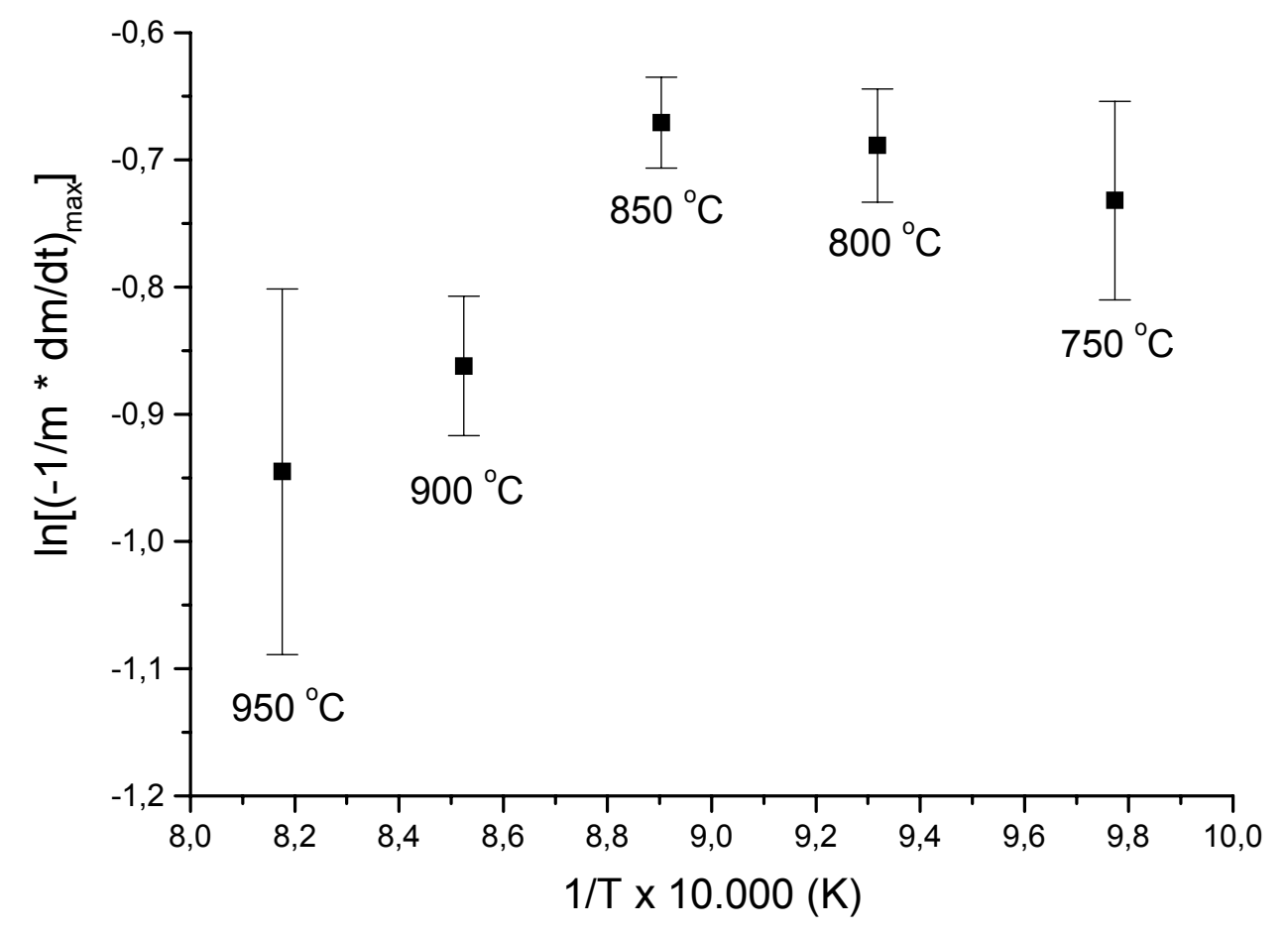

Figura 8: Valores médios de $\ln \left[-\left(\frac{1}{m} \frac{d m}{d t}\right)_{\max }\right\rfloor$ versus $1 / T$ para os ensaios isotérmicos nas temperaturas de 750 à $950{ }^{\circ} \mathrm{C}$ em atmosfera dinâmica de ar. As barras indicam o desvio padrão em relação à média. 
Observa-se na Figura 8 que as taxas de reação média para as temperaturas de 900 e $950{ }^{\circ} \mathrm{C}$ são bem mais baixas que as taxas para as temperaturas de 750 a $850{ }^{\circ} \mathrm{C}$. Este mesmo comportamento foi observado por Crnkovic (2003) para calcário dolomítico com granulometria média de $650 \mu \mathrm{m}$ em atmosfera de ar. Esse comportamento indica uma mudança no mecanismo de reação nas temperaturas mais elevadas, possivelmente devido à sinterização do sorvente e/ou re-emissão do $\mathrm{SO}_{2}$. Neste caso escolheu-se analisar a faixa de temperatura inferior a $850{ }^{\circ} \mathrm{C}$, onde tais efeitos não ocorrem.

Devido à exclusão das duas temperaturas mais elevadas, foram feitos ensaios complementares nas temperaturas de 650 e $700{ }^{\circ} \mathrm{C}$. Assim, aplica-se análise a partir de 5 pontos como previsto inicialmente, mantendo a qualidade na caracterização do comportamento cinético. Os parâmetros cinéticos em atmosfera de ar foram obtidos entre as temperaturas de 650 e $850{ }^{\circ} \mathrm{C}$. O resultado é apresentado na Figura 9.

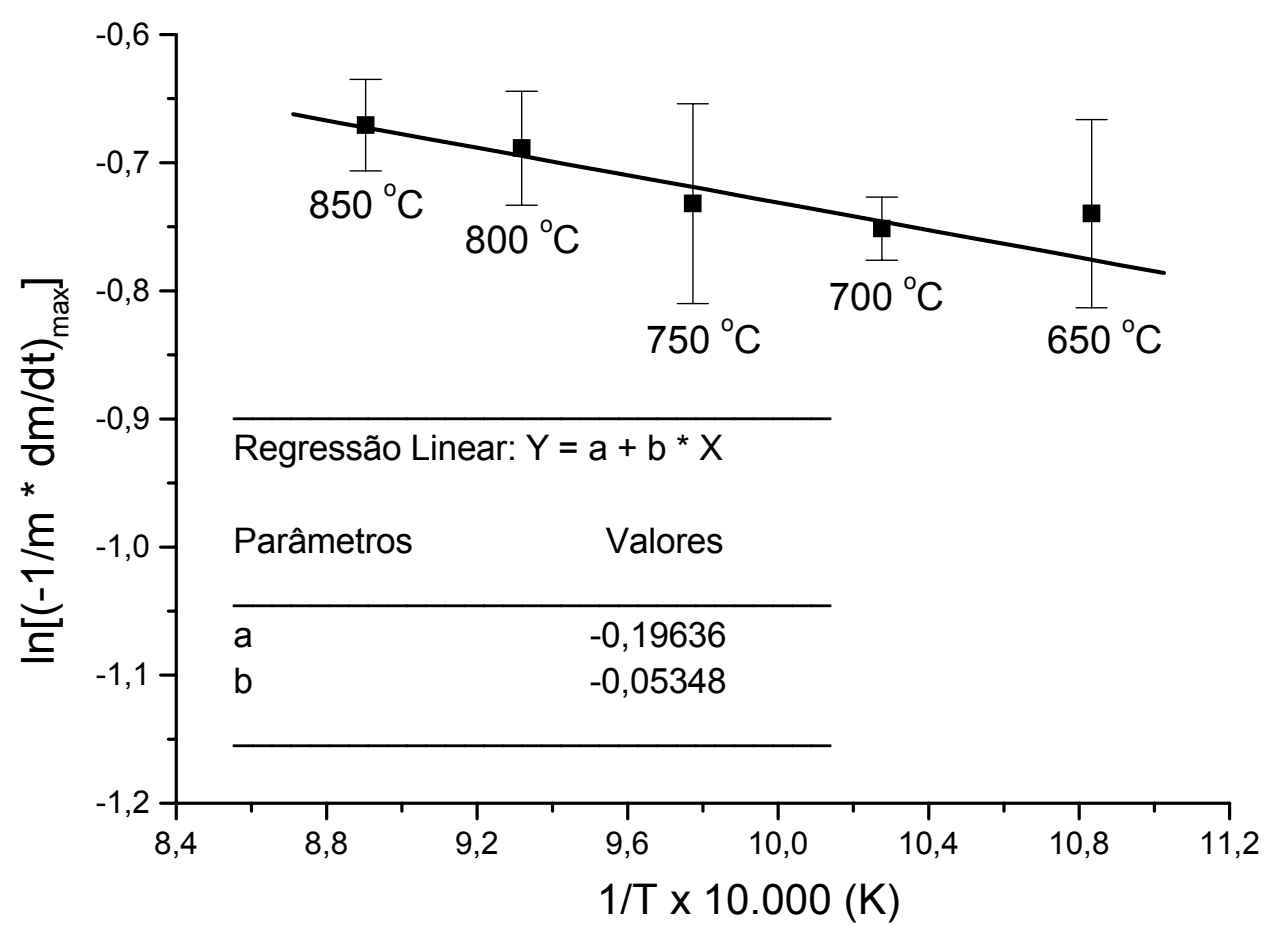

Figura 9: Valores médios de $\ln \left[-\left(\frac{1}{m} \frac{d m}{d t}\right)_{\max }\right\rfloor$ versus 1/T para os ensaios isotérmicos nas temperaturas de 650 a $850{ }^{\circ} \mathrm{C}$ em atmosfera dinâmica de ar. As barras indicam o desvio padrão em relação à média. 
A partir dos parâmetros obtidos na regressão linear calcula-se o fator pré-exponencial $(A)$ e a energia de ativação aparente $\left(E_{a}\right)$. Em atmosfera de ar o coeficiente de taxa de reação máxima $\left(k_{\max }\right)$ é dado pela equação:

$$
k_{\max }(T)=0,822 \exp \left(\frac{4,446}{\mathrm{RT}}\right)
$$

Nos ensaios em atmosfera de nitrogênio não foi observada mudança de mecanismo de reação nas temperaturas de 900 e $950{ }^{\circ} \mathrm{C}$. Devido a isto, os parâmetros cinéticos foram determinados como inicialmente previsto, ou seja, entre as temperaturas de 750 e $950{ }^{\circ} \mathrm{C}$.

A Figura 10 apresenta os resultados obtidos em atmosfera de nitrogênio.

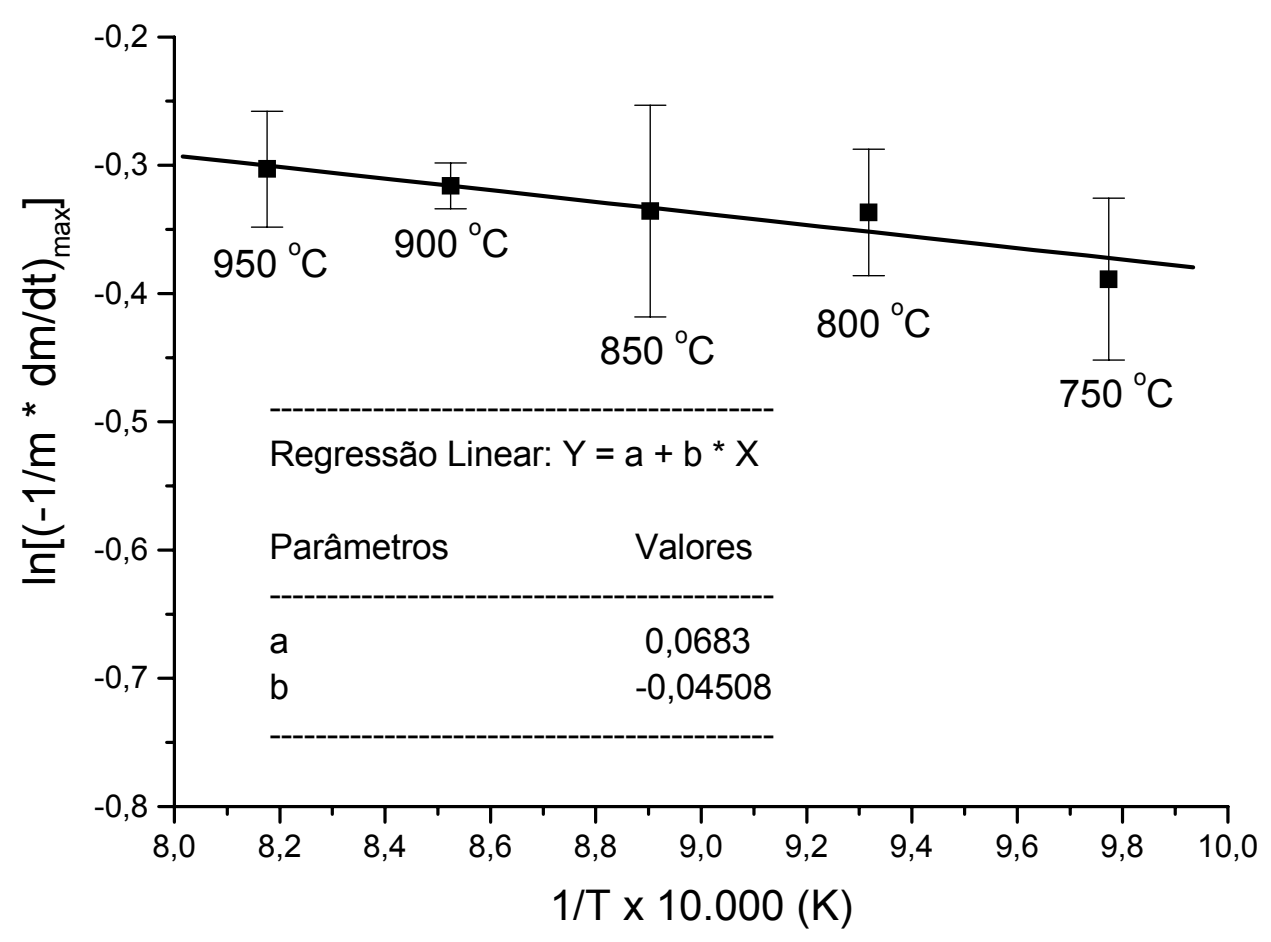

Figura 10: Valores médios de $\ln \left[-\left(\frac{1}{m} \frac{d m}{d t}\right)_{\max }\right\rfloor$ versus 1/T para os ensaios isotérmicos nas temperaturas de 750 à $950^{\circ} \mathrm{C}$ em atmosfera dinâmica de nitrogênio. As barras indicam o desvio padrão em relação à média.

Por regressão linear, obtém-se $k_{\max }$ em atmosfera de nitrogênio dado pela equação: 


$$
k_{\max }(T)=1,071 \exp \left(\frac{3,748}{R T}\right)
$$

As $E_{a}$ reportadas na literatura variam desde unidades até centenas de $\mathrm{kJ} \mathrm{mol}^{-1}$ (IISA e HUPA, 1992; HAJALIGOL et al., 1988; CRNKOVIC, 2003, FUERTES et al., 1994). Essas diferenças se devem a vários fatores, incluindo tipo de calcário, idade geológica, composição química, heterogeneidade dos calcários, granulometria do calcário e condições de ensaios, como atmosfera da balança, pressão, entre outros.

Devido a todos estes fatores pode-se dizer que a diferença entre os parâmetros cinéticos obtidos nas duas atmosferas estudadas não é significativa, mesmo considerando-se que foram obtidos em faixas de temperaturas diferentes.

As energias de ativação aparente obtidas neste trabalho estão dentro de faixas relatadas na literatura. A ordem de grandeza dos resultados obtidos sugere que o processo reativo seja controlado por difusão de Knudsen, que resulta em valores de $E_{a}$ da ordem de $4 \mathrm{~kJ} \mathrm{~mol}^{-1}$ segundo Fuertes et al. (1994).

A difusão de Knudsen ocorre quando o livre caminho médio entre moléculas do gás é maior que o diâmetro de poros do sólido. Neste caso, as moléculas colidem mais freqüentemente com as paredes dos poros do que entre si (FOGLER, 2002).

Na Figura 8, Figura 9 e Figura 10 observa-se também dispersões dos resultados ao redor dos valores médios. Estas serão estatisticamente avaliadas posteriormente, no item 4.4 .

\subsection{EfETIVIDADE dA ReAÇÃo de SulfataÇÃo}

Neste trabalho convencionou-se padronizar os resultados estabelecendo-se os seguintes critérios: chamou-se de tempo zero $\left(t_{0}\right), 100 \mathrm{~s}$ antes do pico máximo da curva DTG, e tempo final $\left(t_{\infty}\right), 200 \mathrm{~s}$ após o tempo zero. Observa-se que, em todos os ensaios, em $t=t_{0}$ a amostra encontrava-se totalmente calcinada, em atmosfera sem $\mathrm{SO}_{2}$, e na temperatura de ensaio 
(DTG igual zero). Em $t=t_{\infty}$ a amostra encontrava-se, em todas os ensaios, completamente sulfatada (DTG igual a zero).

Com os dados das curvas TG e DTG calculou-se a efetividade $\left(\eta=k / k_{\max }\right)$ para os 4 ensaios em cada uma das temperaturas estudadas. As curvas médias dos 4 ensaios são apresentadas na Figura 11 para atmosfera de ar, e na Figura 12 para atmosfera de nitrogênio.

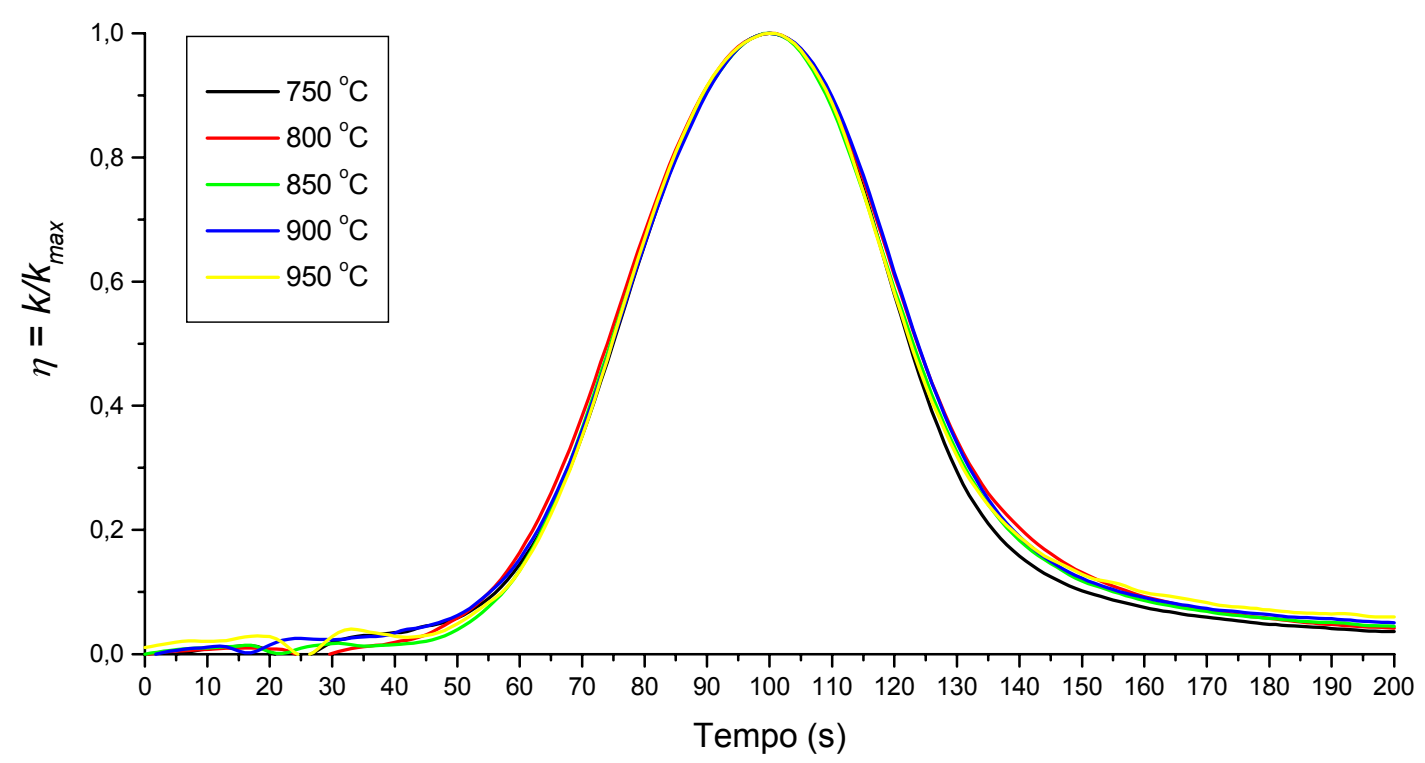

Figura 11: Efetividade versus tempo de sulfatação em atmosfera dinâmica de ar nas temperaturas estudadas. O tempo de 100 s equivale ao tempo de $k_{\max }=\left\lfloor-\left(\frac{1}{m} \frac{d m}{d t}\right)_{\max }\right\rfloor$.

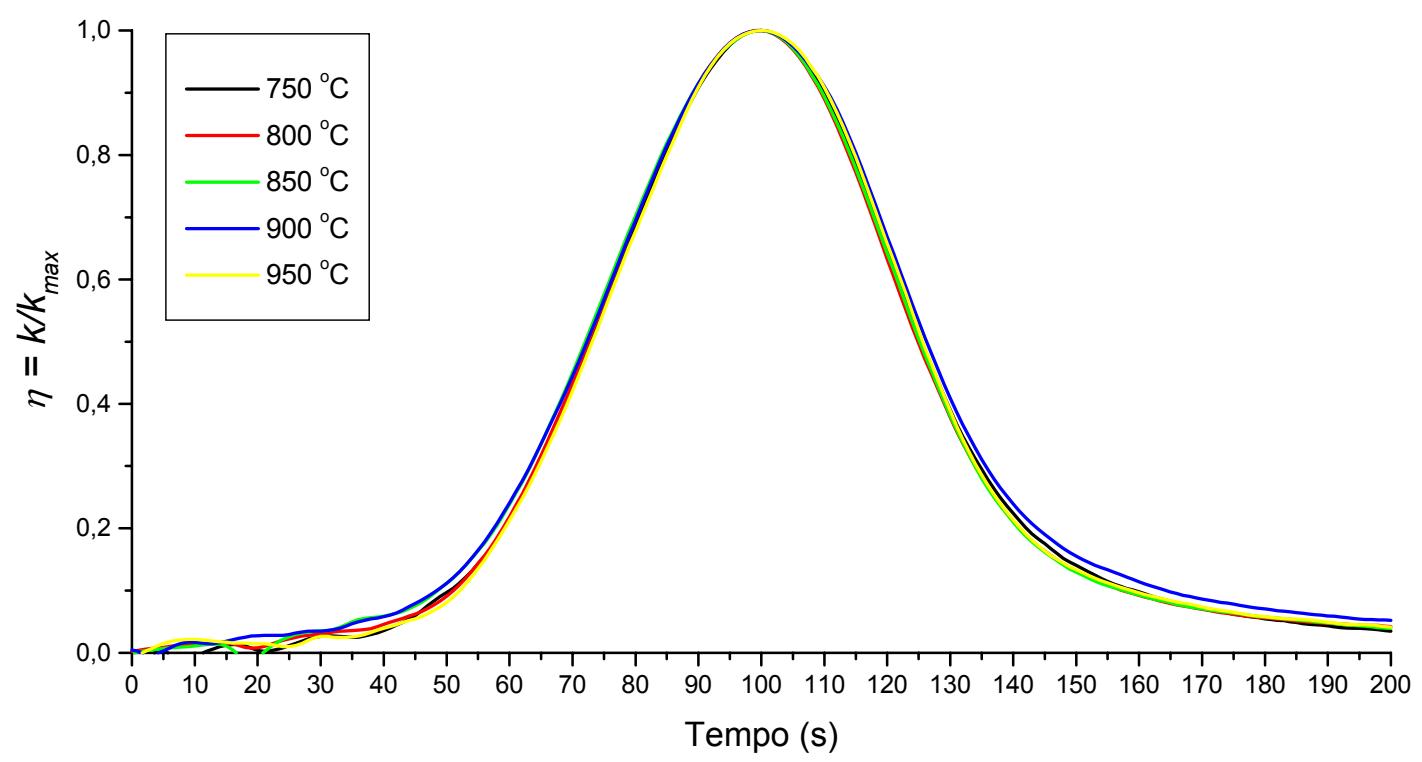

Figura 12: Efetividade versus tempo de sulfatação em atmosfera dinâmica de nitrogênio nas temperaturas estudadas. O tempo de 100 s equivale ao tempo de $k_{\max }=\left\lfloor-\left(\frac{1}{m} \frac{d m}{d t}\right)_{\max }\right\rfloor$. 
Observa-se que as curvas obtidas nas duas atmosferas estudadas são semelhantes e não apresentam diferenças qualitativas. Porém, nota-se que em atmosfera de ar, a partir de $120 \mathrm{~s}$, a efetividade foi mais afetada pela temperatura.

Para melhor comparação quantitativa dos resultados, calculou-se a área abaixo das curvas de efetividade. Os resultados são apresentados na Tabela 5 e Tabela 6 para as atmosfera de ar e de nitrogênio, respectivamente.

Tabela 5: Área abaixo da curva de efetividade e efetividade média na sulfatação do calcário, em atmosfera de ar nas temperaturas estudadas

\begin{tabular}{|c|c|c|c|c|}
\hline \multirow{2}{*}{$\begin{array}{c}\text { Temperatura } \\
\left({ }^{\circ} \mathrm{C}\right)\end{array}$} & \multicolumn{3}{|c|}{ Área da Curva de Efetividade (s) } & \multirow{2}{*}{$\begin{array}{c}\text { Efetividade } \\
\text { Média }\end{array}$} \\
\hline & $0 \mathrm{a} 100 \mathrm{~s}$ & 100 a $200 \mathrm{~s}$ & 0 a $200 \mathrm{~s}$ & \\
\hline 750 & 26,8214 & 27,6614 & 54,4829 & 0,2724 \\
\hline 800 & 27,3405 & 29,7413 & 57,0818 & 0,2854 \\
\hline 850 & 26,5898 & 28,8169 & 55,4066 & 0,2770 \\
\hline 900 & 27,2424 & 29,7500 & 56,9924 & 0,2850 \\
\hline 950 & 27,2054 & 29,5345 & 56,7399 & 0,2837 \\
\hline
\end{tabular}

Tabela 6: Área abaixo da curva de efetividade e efetividade média na sulfatação do calcário, em atmosfera de nitrogênio nas temperaturas estudadas

\begin{tabular}{|c|c|c|c|c|}
\hline \multirow{2}{*}{$\begin{array}{c}\text { Temperatura } \\
\left({ }^{\circ} \mathrm{C}\right)\end{array}$} & \multicolumn{3}{|c|}{ Área da Curva de Efetividade } & \multirow{2}{*}{$\begin{array}{c}\text { Efetividade } \\
\text { Média }\end{array}$} \\
\hline & $0 \mathrm{a} 100 \mathrm{~s}$ & 100 a $200 \mathrm{~s}$ & $0 \mathrm{a} 200 \mathrm{~s}$ & \\
\hline 750 & 29,0416 & 30,8742 & 59,9158 & 0,2996 \\
\hline 800 & 29,607 & 30,3084 & 59,9154 & 0,2996 \\
\hline 850 & 30,2848 & 30,4574 & 60,7422 & 0,3037 \\
\hline 900 & 30,4327 & 32,4034 & 62,836 & 0,3142 \\
\hline 950 & 28,9626 & 31,0128 & 59,9755 & 0,2999 \\
\hline
\end{tabular}

A segunda coluna na Tabela 5 e Tabela 6 apresenta os valores da área abaixo da curva de efetividade no intervalo de tempo de 0 a 100 s. Nota-se na Figura 11 e Figura 12 que este intervalo de tempo a efetividade está 
aumentando com o tempo até o seu valor máximo $(\eta=1)$. Esse crescimento corresponde ao tempo necessário para que o gás reativo difunda-se para o interior das partículas, até que a condição de máxima efetividade de reação seja atingida.

A terceira coluna na Tabela 5 e Tabela 6, apresenta os valores da área abaixo da curva de efetividade no intervalo de tempo de 100 a 200 s. Nota-se na Figura 11 e Figura 12 que neste intervalo de tempo a efetividade é progressivamente reduzida ao longo do tempo. Ocorre que com a evolução do processo reativo os poros das partículas de calcário são progressivamente bloqueados pelo produto $\mathrm{CaSO}_{4}$, e a área superficial interna é reduzida e/ou tornada inacessível.

A quarta coluna na Tabela 5 e Tabela 6, apresenta os valores da área total abaixo da curva de efetividade (de 0 a $200 \mathrm{~s}$ ) e, finalmente, a quinta coluna apresenta a efetividade média. O cálculo da efetividade média ( $\eta_{\text {Média }}$ ), é dado pela equação:

$$
\eta_{\text {Média }}=\frac{\text { Área total abaixo da curva de efetividade }}{\text { Tempo de processo }}
$$

Neste trabalho o tempo de processo considerado foi $200 \mathrm{~s}$ para todas as temperaturas estudadas.

Observa-se na Tabela 5 e Tabela 6 que em todos os ensaios não houve diferenças significativas na área abaixo da curva quando comparado o intervalo de tempo em que a efetividade está aumentando com o intervalo de tempo em que efetividade decresce. Este comportamento é de fato plausível já que tanto o preenchimento dos poros das partículas nas etapas iniciais, quanto o aumento da resistência ao fluxo de gás intra-partícula ao longo do processo, são fenômenos difusivos.

A Figura 13 mostra a efetividade média em função da temperatura nas duas atmosferas estudadas. 


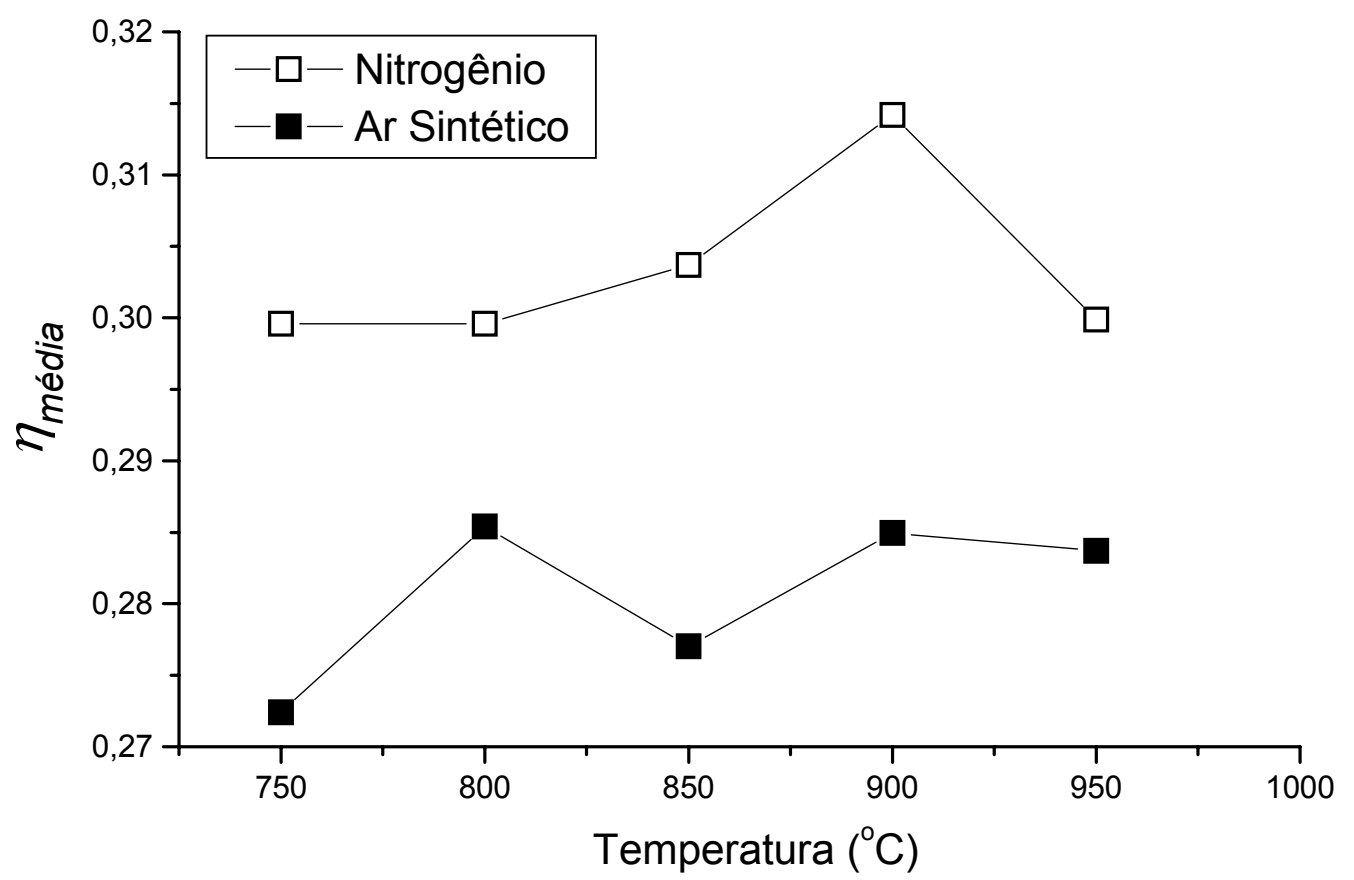

Figura 13: Efetividade média da absorção de enxofre pelo calcário em atmosferas dinâmicas de ar e de nitrogênio, em função da temperatura.

Para todas as temperaturas ensaiadas, a efetividade média no intervalo de $200 \mathrm{~s}$ resultou ligeiramente superior em atmosfera de nitrogênio. Assim, o oxigênio presente na atmosfera de ar parece exercer um leve efeito redutivo sobre as taxas de reação.

Os valores máximos de efetividade média foram encontrados a $800{ }^{\circ} \mathrm{C}$ em atmosferas de $\operatorname{ar}(0,2854)$, e a $900^{\circ} \mathrm{C}$ em atmosfera de nitrogênio $(0,3142)$.

A Tabela 5 e Tabela 6 mostram efetividades médias de reação entre 0,2724 e 0,3142 , estabelecidas ao longo do tempo total de sulfatação de $200 \mathrm{~s}$. Ocorre que, em sistemas de dessulfuração tais como reatores de leito fluidizado, tem-se tempos de exposição do calcário aos gases contendo enxofre muito superiores a 200 s. Nesses casos a eficiência média de sulfatação cai acentuadamente. Considera-se, por exemplo, um tempo de residência do calcário num combustor de leito fluidizado de 1 hora (típico de instalações de pequena escala). Assumindo que o controle da sulfatação seja intrínseco, não afetado pela atmosfera e condições de transporte no meio fluidizado do reator, a efetividade média a $850{ }^{\circ} \mathrm{C}$ resultaria em 0,0169 . 


\subsection{Conversão do $\mathrm{CaO}$ em $\mathrm{CaSO}_{4}$}

Para avaliar o efeito da temperatura e da atmosfera na conversão do $\mathrm{CaO}$ em $\mathrm{CaSO}_{4}$ são utilizadas as curvas TG.

Para o cálculo da conversão assumiu-se, como já descrito no item 4.2, o tempo zero $\left(t_{0}\right)$ a $100 \mathrm{~s}$ antes do pico máximo da curva DTG, e tempo final $\left(t_{\infty}\right)$ de sulfatação a 500 s após o tempo zero. Em todos os ensaios no tempo inicial a amostra encontrava-se totalmente calcinada, em atmosfera sem $\mathrm{SO}_{2}$, e na temperatura de ensaio. O tempo final excede o necessário para sulfatação total. Este fato pode ser verificado nas curvas DTG (Apêndice 1 e Apêndice 2).

$\mathrm{Na}$ Figura 14 e a Figura 15 apresenta-se a variação de massa percentual após injeção de $\mathrm{SO}_{2}$ na balança TG nas atmosferas de ar e nitrogênio, respectivamente. Cada curva corresponde à média de 4 replicatas para cada temperatura estudada.

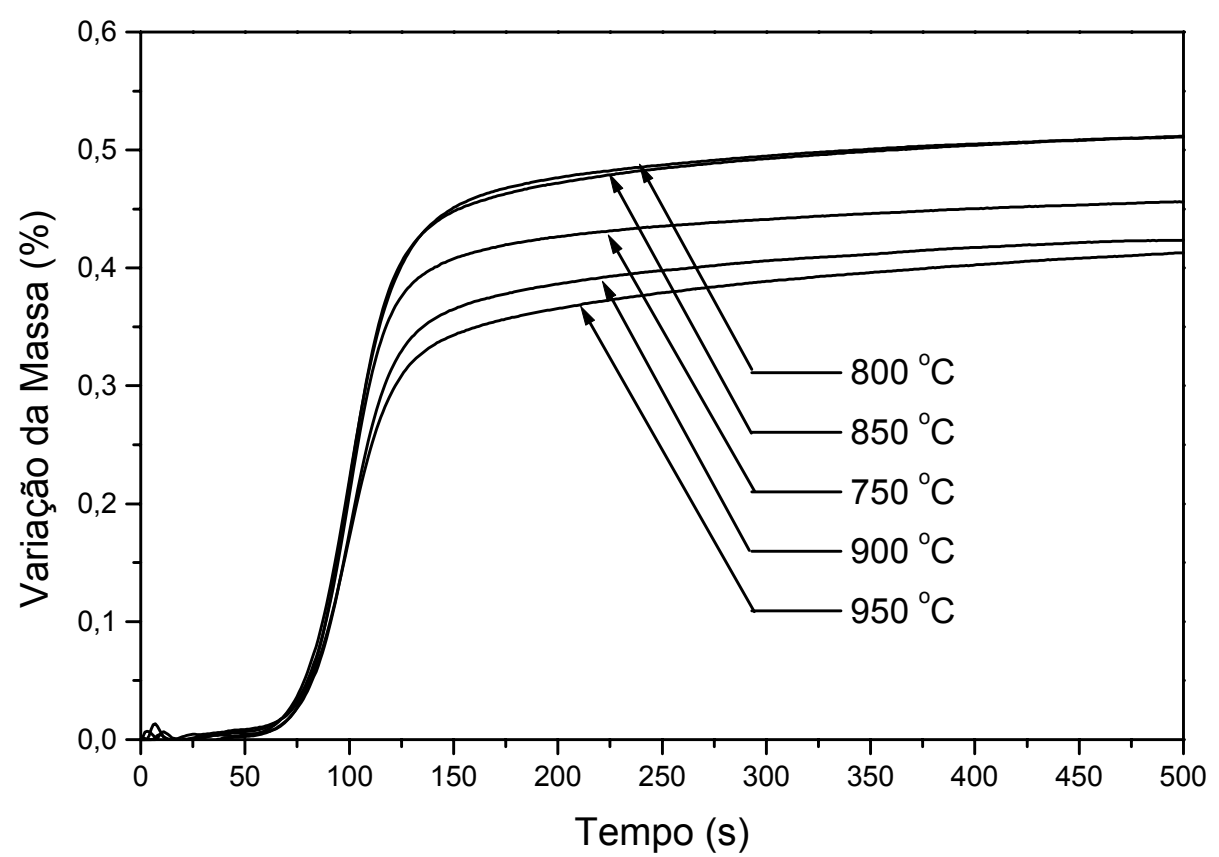

Figura 14: Valores médios da variação de massa na sulfatação do calcário em função do tempo em atmosfera de ar, nas condições isotérmicas de 750, 800, 850, 900 e $950{ }^{\circ} \mathrm{C}$. 


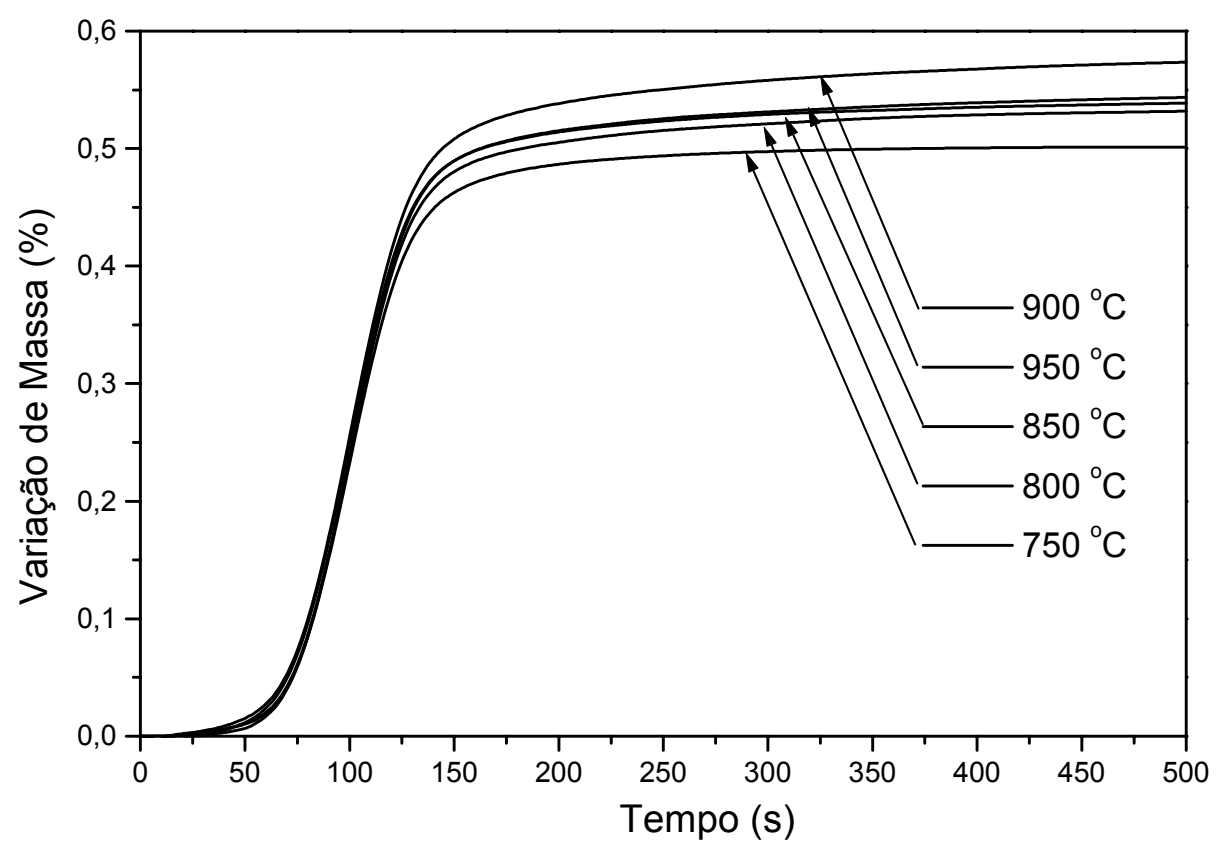

Figura 15: Valores médios da variação de massa na sulfatação do calcário em função do tempo em atmosfera de nitrogênio, nas condições isotérmicas de $750,800,850,900$ e $950{ }^{\circ} \mathrm{C}$.

Observa-se o mesmo comportamento nas curvas de variação de massa em todas as temperaturas estudadas. A Figura 14 mostra que em atmosfera de ar o valor final da variação de massa percentual após a sulfatação decresceu na seguinte ordem: $800 \approx 850>750>900>950{ }^{\circ} \mathrm{C}$. Em atmosfera de nitrogênio obteve-se a seguinte ordem: $900>950 \approx 850>800>750{ }^{\circ} \mathrm{C}$ (Figura 15). As variações de ganho de massa na sulfatação, em ambas as atmosferas, mostram uma forte dependência da temperatura.

Em atmosfera de ar a massa final em altas temperaturas (900 e $\left.950^{\circ} \mathrm{C}\right)$, resultou inferior ao valor encontrado para a temperatura de $750{ }^{\circ} \mathrm{C}$. Em atmosfera de nitrogênio observou-se uma diminuição na massa final a $950{ }^{\circ} \mathrm{C}$ quando comparada ao valor a $900{ }^{\circ} \mathrm{C}$. Nota-se também que em atmosfera de nitrogênio, as curvas permaneceram coincidentes até uma variação de massa maior quando comparadas com as curvas obtidas em atmosfera de ar sintético. Este comportamento anômalo nas curvas em atmosfera de ar sintético e as inversões de comportamento em ambas atmosferas, supostamente devem-se à sinterização do sorvente e/ou re-emissão de $\mathrm{SO}_{2}$.

Crnkovic (2003) investigou o efeito da temperatura na reação de 
sulfatação de um calcário previamente calcinado nas mesmas condições do presente trabalho, em atmosfera de ar. A autora obteve comportamentos semelhantes, atribuindo-os à sinterização, responsável por perda de área superficial interna. O resultado obtido por Crnkovic (2003) é apresentado na Figura 16.

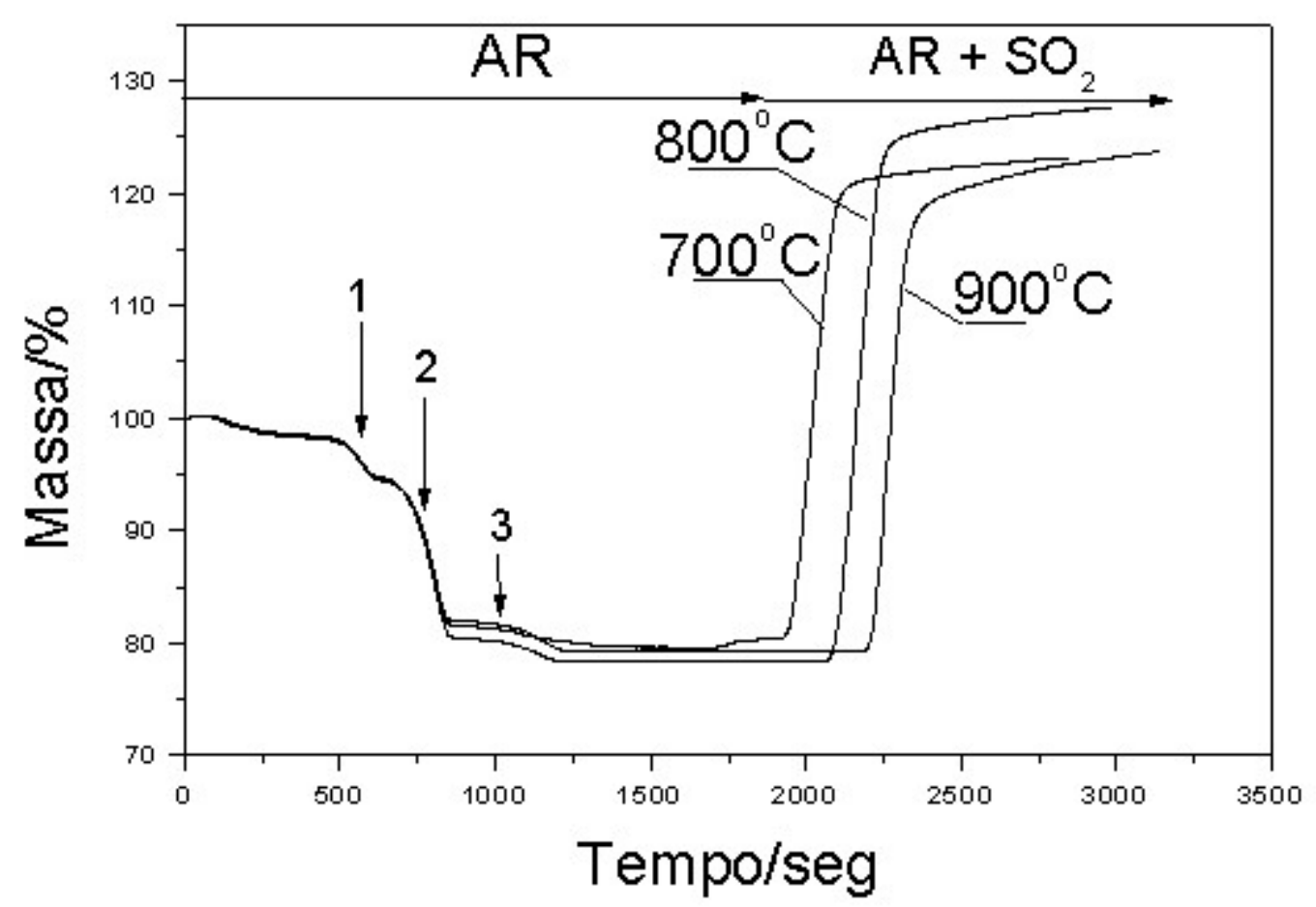

Figura 16: Curvas TG da calcinação do calcário $\mathrm{Cl}$ previamente calcinado e hidratado, seguida de sulfatação nas temperaturas de 700,800 e $900{ }^{\circ} \mathrm{C}$. Condições: razão de aquecimento: $30^{\circ} \mathrm{C} \mathrm{min}{ }^{-1}$. A numeração indica: (1) perda de água (2) desidroxilação e (3) perda de $\mathrm{CO}_{2}$. (CRNKOVIC, 2003).

Com base nas curvas TG obtidas, calculou-se a conversão $(X)$ por meio das equações [30] e [31], para atmosfera de ar e nitrogênio respectivamente.

No cálculo da variação de massa do calcário calcinado após a injeção de $\mathrm{SO}_{2}\left(\Delta M_{S}\right)$ é considerada como massa inicial, a massa calcinada $\left(M_{c}\right)$ no tempo $t_{0}$ e como massa final $\left(M_{F}\right)$, a massa sulfatada no tempo $t_{\infty}$.

Os valores médios de conversão (obtidos para curvas TG médias) são apresentados na Tabela 7 e Figura 17. 
Tabela 7: Conversão média percentual da absorção de Enxofre pelo calcário CaO em atmosferas de ar e nitrogênio

\begin{tabular}{||c|c|c||}
\hline $\begin{array}{c}\text { Temperatura } \\
\left({ }^{\circ} \mathrm{C}\right)\end{array}$ & $\begin{array}{c}\text { Conversão média* em } \\
\text { atmosfera de } \operatorname{Ar}(\%)\end{array}$ & $\begin{array}{c}\text { Conversão média* em } \\
\text { atmosfera de } \mathrm{N}_{2}(\%)\end{array}$ \\
\hline 750 & 38,0 & 50,5 \\
\hline 800 & 41,1 & 54,6 \\
\hline 850 & 41,3 & 55,0 \\
\hline 900 & 36,4 & 58,0 \\
\hline 950 & 35,0 & 56,1 \\
\hline
\end{tabular}

* $\left[\frac{\mathrm{n}^{\circ} \text { moles de } \mathrm{Ca}+\mathrm{Mg} \text { utilizados para absorver } \mathrm{SO}_{2}}{\mathrm{n}^{\circ} \cdot \text { moles de } \mathrm{Ca}+\mathrm{Mg} \text { na amostra }} \times 100\right]$

Observa-se na Tabela 7 que os valores de conversão para cada temperatura estudada resultaram maiores em atmosfera de nitrogênio. Em atmosfera de ar o valor máximo de conversão $(41,3 \%)$ ocorreu na temperatura de $850{ }^{\circ} \mathrm{C}$, enquanto que em atmosfera de $\mathrm{N}_{2}$ o valor máximo $(58,0 \%)$ ocorreu a $900{ }^{\circ} \mathrm{C}$. Assim, levando-se em consideração estes valores máximos, a máxima conversão em atmosfera de nitrogênio resultou aproximadamente $29 \%$ maior que em atmosfera de ar.

Na Figura 17 é apresentada a conversão média percentual em função da temperatura nas duas atmosferas estudadas.

Nota-se na Figura 17 que tanto para a atmosfera de ar quanto de nitrogênio que a conversão aumentou com a temperatura até um ponto de máximo, decaindo a seguir. Considerou-se o ponto de máximo do ajuste polinomial como a temperatura ótima da conversão de $\mathrm{CaO}$ em $\mathrm{CaSO}_{4}$. A temperatura ótima de sulfatação resultou entre 800 e $850{ }^{\circ} \mathrm{C}$ em atmosfera de ar, e muito próxima de $900^{\circ} \mathrm{C}$ para atmosfera de nitrogênio.

Os resultados obtidos neste trabalho são coerentes com dados de literatura. Moss (1975) estudou a eficiência de absorção de $\mathrm{SO}_{2}$ por partículas de calcário com granulometria de 100 a $200 \mu \mathrm{m}$, em leito fluidizado com gases da queima de óleo combustível com $4 \%$ de enxofre. Empregou temperaturas 
de processo entre cerca de 805 e $914{ }^{\circ} \mathrm{C}$, e observou máxima conversão em torno de $865^{\circ} \mathrm{C}$.

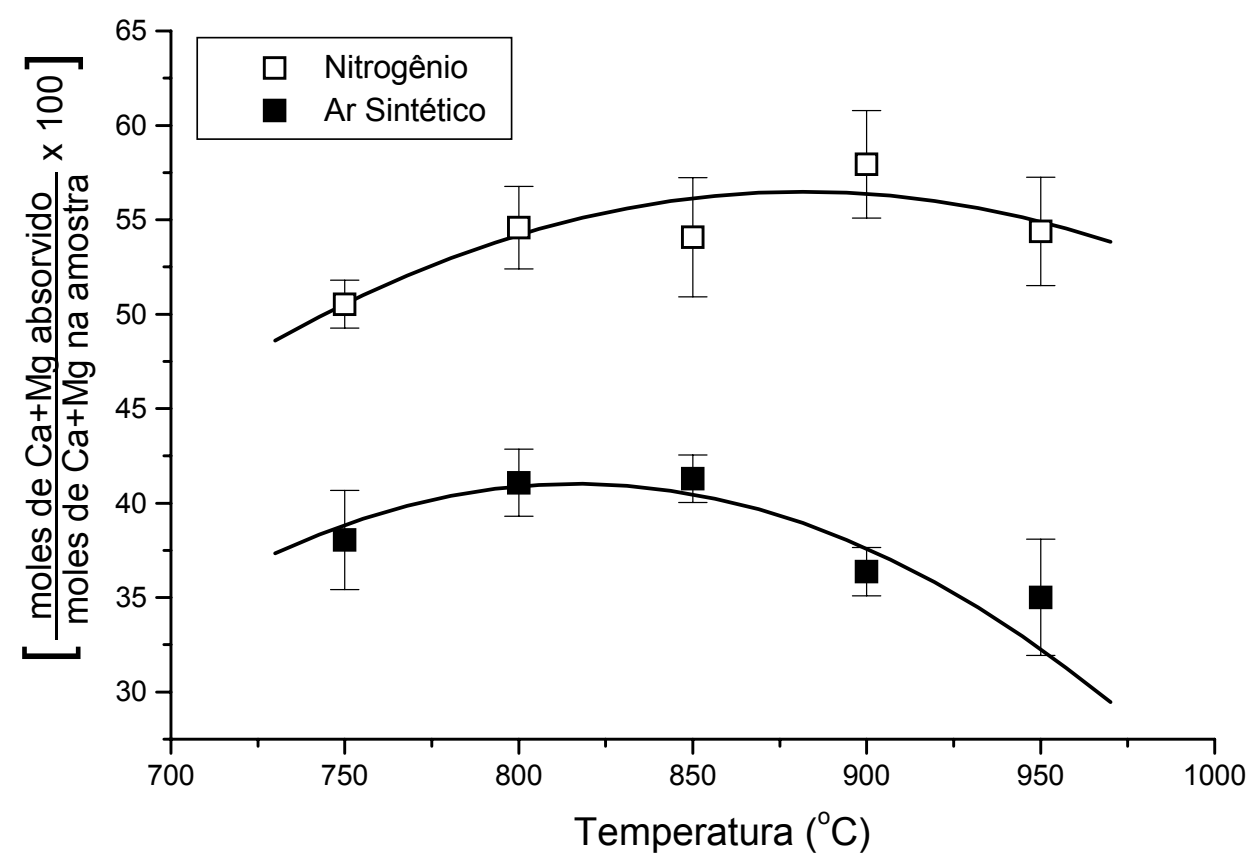

Figura 17: Conversão percentual da absorção de enxofre pelo $\mathrm{CaO}$ em atmosfera dinâmica de ar e de nitrogênio em função da temperatura. As barras indicam o desvio padrão em relação à média.

Costa (2000) estudou o efeito da temperatura sobre a conversão e o coeficiente global de taxa de reação na absorção de $\mathrm{SO}_{2}$ por calcário, com granulometria média de $650 \mu \mathrm{m}$, em leito fluidizado com ar contendo $1000 \mathrm{ppm}$ de $\mathrm{SO}_{2}$. Aplicou temperaturas de processo entre 700 e $958{ }^{\circ} \mathrm{C}$. Embora tenha obtido coeficiente global de taxa de reação máximo em torno de $881{ }^{\circ} \mathrm{C}$, conversão manteve-se crescente com a temperatura, não apresentando um máximo no intervalo estudado.

Não há um consenso na literatura a respeito da influência do $\mathrm{O}_{2}$ na absorção do $\mathrm{SO}_{2}$ pelo calcário.

Os resultados de Liping et al. (2001) indicaram que a maior absorção de enxofre pelo calcário deu-se em atmosfera contendo $\mathrm{O}_{2}$, e a menor em atmosfera de $\mathrm{N}_{2}$.

Dennis e Hayhurst (1990) estudaram a conversão da absorção de $\mathrm{SO}_{2}$ 
por calcário em leito fluidizado, em atmosfera com quantidades variáveis de $\mathrm{O}_{2}$ e $\mathrm{N}_{2}$. Concluíram que a conversão aumentou com o decréscimo da fração molar de $\mathrm{O}_{2}$, porém a adição de uma pequena quantidade de $\mathrm{O}_{2}$ acelerou a taxa de sulfatação sem que ocorresse uma diminuição significativa na conversão.

Dam-Johansen e Ostergaard (1991-IV) observaram que taxas de sulfatação de calcário aparentam independentes da concentração de $\mathrm{O}_{2}$ para temperaturas abaixo de $735{ }^{\circ} \mathrm{C}$, e aumentam na presença de $\mathrm{O}_{2}$ acima de $830{ }^{\circ} \mathrm{C}$.

\subsection{Avaliação Estatística dos Resultados}

De um modo geral, para as 2 atmosferas estudadas, observou-se dispersão dos resultados em torno da média, dado pelo desvio padrão, tanto nos resultados do estudo cinético quanto nos resultados de conversão.

Possivelmente esta dispersão deve-se à heterogeneidade da amostra, tanto em termos de composição química quanto em termos de granulometria.

Para avaliar a precisão dos resultados obtidos nos estudos cinéticoquímicos e de conversão, calculou-se o coeficiente de variação (CV), através da equação [35].

A Tabela 8 apresenta valores do coeficiente de variação (CV) obtidos nos resultados do estudo cinético-químico, que são apresentados no Apêndice 5 e Apêndice 6.

Mesmo que o valor de CV possa ser considerado alto para a temperatura de $850{ }^{\circ} \mathrm{C}$ em atmosfera de nitrogênio, de acordo com a classificação dada por Gomes (1973), este encontra-se dentro da faixa de aceitação adotada neste trabalho, ou seja, < 25\%. (ver item 3.7). 
Tabela 8: Análise estatística dos valores de $\ln \left(k_{\max }\right)$ obtidos no estudo cinético-quimico na absorção de enxofre por calcário em atmosfera de ar e de nitrogênio.

\begin{tabular}{||c|c|c|c|c|c|c||}
\hline \multirow{2}{*}{$\begin{array}{c}\text { Temp. } \\
\left({ }^{\circ} \mathrm{C}\right)\end{array}$} & \multicolumn{3}{|c|}{ Atmosfera de Ar } & \multicolumn{3}{c||}{ Atmosfera de Nitrogênio } \\
\cline { 2 - 7 } & $\begin{array}{c}\text { Média }\left(k_{\text {max }}\right) \\
\text { Pesvio }\end{array}$ & $\begin{array}{c}\text { CV } \\
(\%)\end{array}$ & $\begin{array}{c}\text { Média } \\
\ln \left(k_{\max }\right)\end{array}$ & $\begin{array}{c}\text { Desvio } \\
\text { Padrão }\end{array}$ & $\begin{array}{c}\mathrm{CV} \\
(\%)\end{array}$ \\
\hline 650 & $-0,73976$ & 0,07339 & $-9,92065$ & - & - & - \\
\hline 700 & $-0,75142$ & 0,02471 & $-3,28858$ & - & - & - \\
\hline 750 & $-0,73194$ & 0,07806 & $-10,6655$ & $-0,38885$ & 0,06298 & $-16,1972$ \\
\hline 800 & $-0,68873$ & 0,04454 & $-6,46631$ & $-0,33679$ & 0,04946 & $-14,6865$ \\
\hline 850 & $-0,67082$ & 0,03564 & $-5,31308$ & $-0,33563$ & 0,08252 & $-24,5871$ \\
\hline 900 & $-0,86196$ & 0,05500 & $-6,38049$ & $-0,31609$ & 0,01774 & $-5,61174$ \\
\hline 950 & $-0,94516$ & 0,14382 & $-15,2164$ & $-0,30301$ & 0,04518 & $-14,9091$ \\
\hline
\end{tabular}

A Tabela 9 apresenta valores dos coeficientes de variação (CV) obtidos nos resultados da conversão de calcário, que são apresentados no Apêndice 7 e Apêndice 8.

Tabela 9: Análise estatística dos resultados de conversão obtidos em atmosferas de ar e de nitrogênio

\begin{tabular}{||c|c|l|c|c|c|c||}
\hline \hline \multirow{2}{*}{$\begin{array}{c}\text { Temperatura } \\
\left({ }^{\circ} \mathrm{C}\right)\end{array}$} & \multicolumn{3}{|c|}{ Atmosfera de Ar } & \multicolumn{3}{c||}{ Atmosfera de Nitrogênio } \\
\cline { 2 - 7 } & $\begin{array}{c}\text { Média } \\
(\mathrm{X})\end{array}$ & $\begin{array}{c}\text { Desvio } \\
\text { Padrão }\end{array}$ & $\begin{array}{c}\mathrm{CV} \\
(\%)\end{array}$ & $\begin{array}{c}\text { Média } \\
(\mathrm{X})\end{array}$ & $\begin{array}{c}\text { Desvio } \\
\text { Padrão }\end{array}$ & $\begin{array}{c}\mathrm{CV} \\
(\%)\end{array}$ \\
\hline 750 & 38,042 & 2,628 & 6,908 & 50,529 & 1,268 & 2,509 \\
\hline 800 & 41,083 & 1,777 & 4,325 & 54,585 & 2,176 & 3,986 \\
\hline 850 & 41,292 & 1,260 & 3,052 & 54,96 & 4,050 & 7,369 \\
\hline 900 & 36,371 & 1,281 & 3,522 & 57,937 & 2,837 & 4,896 \\
\hline 950 & 35,011 & 3,076 & 8,785 & 56,122 & 3,818 & 6,803 \\
\hline
\end{tabular}

De acordo com a classificação de Gomes (1973), os resultados de CV obtidos na resultados de conversão, são considerados baixos para todas as temperaturas em ambas atmosferas estudadas. 
Nota-se que a comparação com os resultados de Gomes (1973) é apenas ilustrativo já que os processos em questão são de naturezas bastante distintas. Os valores de CV dados na Tabela 8 e Tabela 9 foram obtidos a partir de 4 experimentos em cada temperatura. Fica claro que podem ser reduzidos realizando-se maior números de ensaios. Entretanto, 4 replicatas em cada caso ensaiado, já configura número de ensaios relativamente alto em estudos termogravimétricos de processos heterogêneos. 


\section{Capítulo 5}

\section{CONCLUSÕES E SUgestõES}

\subsection{CONCLUSÕES}

Para as condições experimentais do presente estudo isotérmico da absorção de $\mathrm{SO}_{2}$ por calcário em balança termogravimétrica, utilizando-se calcário calcítico de Itaú de Minas com granulometria média de $545 \mu \mathrm{m}$, nas temperaturas de:

- 650 a $950{ }^{\circ} \mathrm{C}$ para atmosfera dinâmica de ar sintético, e

- 750 a $950{ }^{\circ} \mathrm{C}$ para atmosfera dinâmica de nitrogênio, pode-se concluir que:

- Os coeficientes da taxa de reação $(k)$ para o processo de sulfatação obtidas nas condições experimentais deste trabalho são;

$-k(T)=0,822 \exp \left(\frac{4,446}{R T}\right)$, em atmosfera de ar, e

$-k(T)=1,071 \exp \left(\frac{3,748}{\mathrm{RT}}\right)$, em atmosfera nitrogênio.

A diferença entre os parâmetros cinéticos obtidos nas duas atmosferas estudadas não é significativa.

A ordem de grandeza dos valores de energia de ativação obtidos $\left(4,446 \mathrm{~kJ} \mathrm{~mol}^{-1}\right.$ em atmosfera de ar e 3,748 $\mathrm{kJ} \mathrm{mol}^{-1}$ em atmosfera de nitrogênio) sugere que o processo reativo seja controlado por difusão de Knudsen. 
- As curvas de efetividade obtidas nas duas atmosferas estudadas mostraram-se semelhantes e não apresentaram diferenças qualitativas. Entretanto em atmosfera de ar, a partir de $20 \mathrm{~s}$ após o máximo, a efetividade foi mais afetada pela temperatura que em atmosfera de nitrogênio.

- Não observou-se diferenças significativas nas áreas abaixo das curvas de efetividade quando comparado o intervalo de tempo em que a efetividade cresce com o intervalo em que a mesma decresce. Esse comportamento é coerente já que o processo reativo em ambos os intervalos é dominado por fenômenos de difusão.

- Verificou-se também que em atmosfera nitrogênio os valores de efetividade média, calculados para um tempo de processo de $200 \mathrm{~s}$, são discretamente maiores que em atmosfera de ar sintético.

- Os maiores valores encontrados de efetividade média foram a $800{ }^{\circ} \mathrm{C}$ $(0,2854)$ em atmosferas de ar e a $900{ }^{\circ} \mathrm{C}(0,3142)$ em atmosfera de nitrogênio.

- As efetividades médias resultaram entre 0,2724 e 0,3142 no intervalo de tempo de $200 \mathrm{~s}$ em que a sulfatação foi considerada completa em todos os ensaios. Considerando um tempo de residência em reator de leito fluidizado de 1 hora, e controle de sulfatação intrínseco, a efetividade média resultaria em 0,0169.

- Nas duas atmosferas estudadas, observou-se 0 mesmo comportamento das curvas de ganho de massa no processo de sulfatação do calcário em todas as temperaturas estudadas.

- Em atmosfera de ar, o ganho de massa na sulfatação a 900 e $950{ }^{\circ} \mathrm{C}$ resultou inferior ao valor encontrado a $750{ }^{\circ} \mathrm{C}$. Em atmosfera de nitrogênio, o ganho de massa a $950{ }^{\circ} \mathrm{C}$ resultou inferior a $900{ }^{\circ} \mathrm{C}$. Essas quedas nas temperaturas mais elevadas devem-se, possivelmente, à sinterização e/ou re-emissão de $\mathrm{SO}_{2}$. 
- A temperatura ótima de conversão resultou entre 800 e $850{ }^{\circ} \mathrm{C}$ em atmosfera de ar, e muito próxima de $900{ }^{\circ} \mathrm{C}$ para atmosfera de nitrogênio.

- Os máximos valores de conversão resultaram até $29 \%$ maiores em atmosfera de nitrogênio em relação à atmosfera de ar.

- A precisão dos resultados obtidos nos experimentos foi avaliada pelo cálculo do coeficiente de variação (CV). Obteve-se valores de CV inferiores a $25 \%$ em todos os ensaios, considerando-se 4 replicatas realizadas em cada caso.

- A metodologia aplicada neste trabalho mostrou-se viável para a determinação dos parâmetros cinéticos, efetividade e conversão da reação de sulfatação de materiais calcários, atingindo assim os objetivos específicos propostos inicialmente.

\subsection{Sugestões Para Trabalhos Futuros}

- Avaliar a viabilidade de aplicar outros modelos cinéticos para estabelecer fatores pré-exponenciais e energias de ativação, e comparar com o método aplicado neste trabalho.

- Utilizar o método descrito por Borgwardt e Harvey (1972) para obter o fator de efetividade. Neste caso deve-se realizar ensaios com diferentes tamanhos de partícula, e avaliar a taxa de reação nos seus instantes iniciais.

- Analisar efeitos de condições operacionais sobre os parâmetros cinéticos e regiões reativas. Considerar, por exemplo, efeitos do tamanho do particulado e das frações de $\mathrm{O}_{2}$ e $\mathrm{CO}_{2}$ na atmosfera reativa.

- Estudar a cinética de absorção de $\mathrm{SO}_{2}$ por outros tipos de calcário.

- Investigar, a possibilidade de absorção de $\mathrm{SO}_{2}$ pelo $\mathrm{MgO}$ presente nos calcários calcinados. 
- Estudar a cinética da sulfatação direta.

- Analisar a composição de calcários sulfatados quanto à presença de diferentes espécies contendo enxofre (notadamente $\mathrm{CaSO}_{4}, \mathrm{CaSO}_{3}$, CaS).

- Investigar o grau de sinterização e a perda de porosidade de calcários sulfatados a altas temperaturas.

- Estudar a possível re-emissão de $\mathrm{SO}_{2}$ a altas temperaturas de calcários sulfatados.

- Estudar a evolução da porosidade de calcários ao longo da sulfatação.

- Determinar coeficientes globais de taxa de sulfatação de calcários em reator de leito fluidizado, comparando-os com os coeficientes intrínsecos obtidos via termogravimetria, para estudo de controle de reação em reator de leito fluidizado. 


\section{REFERÊNCIAS BIBLIOGRÁFICAS}

ADÁNEZ, J.; FIERRO, V; DIEGO, J.A. de; DIEGO, L.F. de; GARCÍA-LABIANO, F. (1996) The effect of the porous structure on sorbent sulfation under coal-fired boiler conditions. Thermochimica Acta, 277, 151-164.

ADÁNEZ, J.; GARCIÁ-LABIANO, F.; GAYÁN, P. (1993) Sulfur Retention in AFBC. Modelling and Sorbent Characterization Methods. Fuel Processing Technology, 36, 73-79.

ANTHONY, E.J.; GRANATSTEIN, D.L. (2001) Sulfation phenomena in fluidized bed combustion systems. Progress in Energy and Combustion Science 27 215-236.

ATKINS, P.; JONES, L. (2001) Princípios de Química. Ed. Bookman, 911 p. Porto Alegre.

BORGWARDT, R. H. (1985) Calcination Kinetics an surface area of dispersed limestone particles. AIChE J., 32, 239-246.

BORGWARDT, R. H.; BRUCE, K. R. (1986) Effect of specific surface area on the reactivity of $\mathrm{CaO}$ with $\mathrm{SO}_{2}$. AIChE J., v.31, n.1, 103-111.

BORGWARDT, R. H.; HARVEY, R. D. (1972) Properties of carbonate rocks to $\mathrm{SO}_{2}$ reactivity. Env. Sc. Tech., 6, 350-360.

BROWN, M. E. Introduction to Thermal Analysis. Chapman and Hall Ltd. 1988, New York.

BRUCE, K.R.; GULLETT, B.K; BEACH, L.O. (1989). Comparative $\mathrm{SO}_{2}$ reactivity of $\mathrm{CaO}$ derive from $\mathrm{CaCO}_{3}$ and $\mathrm{Ca}(\mathrm{OH})_{2}$. AlChE Jornal, vol.35, no.1. 
BURNHAM, A. K.; BRAUN, R. L. (1999) Global kinetic analysis of complex materials. Energy \& Fuels, 13-1, 1-22.

CAMARGO, F.L. (2001) Qualificação de calcários Brasileiros quanto à absorção de $\mathrm{SO}_{2}$ em leito fluidizado para condições típicas de combustão de carvão. Dissertação de Mestrado, EESC-USP.

CARELLO, S.A.; VILELA, A.C.F. (1993) Evaluation of the reactivity of south brasilian limestones in relation to pure $\mathrm{SO}_{2}$ througt termoanalysis and scanning electron microscopy. Ind. Eng. Chem. Res., v. 32, 3135-42.

CHENG, J. et al. (2003) Sulfur removal at high temperature during coal combustion in furnaces: a review. Progress in Energy and Combustion Science 29, 381-405.

COSTA, M. C. D. (2000) Efeito da temperatura sobre a conversão e o coeficiente de taxa de reação na absorção de $\mathrm{SO}_{2}$ por calcário em reator de leito fluidizado, Dissertação de Mestrado, EESC-USP, 174p.

CRNKOVIC, P. C. G. M. (2003) Análise termogravimétrica para a determinação de fatores que afetam a eficiência de sorção de $\mathrm{SO}_{2}$ por calcários na combustão de carvões. Tese de Doutorado, IQSC-USP, 127p.

DAM-JOHANSEN, K.; OSTERGAARD, K. (1991) High-Temperature Reaction between Sulphur dioxide and Limestone - I. Comparison of limestones in two laboratory reactors and a pilot plant. Chemical Engineering Science, 46, No. 3, p.827-837.

DAM-JOHANSEN, K.; OSTERGAARD, K. (1991) High-Temperature Reaction between Sulphur dioxide and Limestone - II. An improved experimental basis for a mathematical model. Chemical Engineering Science, Vol.46, no.3, p.839-845.

DAM-JOHANSEN, K.; OSTERGAARD, K. (1991) High-Temperature Reaction between Sulphur dioxide and Limestone - III. A grain-micrograin model and its verification. Chemical Engineering Science, Vol.46, No.3, p.847-853.

DAM-JOHANSEN, K.; OSTERGAARD, K. (1991) High-Temperature Reaction between Sulphur dioxide and Limestone - IV. A discussion of chemical reaction mechanisms and kinetics. Chemical Engineering Science, Vol.46, No.3, p.855-859. 
DAVINI, P.; DEMICHELE, G., BERTACCHI, S. (1991) Reaction between calcium-based sorbents and sulphur dioxide: a thermogravimetric investigation, Fuel, 70, 201-204.

DENNIS, S.; HAYHURST, A.N. (1984) The effect of pressure on the kinetics an extent of sulphation of calcareous materials. I. Chem. E. Symposium series no. 87.

DENNIS, S.; HAYHURST, A.N. (1987) The effect of $\mathrm{CO}_{2}$ on the kinetics and extent of calcination of limestone and dolomite particles in fluidised beds. Chemical Engineering Science, 42, 2361-2372.

DENNIS, S.; HAYHURST, A.N. (1990) Mechanism of the sulphation of calcined limestone particles in combustion gases. Chemical Engineering Science, 45 1175-1187.

FOGLER, H.S. Elementos de Engenharia Química. LTC - Livros Técnicos e Científicos Editora S.A. $3^{\text {a }}$. Ed. 1999. Rio de Janeiro.

FUeRTES, A. B.; VelASCO, G.; FUenTE, E.; ALVAREZ, T. (1994) Study of the direct sulfation of limestone particles at high $\mathrm{CO}_{2}$ partial pressures. Fuel Processing Technology, 38, 181-192.

GOMES, F. P. C. (1973) Curso de Estatística Experimental. 5a . Ed. Livraria Nobel S.A. São Paulo.

HAJALIGOL, M. R.; LONGWELL, J. P.; Sarofim, A. F. (1988) Analysis and modelling of the direct sulfation of $\mathrm{CaCO}_{3}$. Ind. Eng. Chem. Res., 27, 22032210.

HARTMAN, M.; COUCHLIN, R. W. (1976) Reaction of Sulfur Dioxide with limestone and the grain model. AIChE J., v.22, n.3, 490-8.

HSIA, C.; PIERRE, G. R. S.T; RAGHUNATAHN, K.; Fan, L. S. (1993) Diffusion through $\mathrm{CaSO}_{4}$ formed during the reaction of $\mathrm{CaO}$ with $\mathrm{SO}_{2}$ and $\mathrm{O}_{2}$. AIChE J., 39-4, 698-700.

IISA, K.; HUPA, M. (1992) Rate-limiting processes for the desulphurisation reaction at elevated pressures. J. Inst. Energy, 65, 201-205. 
IONASHIRO, M.; GIOLITO, I. (1980) Nomenclatura, padrões e apresentação dos resultados em análise térmica. Cerâmica, v. 26, p. 17 - 24,. http://www.abratec.com.br/cgi-bin/abratec/db/db.cgi?socioseauthorize)

IONASHIRO, M.; GIOLITO, I. (1988) A nomenclatura em análise térmica Parte II. Cerâmica, v. 34, p. 163 - 24, (http://www.abratec.com.br/cgibin/abratec/db/db.cgi?socioseauthorize)

LAURSEN, K et al. (2000) Sulfation and reactivation characteristics of nine limestone. Fuel 79, 153-163.

LEITE, F. (1996) Validação em Análise Química. Editora Átomo. Campinas

LI, Y.; SADAKATA, M. (1999) Study of gypsum formation of appropriate dry desulfurization process of flue gas. Fuel, 78, 1089-1095.

LINDO, J.E.S. (2003). Efeito da concentração de $\mathrm{SO}_{2}$ nas reações de calcinação e sulfatação de calcários em reator de leito fluidizado. Dissertação de Mestrado, EESC-USP, 116p.

LIPING, C.; WEIREN, B., KECHANG, X. (2001) Study on the factors influencing limestone capturing sulfur during coal combustion. Energy Sources, 23, 287-293.

LOW, M. J. D.; GOODSEL, A. J.; TAKEZAWA, N. (1971) Reactions of gaseous pollutants with solids. I. Infrared study of the sorption of $\mathrm{SO}_{2}$ in CaO. Environ. Sci. Technol., 5, 1191-1195.

MACKENZIE, R.C. (1979) Nomenclature in thermal analysis, part IV. Thermochimica Acta, 28, 1-C.

MAI, M. C.; EDGAR, T. F. (1989) Surface area evolution of calcium hydroxide during calcination and sintering. AIChE J., 35-1, 30-36.

MATTISSON, T.; LYNGFELT, A. (1998) Reaction between sulfur dioxide and limestone under periodically changing oxidizing and reducting. Energy Fuels, 12, 905-912.

McCAULEY, R. A.; Johnson, L. A. (1991). Decrepitation and thermal decomposition of dolomite. Thermochimlca Acta , v.185, p. 271-282. 
McINTOSH, R.M., SHARP, J.H., WILBURN, F.W. (1990). The thermal decomposition of dolomite. Thermochim. Acta, v. 165, p. 281-296.

MICHELS Jr., Valdir. (2004) Influência da temperatura na absorção de $\mathrm{SO}_{2}$ por calcários na combustão em leito fluidizado de carvão mineral. Dissertação de Mestrado, EESC-USP, $111 \mathrm{f}$.

MOSS, G. (1975) The mechanism of sulphur absorption in fluidized beds of lime. Institute of fuel symposium series NO.1: Fluidised Combustion. D2.

OZAWA, T. (1965) A new method of analyzing thermogravimetric data. Bulletin of the Chemical Society of Japan, 38-11, 1881-1886.

PAGLIUSO, J.D.; MILIOLI, F.E.; CRNKOVIC, P.M.; COSTA, M.L.D.; SILVA, G.F.; CAMARGO, F.L. (2002) Absorption of sulfur dioxide by different types of limestone in fluidized bed reactor and TGA. AICHE Annual Meeting, Indianápolis.

PARADINE, C. G.; RIVETT, B.H. (1974) Métodos Estatísticos para Tecnologistas. Ed. Polígono - Ed. Da USP. São Paulo.

PETTIJOHN, F.J. (1957) Sedimentary Rocks. Harper, NY.

PIGFORD, R.; SLIGER, G. (1973) Rate of diffusion-controlled reaction between a gas and a porous solid sphere- reaction of $\mathrm{SO}_{2}$ with $\mathrm{CaCO}_{3}$. Ind. Eng. Chem. Process Des. Develop, 12-1, 85-91.

PRASAD, T. P.; KANUNGO, S. B.; RAY, H. S. (1992) Non-isothermal kinetics: some merits and limitations. Thermochimica Acta, 203, 503-514.

SHIMAKURA, S.E.; RIBEIRO Jr. P.J. (2005) Apostila de Estatística. Departamento de Estatística/ UFPR. Disponível na Internet no endereço: http://www.est.ufpr.br/ paulojus/CE003/ce003.pdf em 25/02/05

SILVA, F.F. (2003) Efeito da distribuição granulométrica do calcário na absorção de $\mathrm{SO}_{2}$ em reator de leito fluidizado. Dissertação de Mestrado, EESC-USP, 114p.

SILVA, G. F. (2001) Efeito do tamanho médio de particulado sobre a conversão e o coeficiente global de taxa de reação na absorção de $\mathrm{SO}_{2}$ por calcário em reator de leito fluidizado. Dissertação de Mestrado, EESCUSP, 106p. 
SIMONS, G.A.; GARMAN, A.R.; BONI, A.A. (1987) The kinetic rate of $\mathrm{SO}_{2}$ sorption by CaO. Am. Inst. Chem. Eng. J., 33(2): 211-217.

SNOW, M. J. H.; LONGWELL, J. P.; SAROFIM, A. F. (1988) Direct sulfation of calcium carbonate. Ind. Eng. Chem. Res., 27, 268-273.

TULLIN, C.; NYMAN, G.; GHARDASHKHANI, S., (1993) Direct sulfation of $\mathrm{CaCO}_{3}$ : the influence of $\mathrm{CO}_{2}$ partial pressure. Energy Fuel, 7, 512-519.

VAN HOUTE, G.; DELMON, B. (1979) Kinetics of reation of $\mathrm{CaCO}_{3}$ with $\mathrm{SO}_{2}$ and $\mathrm{O}_{2}$ below $650^{\circ} \mathrm{C}$. J. Chem. Soc. Faraday Trans. I., 75, 1593-1605.

WENDLANDT, W. (1985) Thermal Analysis. A Wiley-Interscience Puclication, New York.

WIECZOREK-CIUROWA, K. (1992) The thermal bihaviour of compounds in the Ca-S-O System. J. Therm. Anal, v. 38, 523-30.

YRJAS, P.; IISA, K.; HUPA, M. (1995) Comparison of $\mathrm{SO}_{2}$ capture capacities of limestones and dolomites under pressure. Fuel, 74-3, 395. 
APÊNDICES 
Apêndice 1: Curvas TG e DTG de todas as temperaturas ensaiadas em atmosfera de ar

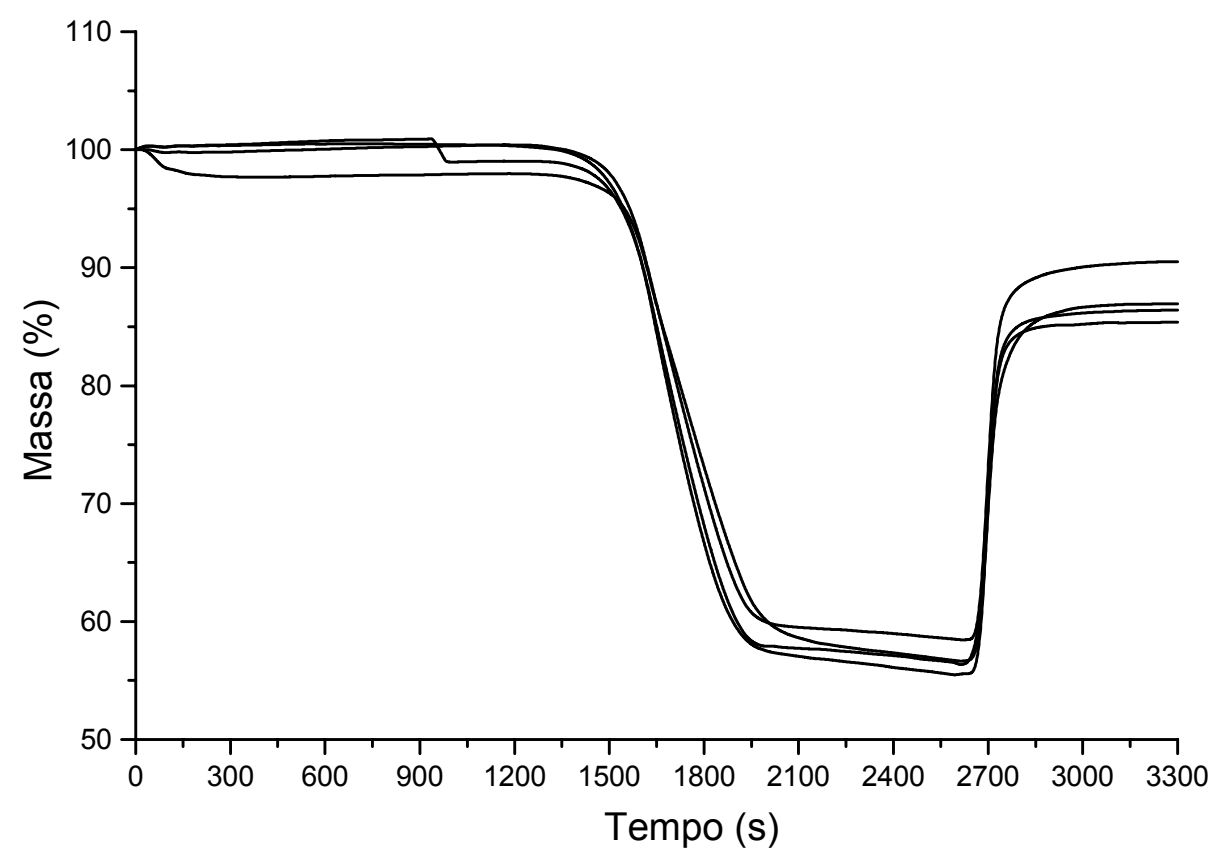

Figura A - 1- Conjunto de curvas TG de 4 testes aplicados a $650{ }^{\circ} \mathrm{C}$ em atmosfera de ar.

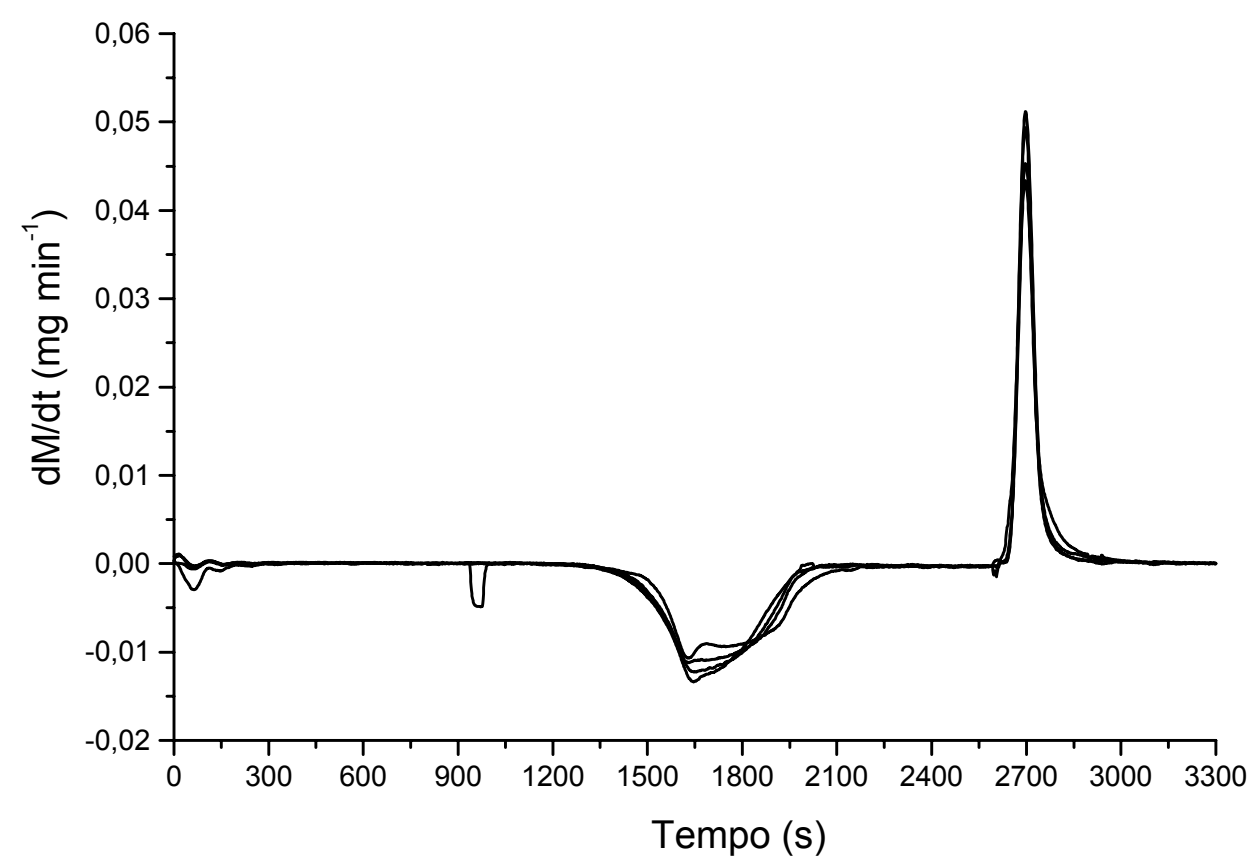

Figura A - 2- Conjunto de curvas DTG de 4 testes aplicados a $650{ }^{\circ} \mathrm{C}$ em atmosfera de ar. 


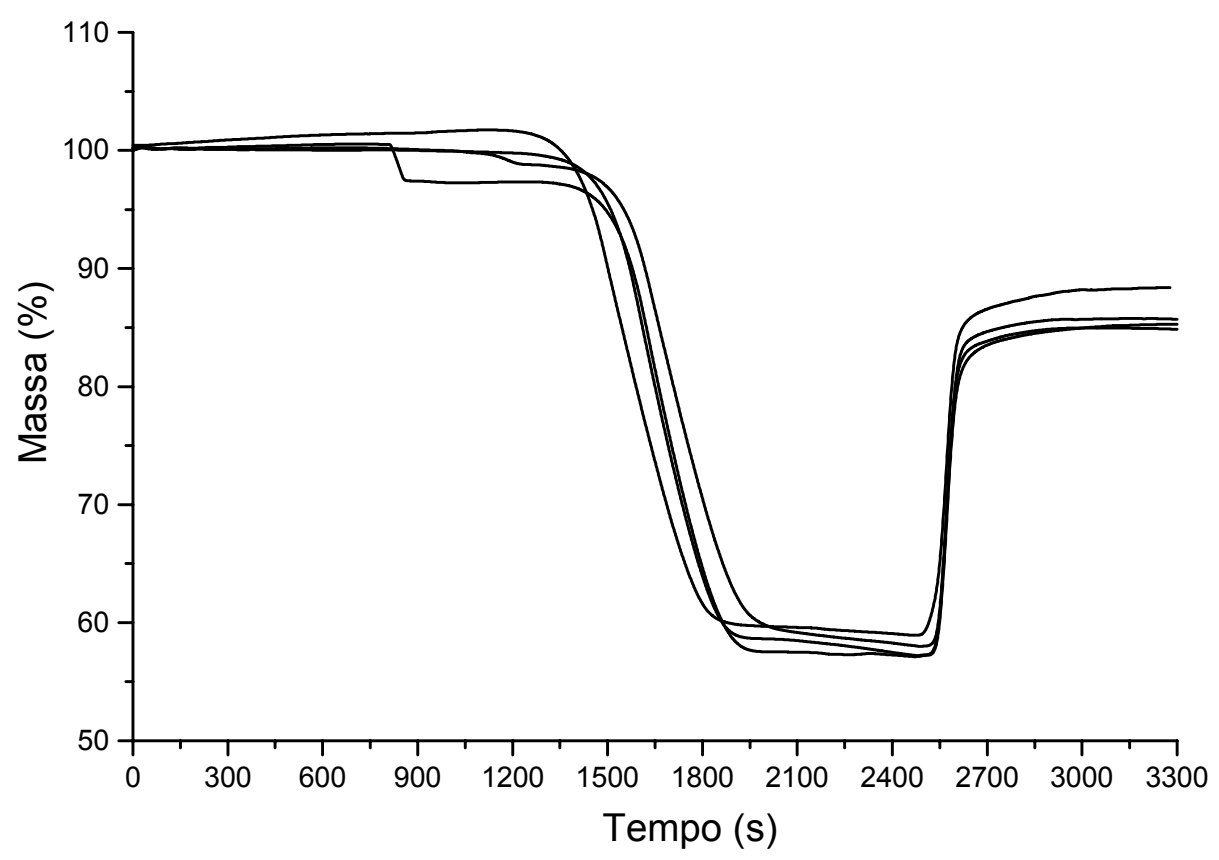

Figura A - 3- Conjunto de curvas TG de 4 testes aplicados a $700^{\circ} \mathrm{C} \mathrm{em}$ atmosfera de ar.

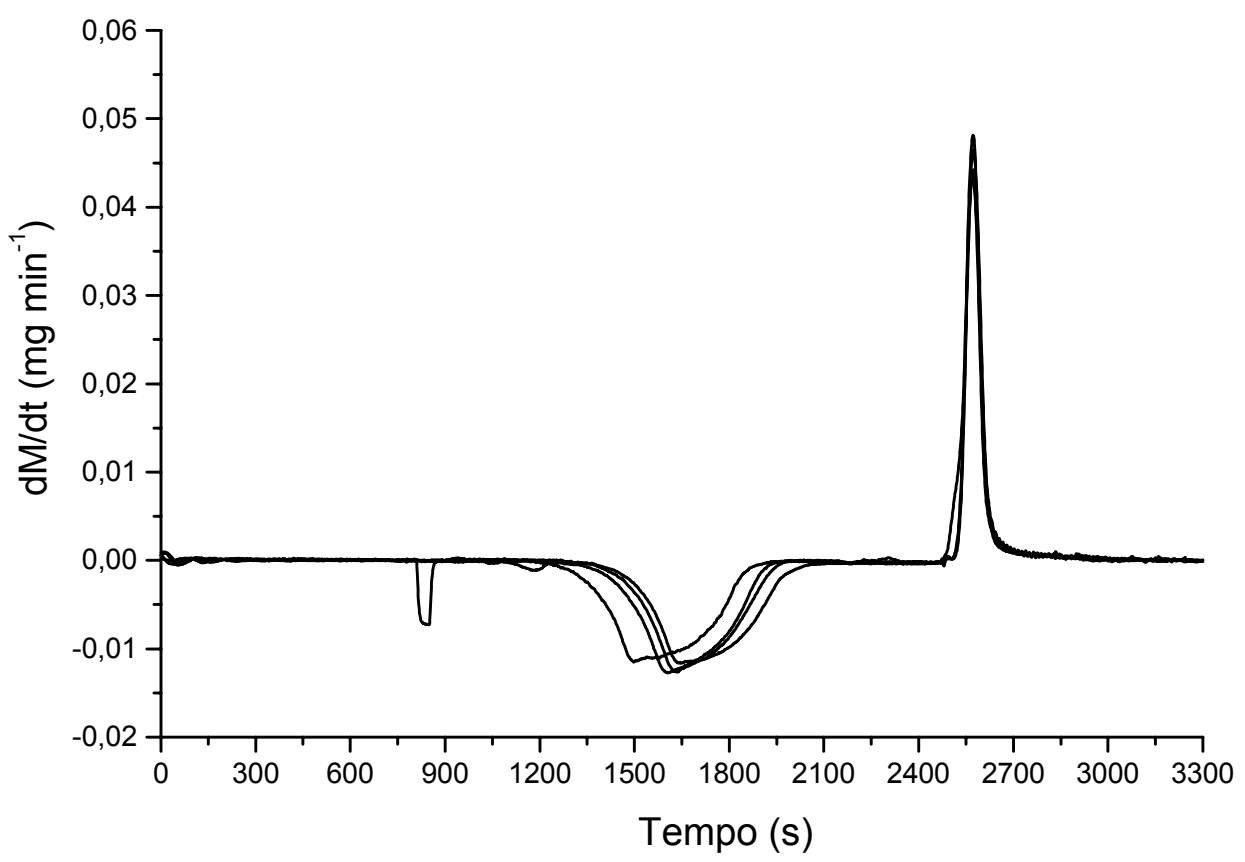

Figura A - 4- Conjunto de curvas DTG de 4 testes aplicados a $700^{\circ} \mathrm{C}$ em atmosfera de ar. 


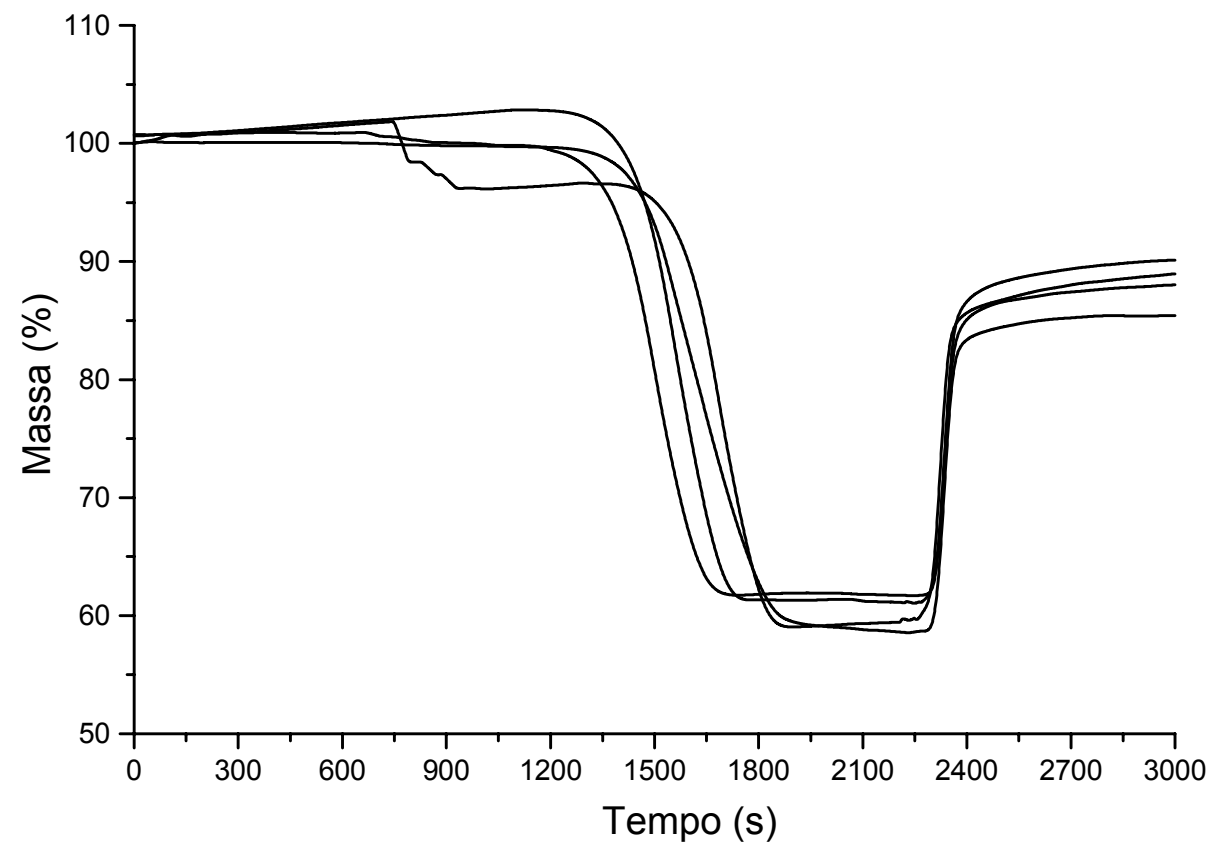

Figura A - 5- Conjunto de curvas TG de 4 testes aplicados a $750{ }^{\circ} \mathrm{C}$ em atmosfera de ar.

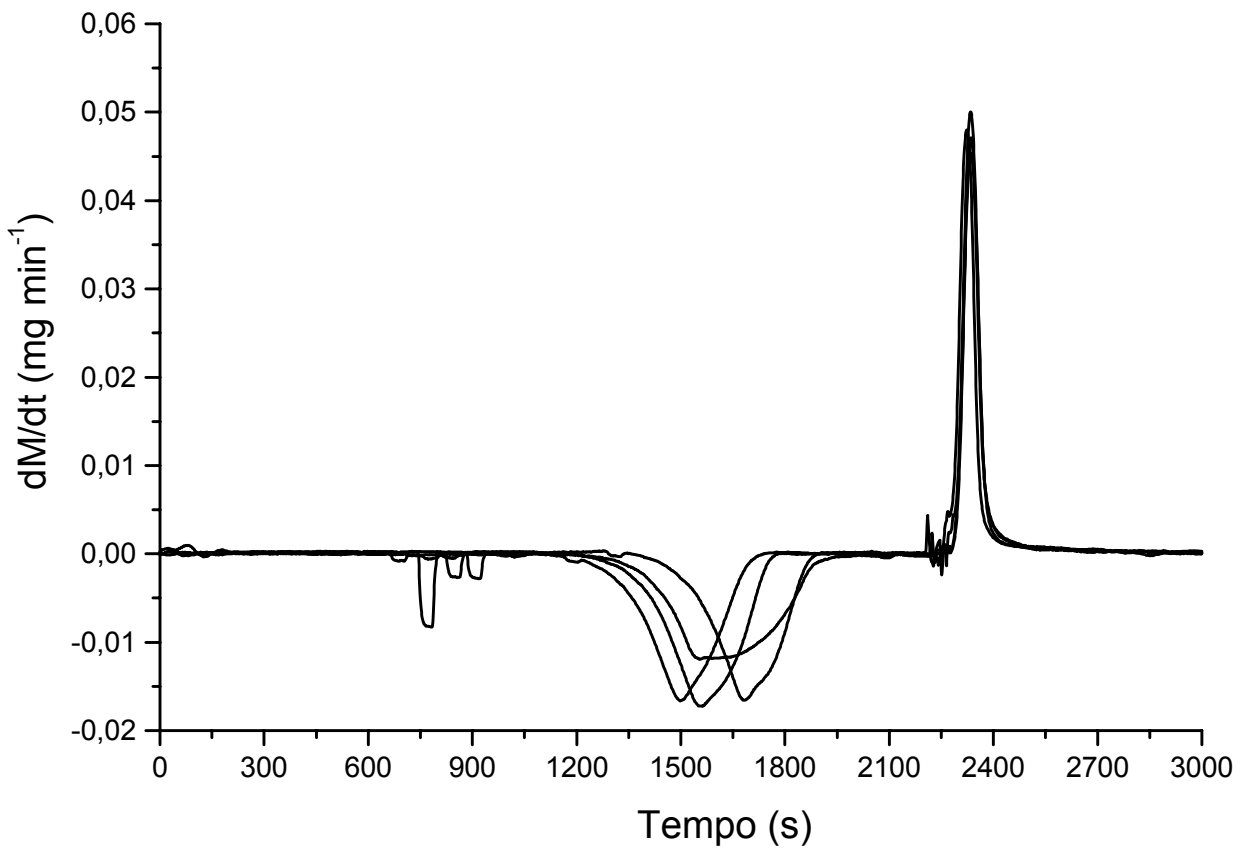

Figura A - 6- Conjunto de curvas DTG de 4 testes aplicados a $750^{\circ} \mathrm{C}$ em atmosfera de ar. 


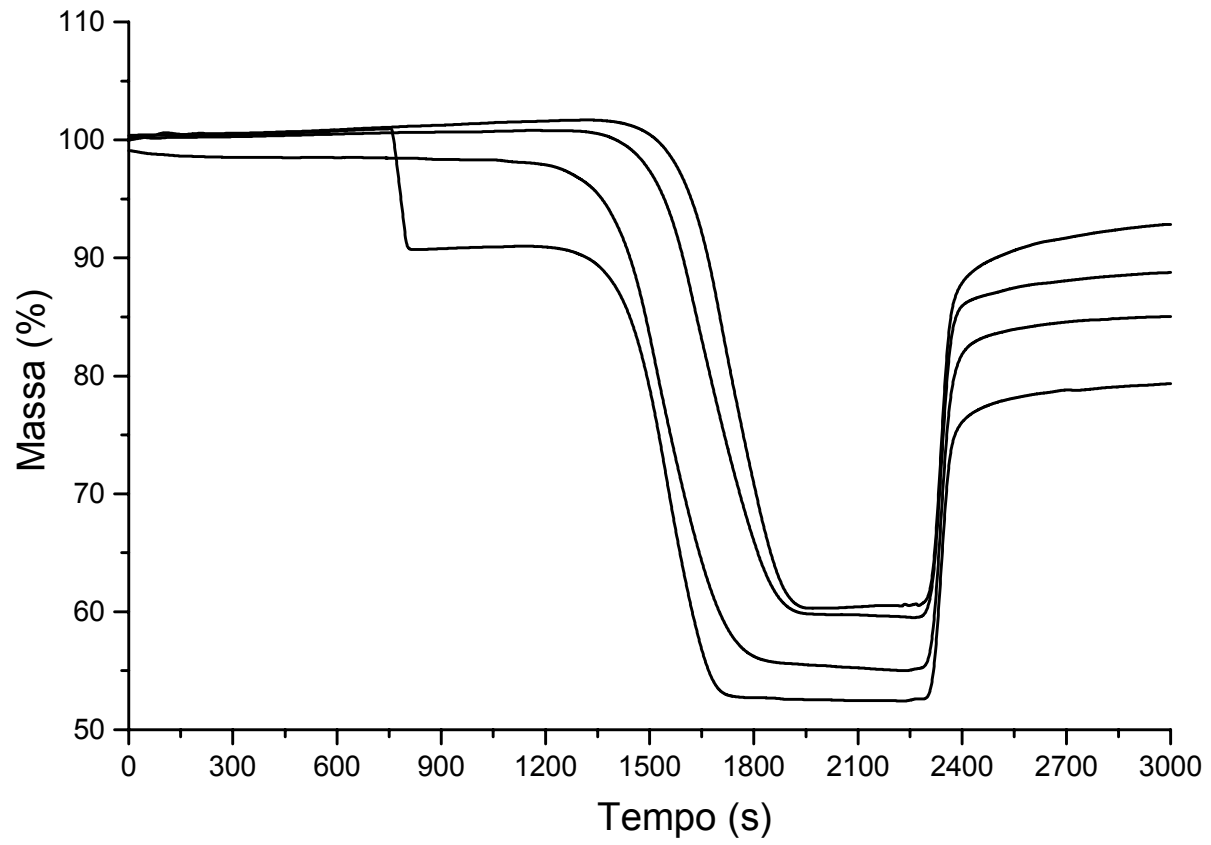

Figura A - 7- Conjunto de curvas TG de 4 testes aplicados a $800{ }^{\circ} \mathrm{C}$ em atmosfera de ar.

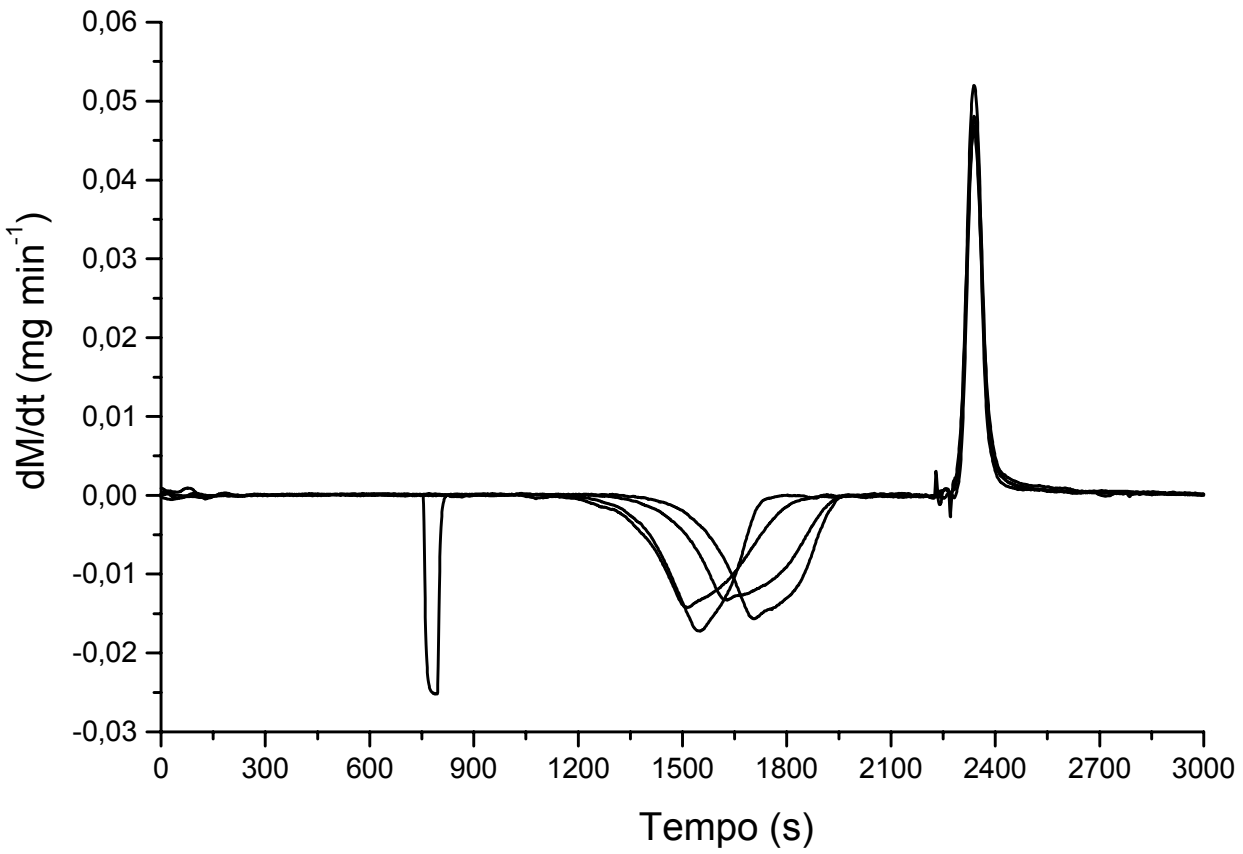

Figura A - 8- Conjunto de curvas DTG de 4 testes aplicados a $800^{\circ} \mathrm{C}$ em atmosfera de ar. 


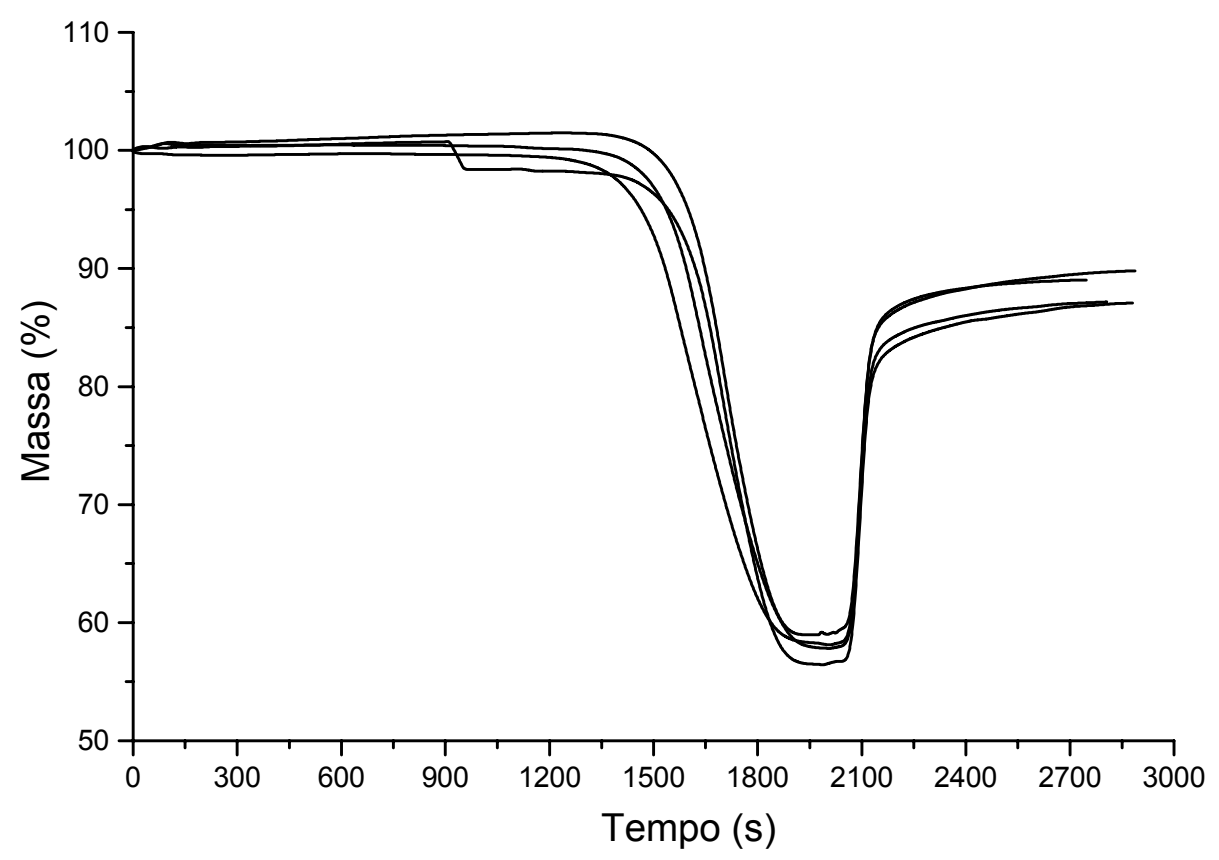

Figura A - 9- Conjunto de curvas TG de 4 testes aplicados a $850^{\circ} \mathrm{C}$ em atmosfera de ar.

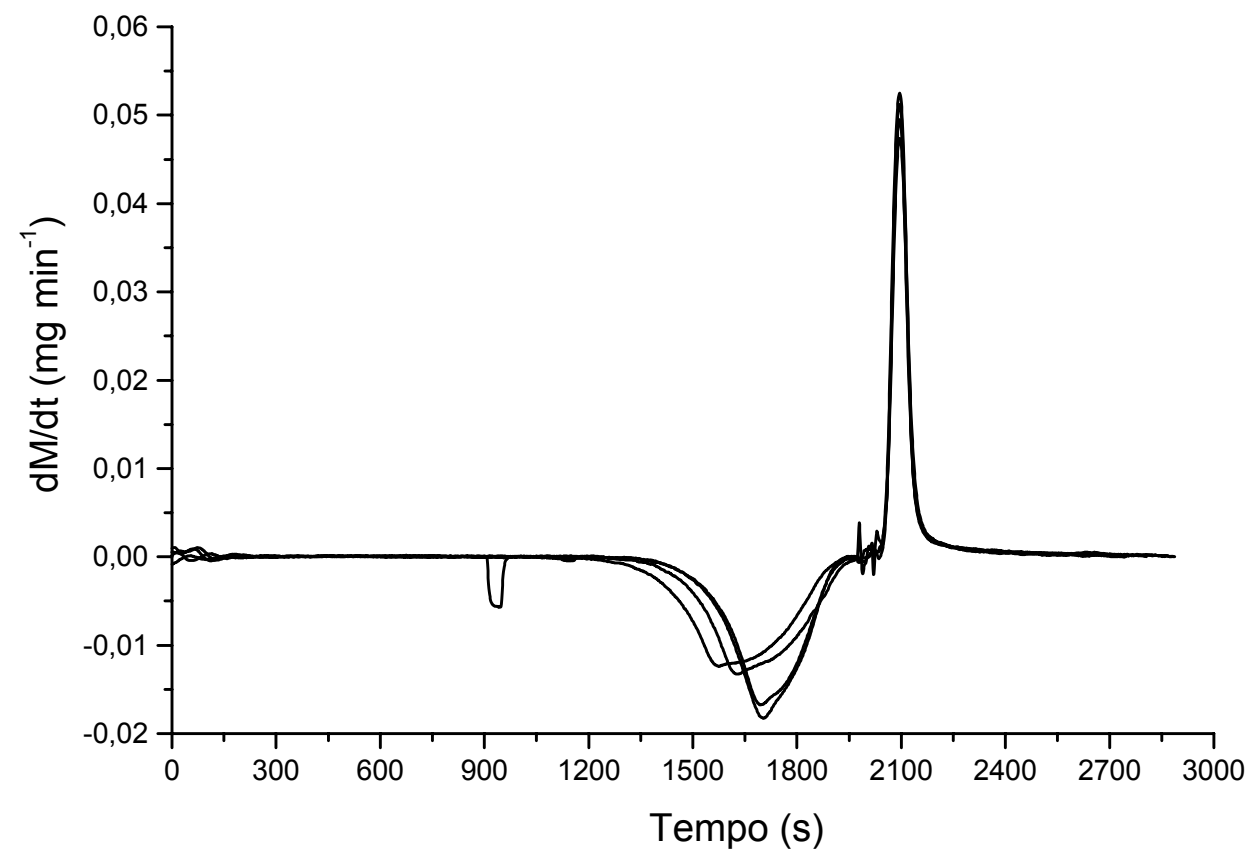

Figura A - 10- Conjunto de curvas DTG de 4 testes aplicados a $850{ }^{\circ} \mathrm{C}$ em atmosfera de ar. 


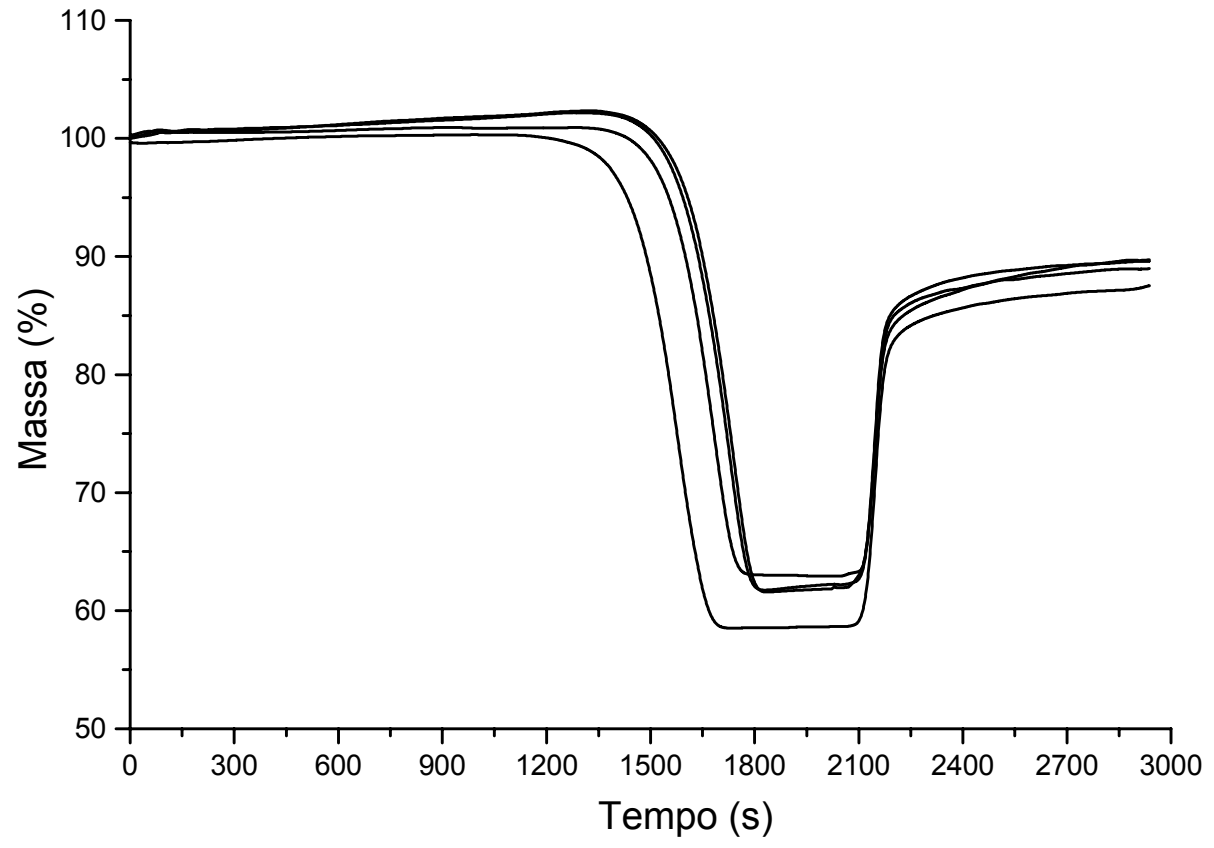

Figura A - 11- Conjunto de curvas TG de 4 testes aplicados a $900{ }^{\circ} \mathrm{C}$ em atmosfera de ar.

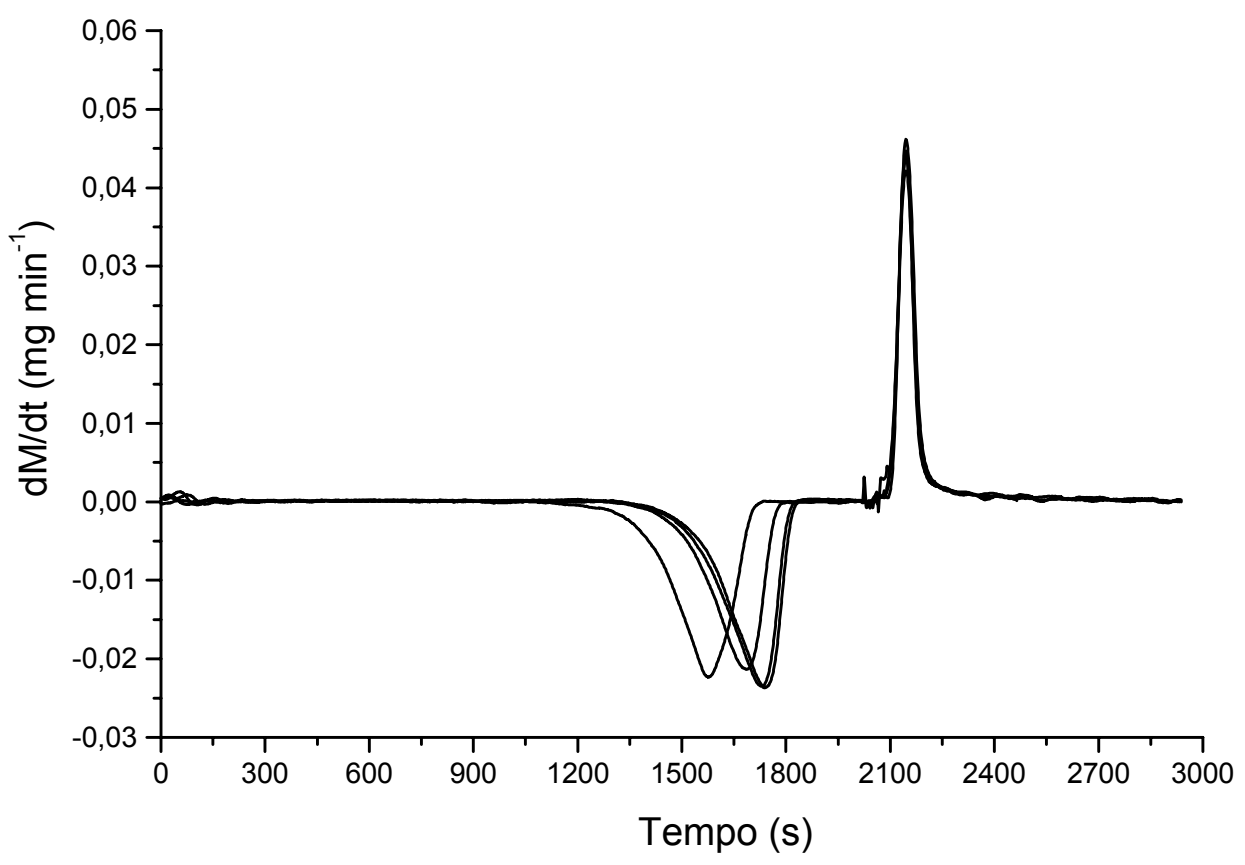

Figura A - 12- Conjunto de curvas DTG de 4 testes aplicados a $900{ }^{\circ} \mathrm{C}$ em atmosfera de ar. 


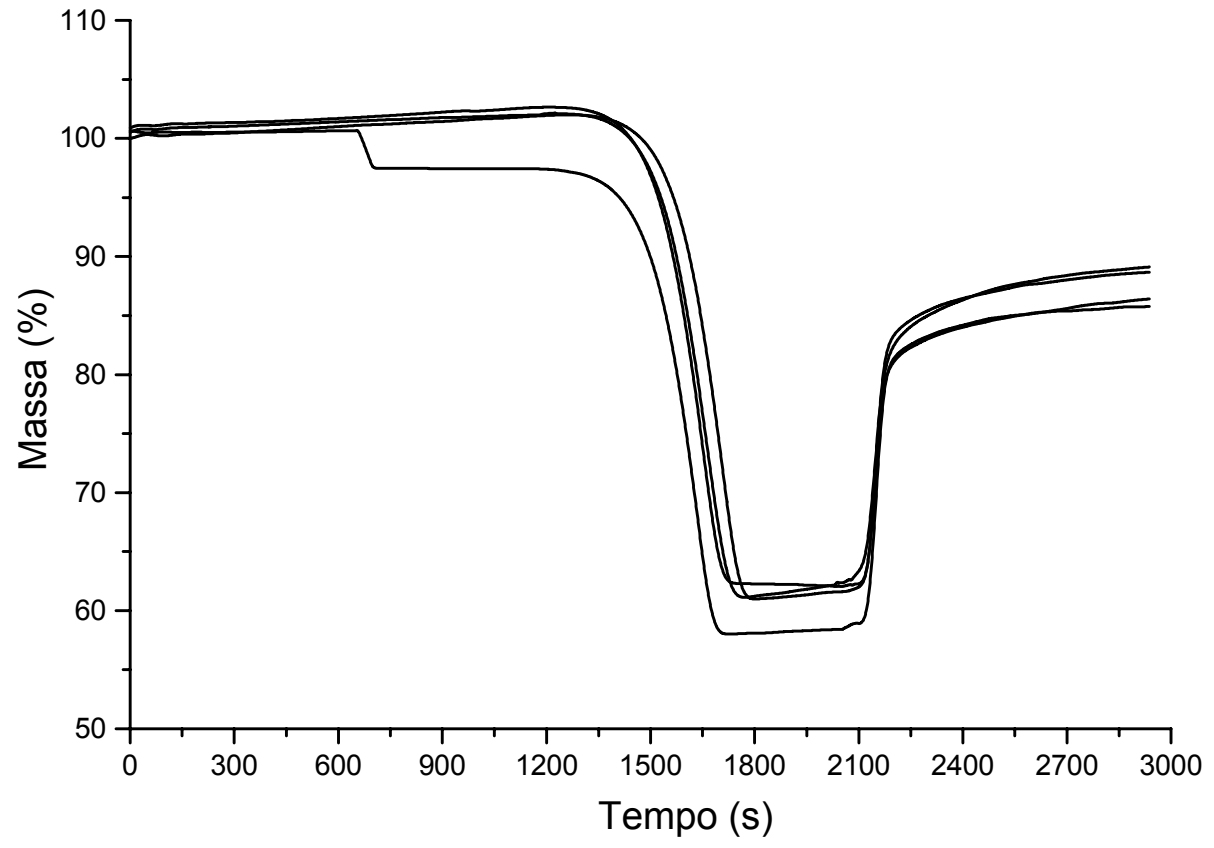

Figura A - 13- Conjunto de curvas TG de 4 testes aplicados a $950{ }^{\circ} \mathrm{C}$ em atmosfera de ar.

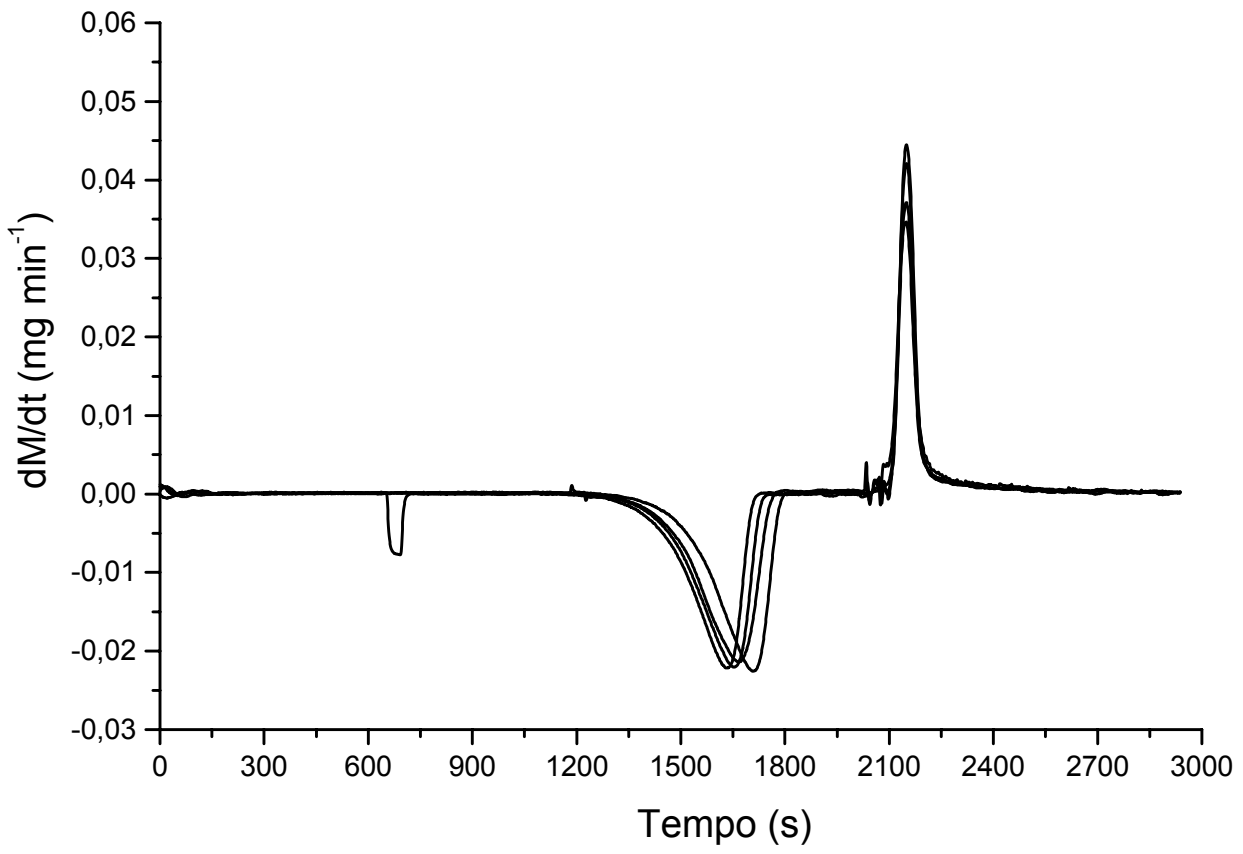

Figura A - 14- Conjunto de curvas DTG de 4 testes aplicados a $950{ }^{\circ} \mathrm{C}$ em atmosfera de ar. 
Apêndice 2: Curvas TG e DTG de todas as temperaturas ensaiadas em atmosfera de nitrogênio

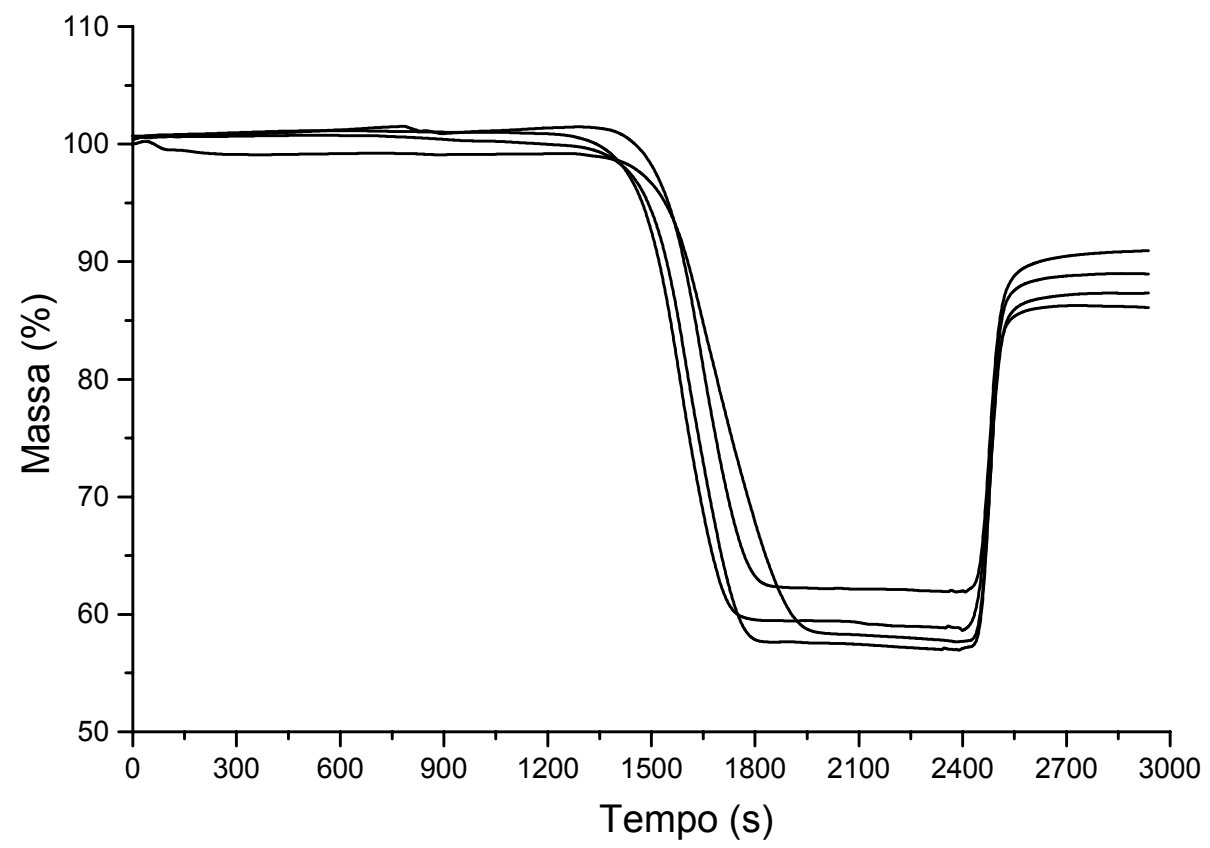

Figura A - 15- Conjunto de curvas TG de 4 testes aplicados a $750{ }^{\circ} \mathrm{C}$ em atmosfera de nitrogênio.

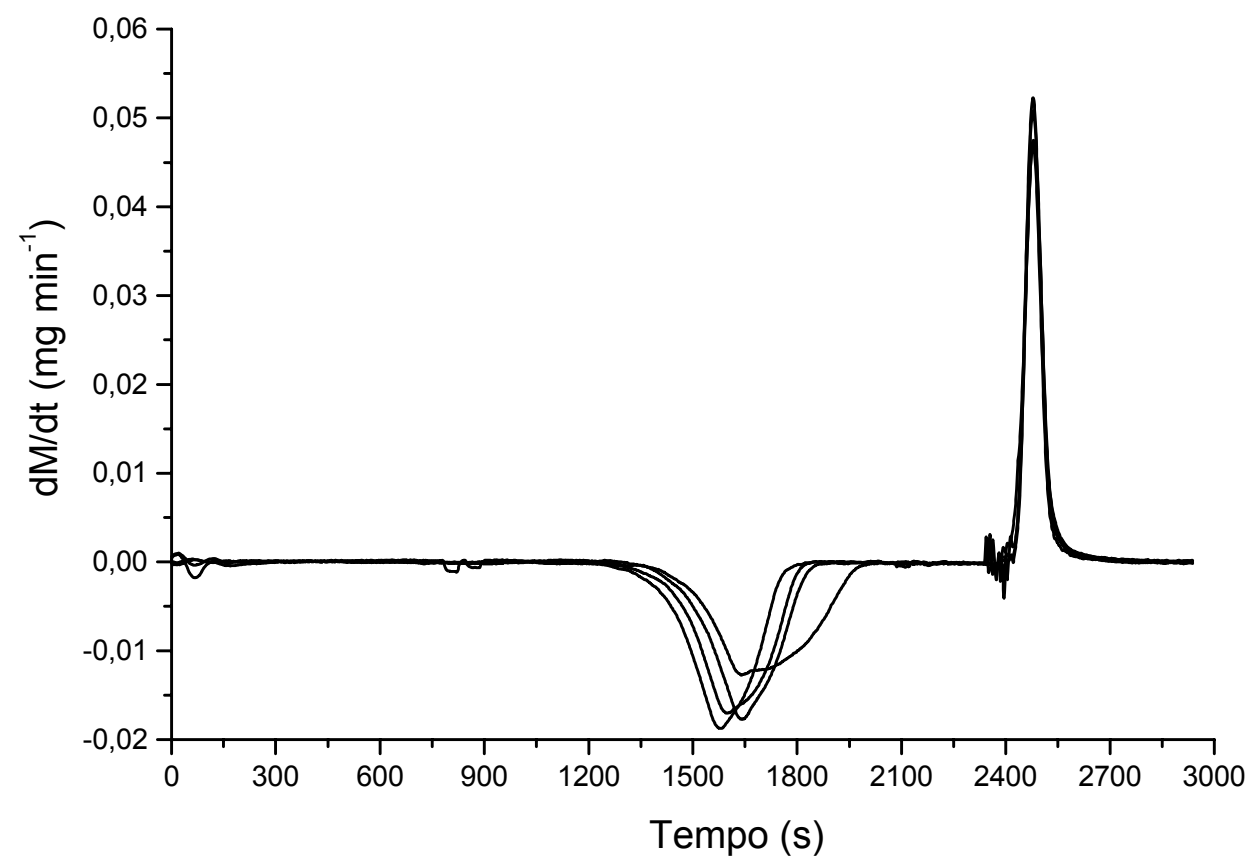

Figura A - 16- Conjunto de curvas DTG de 4 testes aplicados a $750{ }^{\circ} \mathrm{C}$ em atmosfera de nitrogênio. 


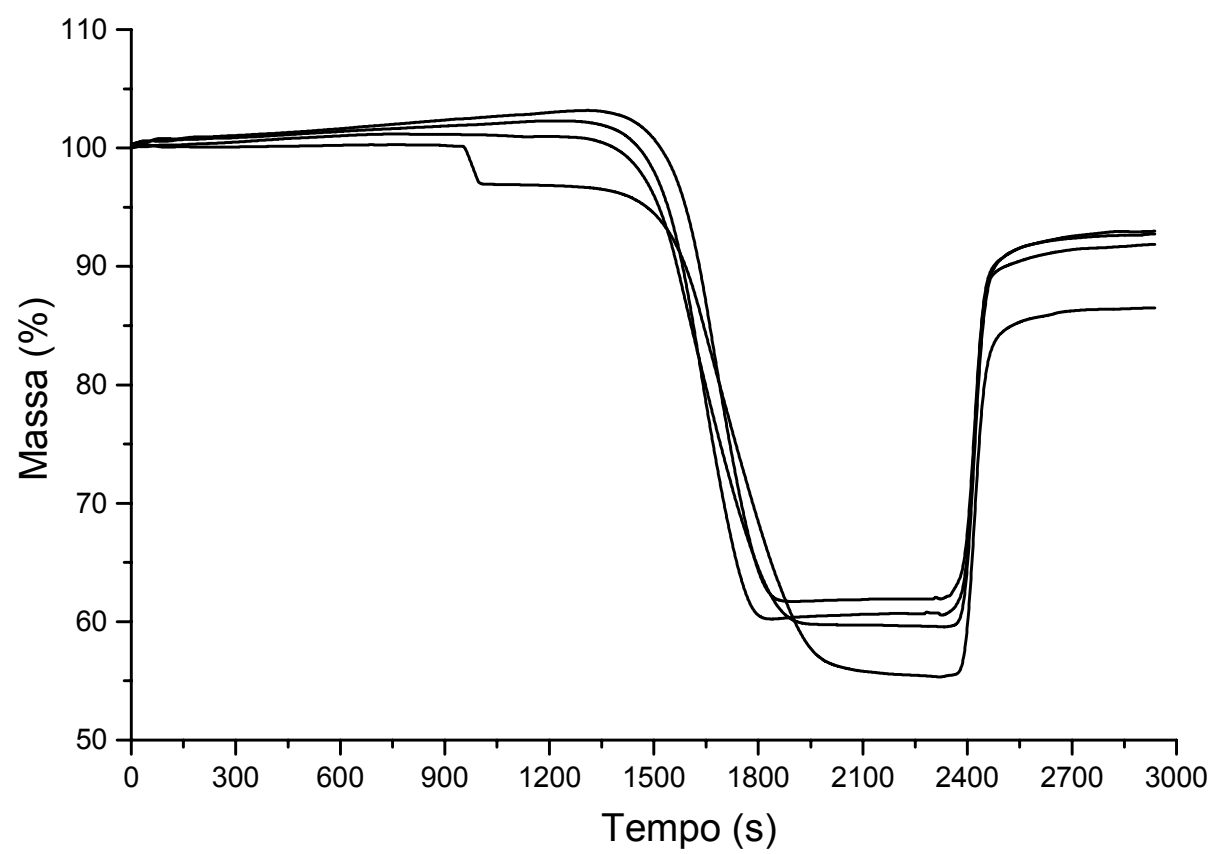

Figura A - 17- Conjunto de curvas TG de 4 testes aplicados a $800{ }^{\circ} \mathrm{C}$ em atmosfera de nitrogênio.

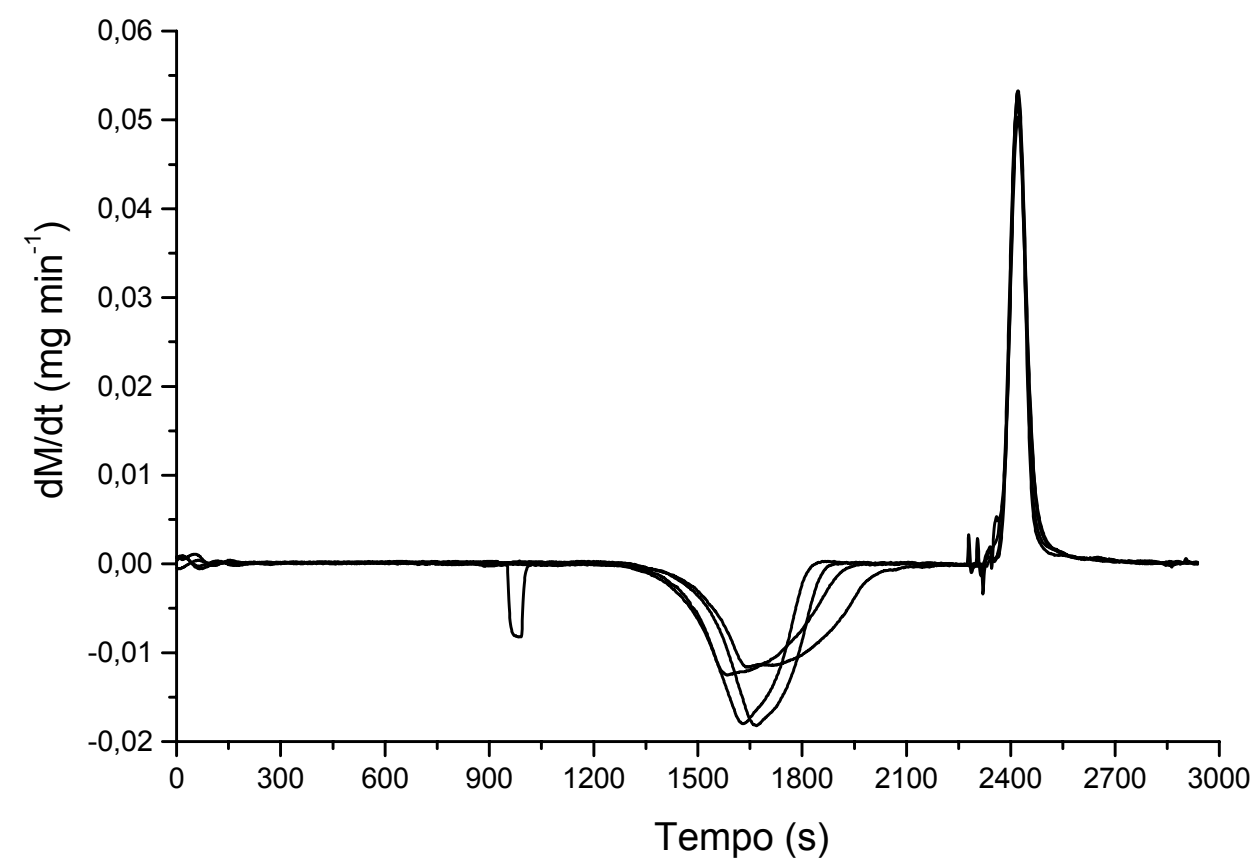

Figura A - 18- Conjunto de curvas DTG de 4 testes aplicados a $800{ }^{\circ} \mathrm{C}$ em atmosfera de nitrogênio. 


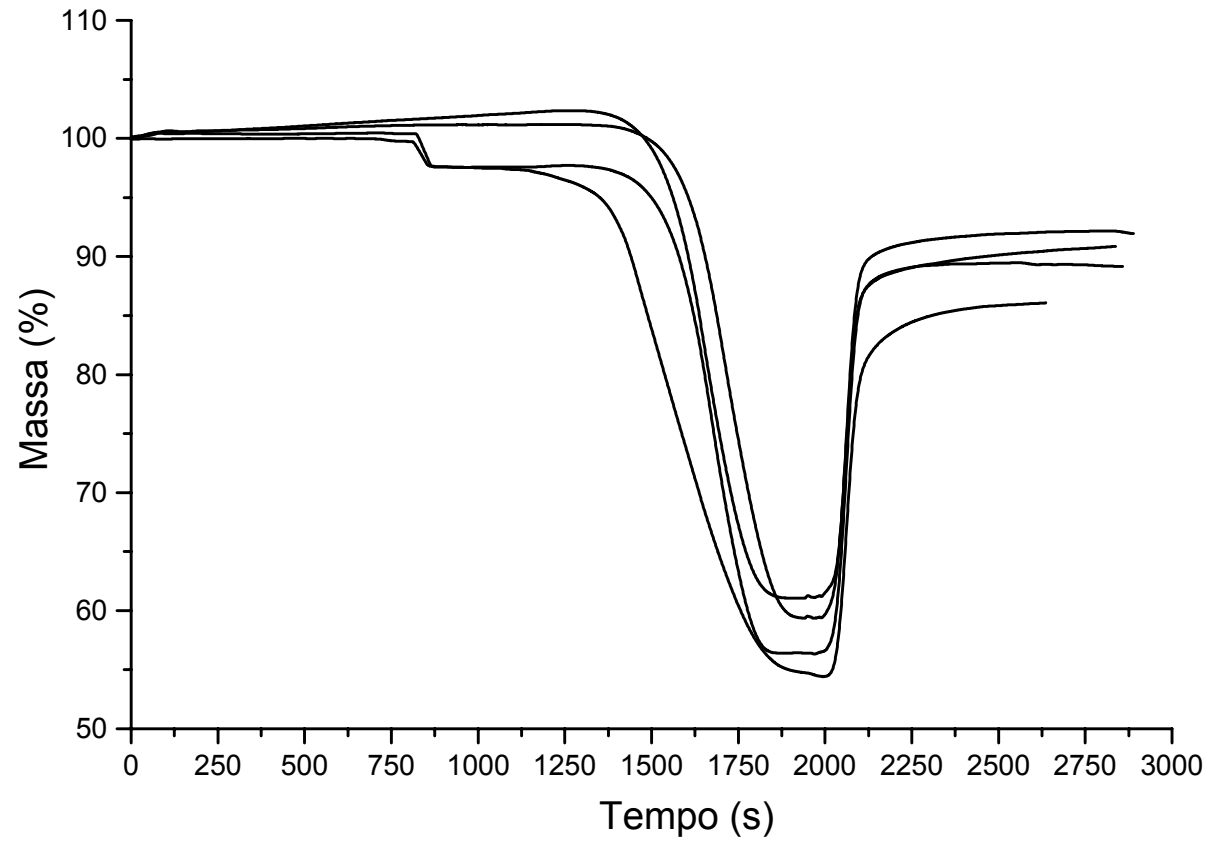

Figura A - 19- Conjunto de curvas TG de 4 testes aplicados a $850{ }^{\circ} \mathrm{C}$ em atmosfera de nitrogênio.

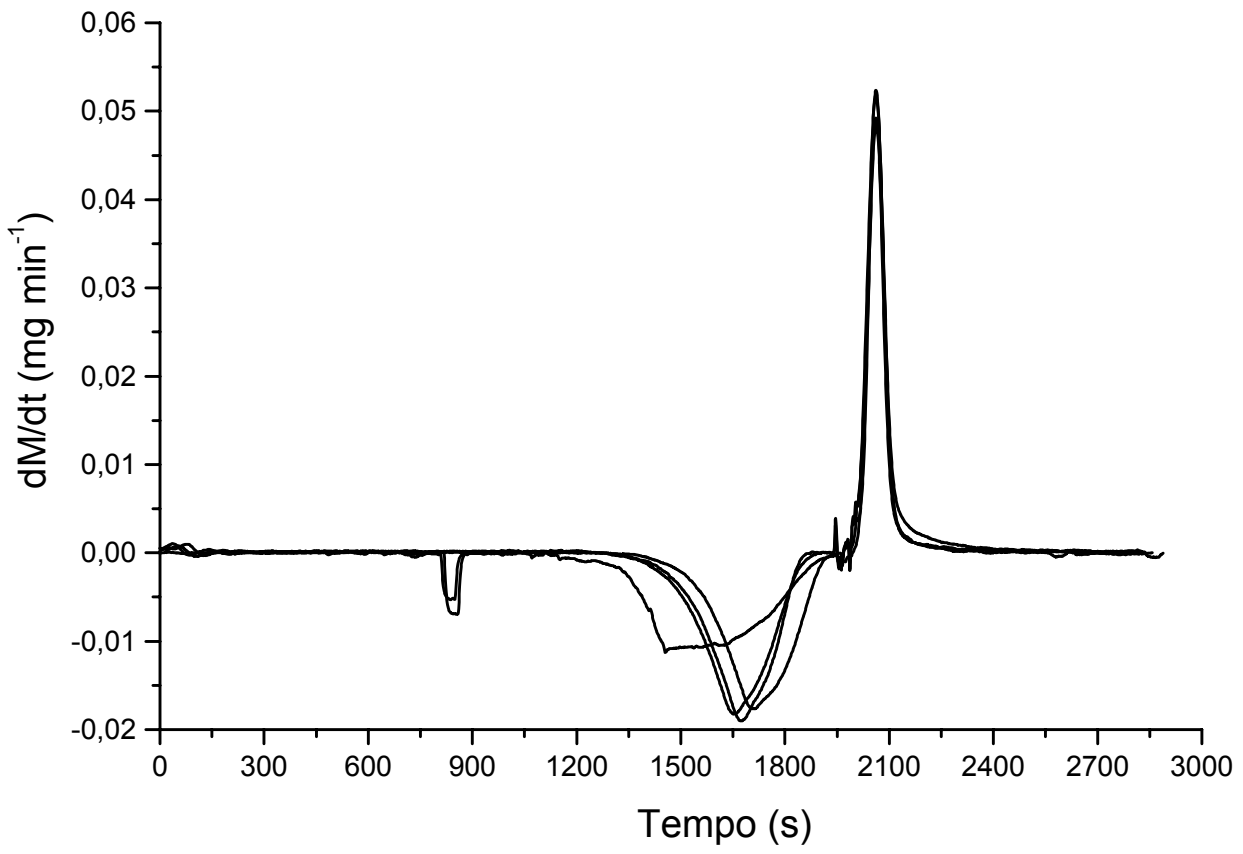

Figura A - 20- Conjunto de curvas DTG de 4 testes aplicados a $850{ }^{\circ} \mathrm{C} \mathrm{em}$ atmosfera de nitrogênio. 


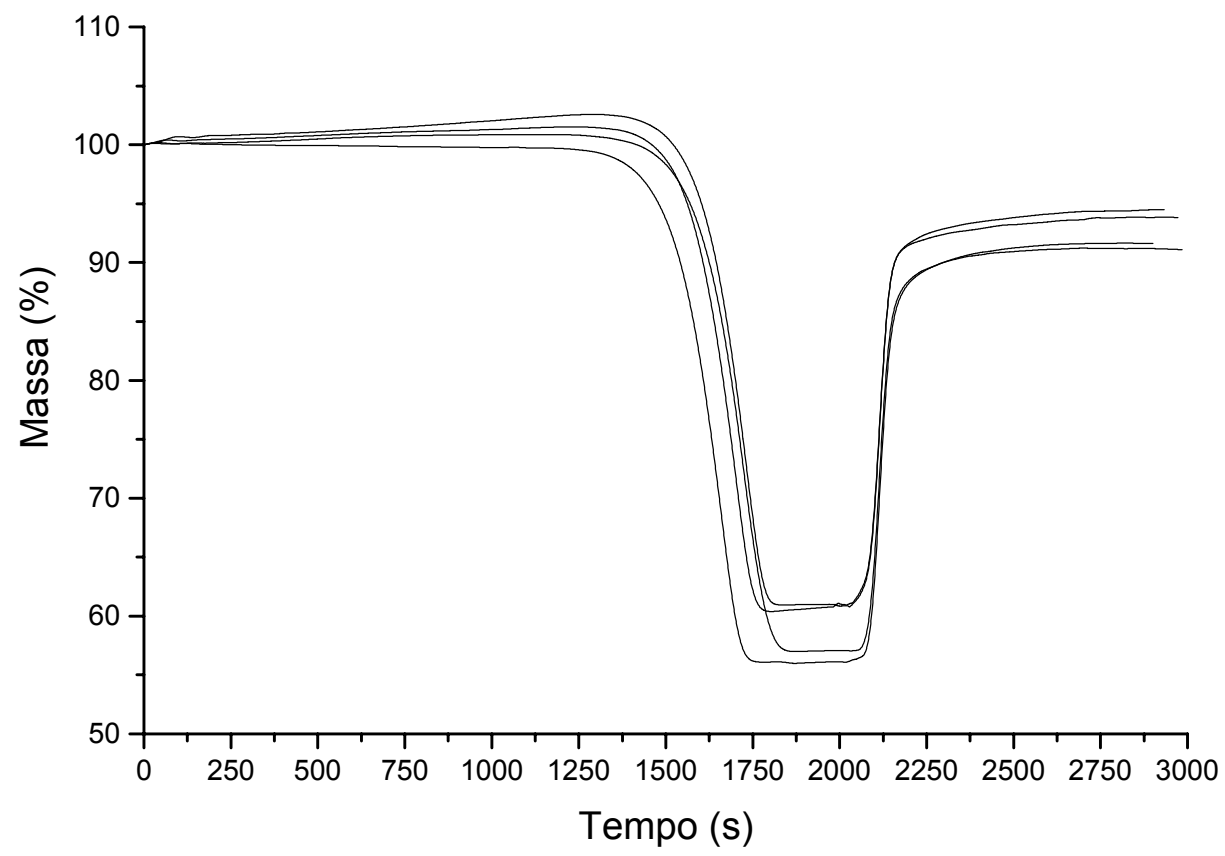

Figura A - 21- Conjunto de curvas TG de 4 testes aplicados a $900{ }^{\circ} \mathrm{C}$ em atmosfera de nitrogênio.

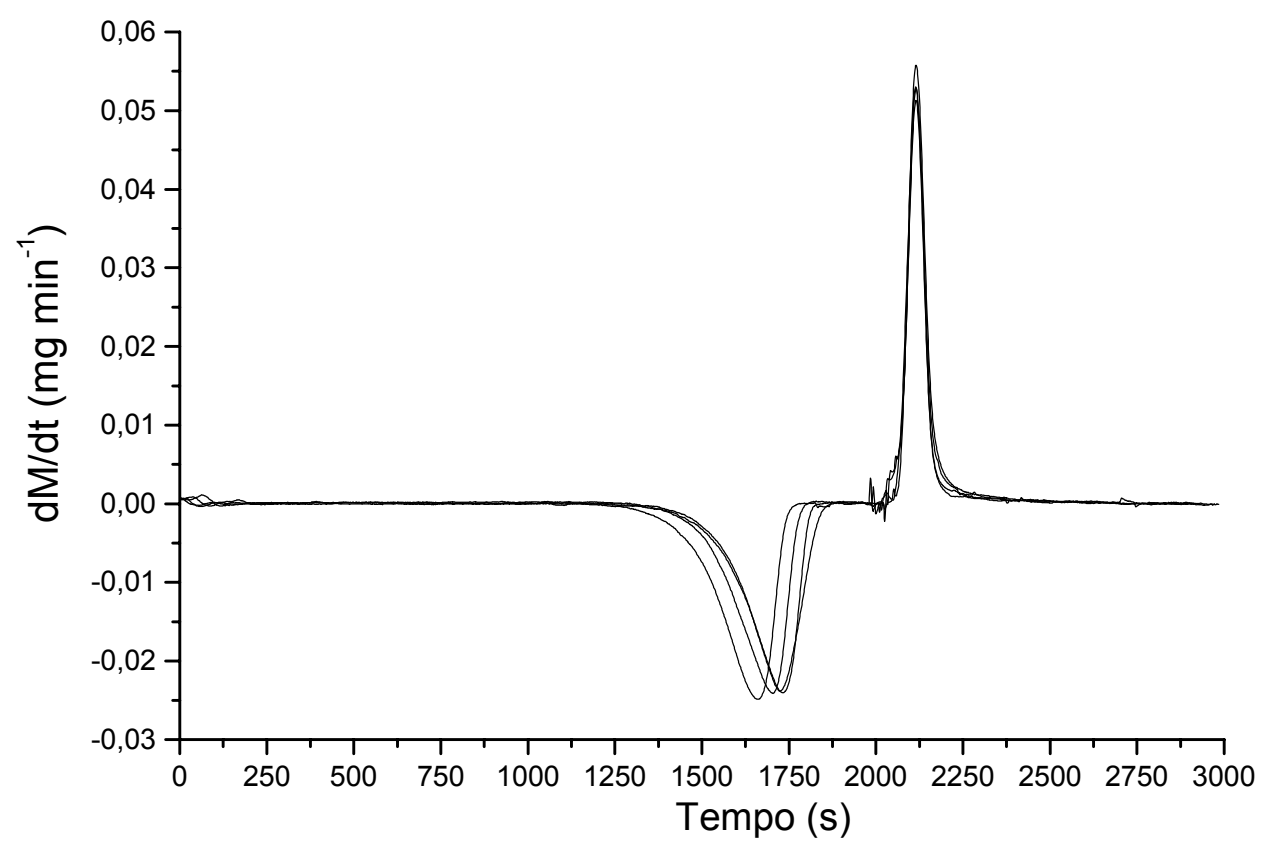

Figura A - 22- Conjunto de curvas DTG de 4 testes aplicados a $900{ }^{\circ} \mathrm{C} \mathrm{em}$ atmosfera de nitrogênio. 


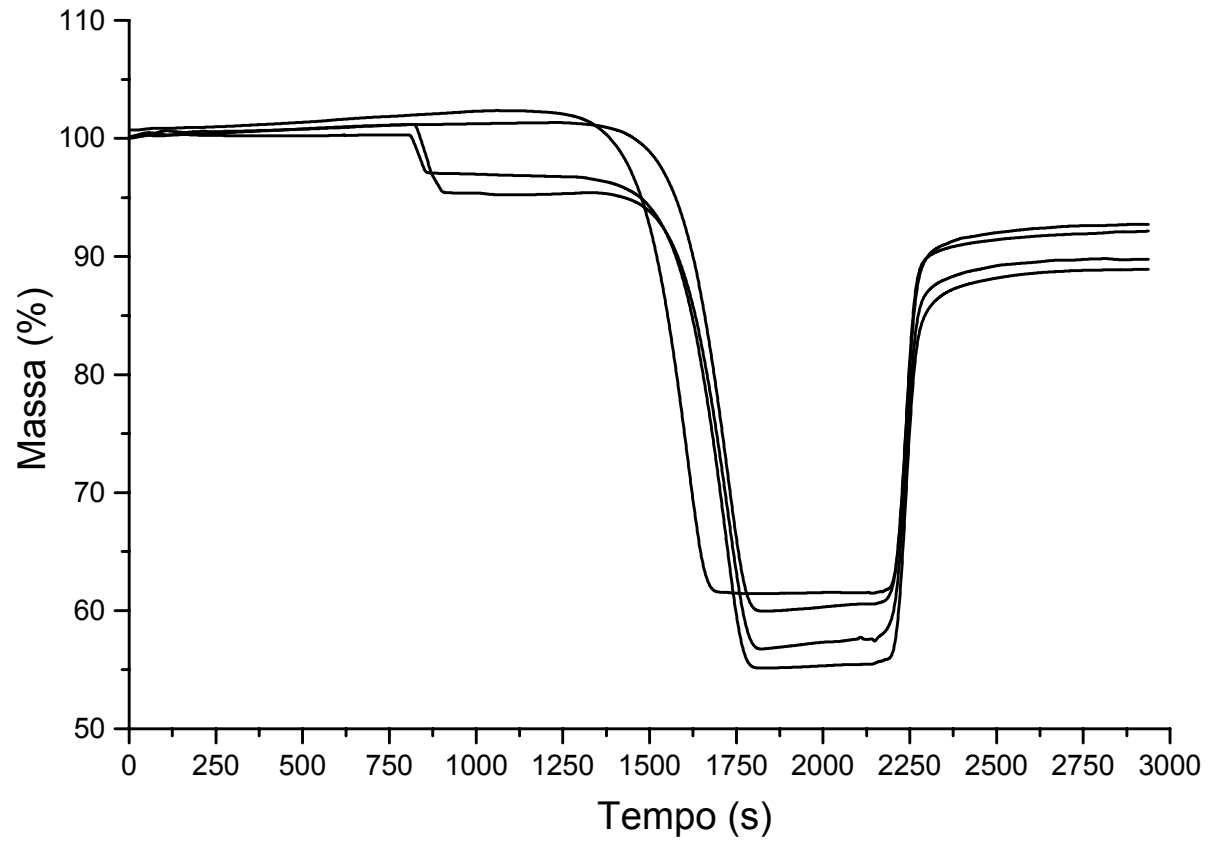

Figura A - 23- Conjunto de curvas TG de 4 testes aplicados a $950{ }^{\circ} \mathrm{C}$ em atmosfera de nitrogênio.

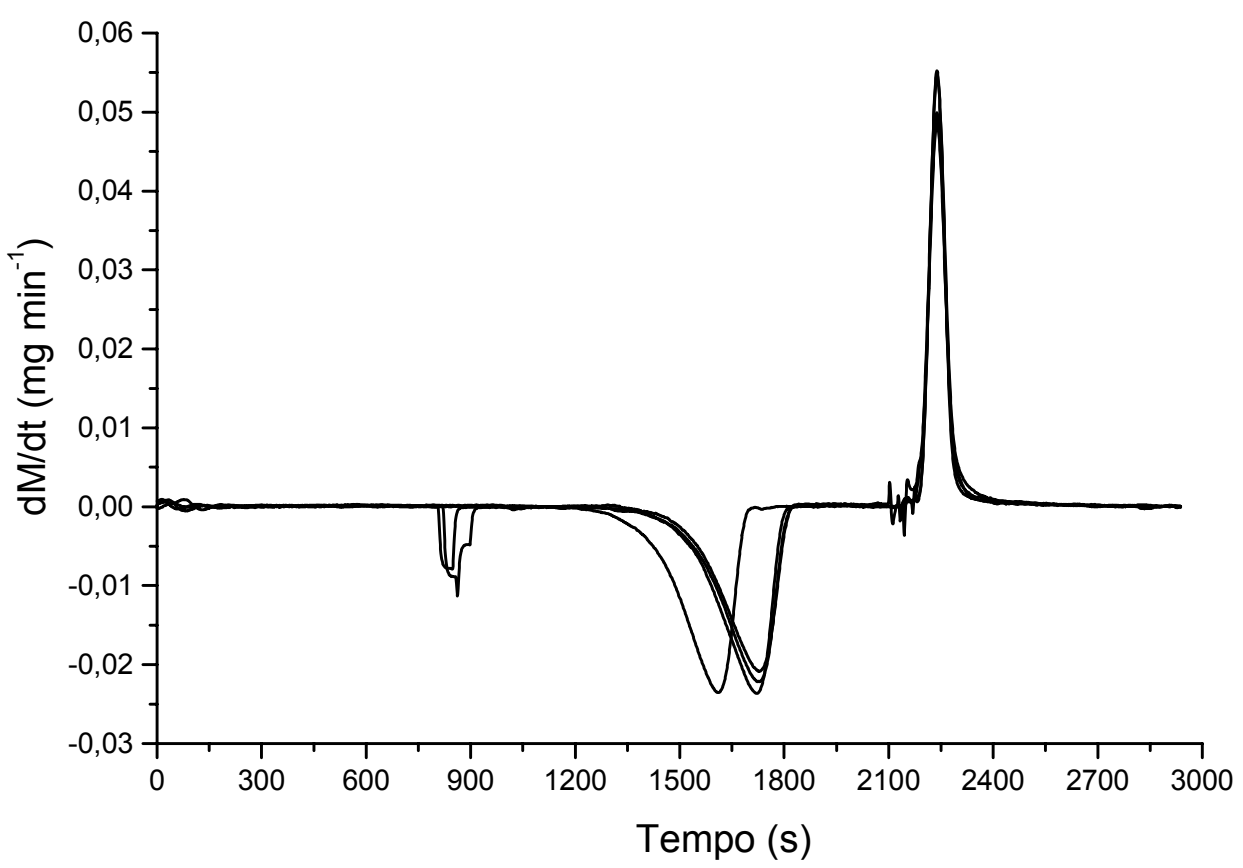

Figura A - 24- Conjunto de curvas DTG de 4 testes aplicados a $950{ }^{\circ} \mathrm{C}$ em atmosfera de nitrogênio. 
Apêndice 3: Resumo dos dados e equações utilizadas para os cálculos em atmosfera de Ar Sintético

\begin{tabular}{||c|c|c|c|c|c||}
\hline \multicolumn{2}{|c|}{ Fração Molar } & \multicolumn{4}{c||}{ Massa Molecular (W) } \\
\hline $\mathrm{Y}_{\mathrm{Ca}}$ & $\mathrm{Y}_{\mathrm{Mg}}$ & $\mathrm{W}_{\mathrm{Ca}}$ & $\mathrm{W}_{\mathrm{Mg}}$ & $\mathrm{W}_{\mathrm{SO} 2}$ & $1 / 2 \mathrm{~W}_{\mathrm{O} 2}$ \\
\hline 0,3534 & 0,0035 & 40,078 & 24,305 & 64,064 & 15,999 \\
\hline
\end{tabular}

$$
\begin{gathered}
m=M_{A}\left(Y_{C a}+Y_{M g}\right)-\left\{\left(M_{s}-M_{c}\right) \cdot\left[\frac{\left(W_{C a} Y_{C a}+W_{M g} Y_{M g}\right)}{\left(W_{\mathrm{SO}_{2}}+1 / 2 W_{\mathrm{O}_{2}}\right) \cdot\left(Y_{\mathrm{Ca}}+Y_{M g}\right)}\right]\right\} \\
\frac{d m}{d t}=-\left[\frac{\left(W_{\mathrm{Ca}_{\mathrm{Ca}}}+W_{M g} Y_{M g}\right)}{\left(W_{\mathrm{SO}_{2}}+1 / 2 W_{\mathrm{O}_{2}}\right) \cdot\left(Y_{\mathrm{Ca}}+Y_{\mathrm{Mg}}\right)}\right] \frac{d M_{s}}{d t}=-C_{1} \frac{d M_{S}}{d t}
\end{gathered}
$$

\section{EquAÇÃo PARA OBTENÇÃo dos PARÂMETROS CinÉTICOS}

$$
\ln \left[-\frac{-\left[\frac{\left(W_{C a} Y_{C a}+W_{M g} Y_{M g}\right)}{\left(W_{S_{2}}+1 / 2 W_{O_{2}}\right) \cdot\left(Y_{C a}+Y_{M g}\right)}\right]\left(\frac{d M_{s}}{d t}\right)_{\max }}{M_{A}\left(Y_{C a}+Y_{M g}\right)-\left\{\left(M_{s}-M_{c}\right) \cdot\left[\frac{\left(W_{C a} Y_{C a}+W_{M g} Y_{M g}\right)}{\left(W_{S_{2}}+1 / 2 W_{\mathrm{O}_{2}}\right) \cdot\left(Y_{C a}+Y_{M g}\right)}\right]\right\}}\right]=\ln A-\frac{E_{a}}{R} \frac{1}{T}
$$

\section{EquAÇÃo PARA O CÁlCULO dA CONVERSÃo}

$$
X=\frac{\frac{\Delta M_{S}}{W_{s o_{2}}+W_{1 / 2 O_{2}}}}{M_{A}\left(\frac{Y_{C a}}{W_{C a}}+\frac{Y_{M g}}{W_{M g}}\right)} \times 100 \quad \text { Sendo: } \Delta M_{S}=M_{F}-M_{C}
$$

\section{EQUAÇÃO PARA O CÁLCULO DA EFETIVIDADE}

$$
\eta=\frac{k}{k_{\max }}=\frac{\left[-\frac{1}{m} \frac{d m}{d t}\right]}{\left[-\frac{1}{m} \frac{d m}{d t}\right]_{\max }}
$$


Apêndice 4: Resumo dos dados e equações utilizadas para os cálculos em atmosfera de Nitrogênio

\begin{tabular}{||c|c|c|c|c||}
\hline \hline \multicolumn{2}{|c|}{ Fração molar } & \multicolumn{3}{c||}{ Massa molecular (w) } \\
\hline $\mathrm{Y}_{\mathrm{Ca}}$ & $\mathrm{Y}_{\mathrm{Mg}}$ & $\mathrm{W}_{\mathrm{Ca}}$ & $\mathrm{W}_{\mathrm{Mg}}$ & $\mathrm{W}_{\mathrm{SO} 2}$ \\
\hline 0,3534 & 0,0035 & 40,078 & 24,305 & 64,064 \\
\hline
\end{tabular}

$$
\begin{aligned}
& m=M_{A}\left(Y_{C a}+Y_{M g}\right)-\left\{\left(M_{s}-M_{c}\right) \cdot\left[\frac{\left(W_{C a} Y_{C a}+W_{M g} Y_{M g}\right)}{W_{\mathrm{SO}_{2}}\left(Y_{C a}+Y_{M g}\right)}\right]\right\} \\
& \frac{d m}{d t}=-\left[\frac{\left(W_{C a} Y_{C a}+W_{M g} Y_{M g}\right)}{W_{S_{2}} \cdot\left(Y_{C a}+Y_{M g}\right)}\right] \frac{d M_{s}}{d t}=-C_{2} \frac{d M_{S}}{d t}
\end{aligned}
$$

\section{EQUAÇÃo PARA OBTENÇÃo doS PARÂMETROS CINÉTICOS}

$$
\ln \left[-\frac{-\left[\frac{\left(W_{C a} Y_{C a}+W_{M g} Y_{M g}\right)}{W_{S_{2}} \cdot\left(Y_{C a}+Y_{M g}\right)}\right]\left(\frac{d M_{s}}{d t}\right)_{\max }}{M_{A}\left(Y_{C a}+Y_{M g}\right)-\left\{\left(M_{s}-M_{c}\right) \cdot\left[\frac{\left(W_{C a} Y_{C a}+W_{M g} Y_{M g}\right)}{W_{S O_{2}} \cdot\left(Y_{C a}+Y_{M g}\right)}\right]\right\}}\right]=\ln A-\frac{E_{a}}{R} \frac{1}{T}
$$

\section{EquAÇÃo PARA O CÁlCULO dA CONVERSÃo}

$$
X=\frac{\frac{\Delta M_{S}}{W_{\mathrm{so}_{2}}}}{M_{A}\left(\frac{Y_{C a}}{W_{C a}}+\frac{Y_{M g}}{W_{M g}}\right)} \times 100 \quad \text { Sendo: } \Delta M_{S}=M_{F}-M_{C}
$$

\section{EqUAÇÃo PARA O CÁLCULO dA EFETIVIDADE}

$$
\eta=\frac{k}{k_{\max }}=\frac{\left[-\frac{1}{m} \frac{d m}{d t}\right]}{\left[-\frac{1}{m} \frac{d m}{d t}\right]_{\max }}
$$


Apêndice 5: Planilha de Cálculo dos Dados Cinéticos em atmosfera de ar

\begin{tabular}{|c|c|c|c|c|c|c|c|c|c|c|}
\hline $\begin{array}{l}0 \\
0 \\
\dot{0} \\
\stackrel{0}{0} \\
\stackrel{0}{\circ}\end{array}$ & $\begin{array}{l}8 \\
8 \\
\circ \\
\stackrel{0}{x} \\
\stackrel{5}{F}\end{array}$ & 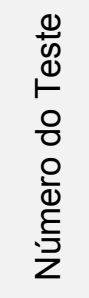 & $\begin{array}{l}\mathrm{M}_{\mathrm{A}} \\
\left(^{*}\right)\end{array}$ & $\begin{array}{c}\mathrm{M}_{\mathrm{C}} \\
\left(^{*}\right)\end{array}$ & $\begin{array}{l}M_{S} \\
\left(^{*}\right)\end{array}$ & $\begin{array}{c}m_{\max } \\
\left({ }^{* *}\right)\end{array}$ & $\begin{array}{l}\mathrm{C}_{1} \\
\left(^{* *}\right)\end{array}$ & $\begin{array}{l}\frac{\sum_{0}^{\infty}}{\infty} \\
\sum_{0}^{\infty} \\
\sum_{0}^{0}\end{array}$ & 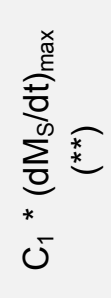 & 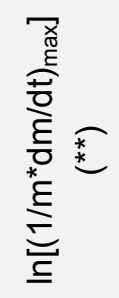 \\
\hline \multirow{4}{*}{ 유 } & \multirow{4}{*}{$\begin{array}{l}\stackrel{\infty}{+} \\
\underset{\widetilde{N}}{\infty} \\
0^{-}\end{array}$} & $7-5$ & 9,92 & 5,52 & 6,77 & 2,917 & 0,499 & 2,96 & 1,476 & $-0,681$ \\
\hline & & $7-7$ & 10,03 & 5,74 & 7,05 & 2,926 & 0,499 & 2,72 & 1,356 & $-0,769$ \\
\hline & & $7-9$ & 10,23 & 6 & 7,27 & 3,018 & 0,499 & 3,07 & 1,531 & $-0,679$ \\
\hline & & $7-11$ & 9,91 & 5,79 & 6,92 & 2,973 & 0,499 & 2,6 & 1,296 & $-0,83$ \\
\hline \multirow{4}{*}{ 옥 } & \multirow{4}{*}{$\begin{array}{l}\text { o } \\
\stackrel{0}{N} \\
\text { N } \\
\stackrel{0}{0}\end{array}$} & $6-1$ & 9,77 & 5,61 & 6,83 & 2,879 & 0,499 & 2,79 & 1,391 & $-0,727$ \\
\hline & & $6-2$ & 9,4 & 5,54 & 6,68 & 2,786 & 0,499 & 2,65 & 1,321 & $-0,746$ \\
\hline & & $6-5$ & 10 & 5,83 & 7,26 & 2,856 & 0,499 & 2,61 & 1,301 & $-0,786$ \\
\hline & & 6-6 & 10,28 & 5,97 & 7,23 & 3,041 & 0,499 & 2,89 & 1,441 & $-0,747$ \\
\hline \multirow{4}{*}{ م } & \multirow{4}{*}{$\begin{array}{l}\infty \\
\stackrel{n}{N} \\
\stackrel{n}{N} \\
\stackrel{n}{\sigma}\end{array}$} & $1-1$ & 9,35 & 5,77 & 7,07 & 2,689 & 0,499 & 2,88 & 1,436 & $-0,627$ \\
\hline & & $1-2$ & 10,13 & 6,08 & 7,28 & 3,017 & 0,499 & 2,83 & 1,411 & $-0,76$ \\
\hline & & $1-3$ & 10,06 & 6,2 & 7,27 & 3,057 & 0,499 & 2,72 & 1,356 & $-0,813$ \\
\hline & & $1-4$ & 10,4 & 6,14 & 7,37 & 3,098 & 0,499 & 3 & 1,496 & $-0,728$ \\
\hline \multirow{4}{*}{ ৪ } & \multirow{4}{*}{$\begin{array}{l}\tilde{0} \\
\tilde{\infty} \\
\infty \\
\tilde{m} \\
\sigma\end{array}$} & $2-1$ & 10,07 & 6,01 & 7,31 & 2,946 & 0,499 & 3,12 & 1,556 & $-0,638$ \\
\hline & & $2-2$ & 9,13 & 5,3 & 6,37 & 2,725 & 0,499 & 2,81 & 1,401 & $-0,665$ \\
\hline & & $2-5$ & 10,07 & 6 & 7,21 & 2,991 & 0,499 & 2,88 & 1,436 & $-0,734$ \\
\hline & & $2-6$ & 9,61 & 5,39 & 6,61 & 2,821 & 0,499 & 2,76 & 1,376 & $-0,718$ \\
\hline \multirow{4}{*}{ ○ } & \multirow{4}{*}{ 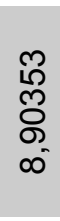 } & $3-2$ & 9,65 & 5,52 & 6,75 & 2,831 & 0,499 & 2,97 & 1,481 & $-0,648$ \\
\hline & & $3-5$ & 10,29 & 6 & 7,28 & 3,034 & 0,499 & 3,07 & 1,531 & $-0,684$ \\
\hline & & $3-6$ & 9,73 & 5,6 & 6,76 & 2,894 & 0,499 & 2,84 & 1,416 & $-0,715$ \\
\hline & & $3-7$ & 10,19 & 5,94 & 7,28 & 2,969 & 0,499 & 3,15 & 1,571 & $-0,637$ \\
\hline \multirow{4}{*}{ ৪্ণ } & \multirow{4}{*}{ 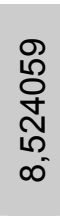 } & $4-2$ & 9,93 & 6,2 & 7,3 & 2,996 & 0,499 & 2,68 & 1,336 & $-0,807$ \\
\hline & & $4-3$ & 10,56 & 6,39 & 7,58 & 3,175 & 0,499 & 2,53 & 1,262 & $-0,923$ \\
\hline & & $4-4$ & 10,58 & 6,49 & 7,64 & 3,203 & 0,499 & 2,63 & 1,311 & $-0,893$ \\
\hline & & $4-5$ & 10,52 & 6,14 & 7,35 & 3,151 & 0,499 & 2,77 & 1,381 & $-0,825$ \\
\hline \multirow{4}{*}{ ది } & \multirow{4}{*}{$\begin{array}{l}\stackrel{N}{\delta} \\
\stackrel{م}{N} \\
\frac{1}{\infty} \\
\infty\end{array}$} & 5-1 & 10,18 & 6,19 & 7,32 & 3,07 & 0,499 & 2,08 & 1,037 & $-1,085$ \\
\hline & & $5-3$ & 10,04 & 6,12 & 7,01 & 3,139 & 0,499 & 2,23 & 1,112 & $-1,038$ \\
\hline & & $5-4$ & 9,57 & 5,71 & 6,79 & 2,877 & 0,499 & 2,67 & 1,331 & $-0,771$ \\
\hline & & 5-6 & 10,05 & 6,09 & 7,14 & 3,063 & 0,499 & 2,53 & 1,262 & $-0,887$ \\
\hline
\end{tabular}

Obs.1: $\left(^{*}\right)$ Dados obtidos experimentalmente

$\left.{ }^{* *}\right)$ Valores calculados 
Apêndice 6: Planilha de Cálculo dos Dados Cinéticos em atmosfera de nitrogênio

\begin{tabular}{|c|c|c|c|c|c|c|c|c|c|c|}
\hline 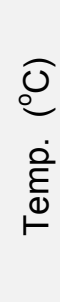 & $\begin{array}{l}8 \\
8 \\
\circ \\
\dot{0} \\
\dot{x} \\
\stackrel{5}{r}\end{array}$ & 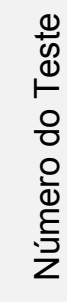 & $\begin{array}{c}M_{A} \\
\left(^{*}\right)\end{array}$ & $\begin{array}{c}\mathrm{M}_{\mathrm{C}} \\
\left(^{*}\right)\end{array}$ & $\begin{array}{c}M_{S} \\
\left(^{*}\right)\end{array}$ & $\begin{array}{c}\mathrm{m}_{\max } \\
\left(^{* *}\right)\end{array}$ & $\begin{array}{c}\mathrm{C}_{2} \\
\left(^{* *}\right)\end{array}$ & $\frac{\sum^{\frac{\pi}{0}}}{\sum_{0}^{\infty}} \underset{0}{\sum_{0}^{0}} \approx$ & 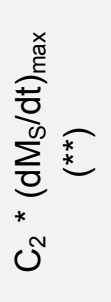 & 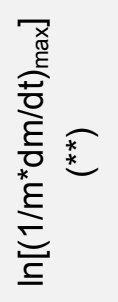 \\
\hline \multirow{4}{*}{ 员 } & \multirow{4}{*}{$\begin{array}{l}\infty \\
\stackrel{N}{N} \\
\stackrel{n}{N} \\
\sigma^{-}\end{array}$} & $1-1$ & 10,2 & 5,97 & 7,4 & 2,749 & 0,623 & 2,85 & 1,776 & $-0,437$ \\
\hline & & $1-2$ & 9,81 & 5,57 & 6,95 & 2,641 & 0,623 & 3,14 & 1,957 & $-0,300$ \\
\hline & & $1-3$ & 10,17 & 6,24 & 7,73 & 2,701 & 0,623 & 2,82 & 1,757 & $-0,43$ \\
\hline & & $1-4$ & 10,23 & 5,97 & 7,33 & 2,804 & 0,623 & 3,05 & 1,901 & $-0,389$ \\
\hline \multirow{4}{*}{ ০০ } & \multirow{4}{*}{$\begin{array}{l}\tilde{0} \\
\infty \\
\infty \\
\infty \\
\infty \\
\infty\end{array}$} & $2-2$ & 9,99 & 5,93 & 7,41 & 2,643 & 0,623 & 3,19 & 1,988 & $-0,285$ \\
\hline & & $2-3$ & 10,41 & 6,27 & 7,71 & 2,818 & 0,623 & 3,02 & 1,882 & $-0,404$ \\
\hline & & $2-4$ & 10,04 & 5,93 & 7,38 & 2,68 & 0,623 & 3,11 & 1,938 & $-0,324$ \\
\hline & & $2-5$ & 10,27 & 5,86 & 7,27 & 2,787 & 0,623 & 3,2 & 1,994 & $-0,335$ \\
\hline \multirow{4}{*}{$\begin{array}{l}\text { ○ } \\
\infty\end{array}$} & \multirow{4}{*}{ 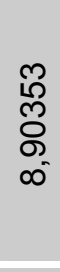 } & $3-1$ & 9,72 & 5,62 & 7,22 & 2,472 & 0,623 & 3,11 & 1,938 & $-0,243$ \\
\hline & & $3-2$ & 10,18 & 5,98 & 7,57 & 2,642 & 0,623 & 3,14 & 1,957 & $-0,300$ \\
\hline & & $3-4$ & 10,35 & 6,2 & 7,57 & 2,84 & 0,623 & 2,95 & 1,838 & $-0,435$ \\
\hline & & $3-6$ & 8,6 & 5,01 & 6,18 & 2,34 & 0,623 & 2,61 & 1,626 & $-0,364$ \\
\hline \multirow{4}{*}{ ৪ి } & \multirow{4}{*}{ 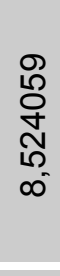 } & 4-1 & 10,46 & 5,89 & 7,38 & 2,805 & 0,623 & 3,35 & 2,088 & $-0,295$ \\
\hline & & $4-2$ & 10,24 & 6,17 & 7,72 & 2,689 & 0,623 & 3,17 & 1,975 & $-0,308$ \\
\hline & & $4-3$ & 10,17 & 6,09 & 7,61 & 2,682 & 0,623 & 3,08 & 1,919 & $-0,335$ \\
\hline & & 4-4 & 10,4 & 5,88 & 7,43 & 2,746 & 0,623 & 3,18 & 1,982 & $-0,326$ \\
\hline \multirow{4}{*}{ 융 } & \multirow{4}{*}{$\begin{array}{l}\frac{N}{0} \\
\frac{0}{2} \\
\frac{1}{\sigma} \\
\infty\end{array}$} & $5-1$ & 9,22 & 5,58 & 6,99 & 2,412 & 0,623 & 2,92 & 1,82 & $-0,282$ \\
\hline & & $5-2$ & 9,79 & 5,6 & 6,99 & 2,628 & 0,623 & 3,28 & 2,044 & $-0,251$ \\
\hline & & $5-3$ & 10,37 & 6,26 & 7,61 & 2,86 & 0,623 & 3,31 & 2,063 & $-0,327$ \\
\hline & & $5-6$ & 9,93 & 5,94 & 7,36 & 2,659 & 0,623 & 3 & 1,87 & $-0,352$ \\
\hline
\end{tabular}

Obs.: $\quad{ }^{*}$ ) Dados obtidos experimentalmente

$\left.{ }^{* *}\right)$ Valores calculados 
Apêndice 7: Planilha de Cálculo da Conversão em atmosfera de ar

\begin{tabular}{|c|c|c|c|c|c|c|c|c|c|}
\hline 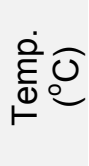 & 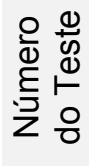 & $\begin{array}{l}\mathrm{M}_{\mathrm{A}} \\
\left(^{*}\right)\end{array}$ & $\begin{array}{l}M_{C} \\
\left(^{*}\right)\end{array}$ & $\begin{array}{l}\mathrm{M}_{\mathrm{F}} \\
\left(^{*}\right)\end{array}$ & $\begin{array}{c}\Delta \mathrm{M}_{\mathrm{S}} \\
\left(^{* *}\right)\end{array}$ & $\frac{\Delta M_{S}}{W_{s O_{2}}+W_{1 / 2 O_{2}}}$ & $M_{A}$ & $\begin{array}{c}\left.\frac{Y_{C a}}{W_{C a}}+\frac{Y_{M g}}{W_{M g}}\right) \\
\left({ }^{* *}\right)\end{array}$ & $\begin{array}{c}X(\%) \\
\left(^{* *}\right)\end{array}$ \\
\hline \multirow{4}{*}{ 웃 } & $1-1$ & 9,35 & 5,77 & 8,5598 & 2,7898 & 0,0348 & & 0,0838 & 41,5849 \\
\hline & $1-2$ & 10,13 & 6,08 & 8,862 & 2,782 & 0,0347 & & 0,0908 & 38,2754 \\
\hline & $1-3$ & 10,06 & 6,2 & 8,7591 & 2,5591 & 0,032 & & 0,0902 & 35,454 \\
\hline & $1-4$ & 10,4 & 6,14 & 8,89 & 2,75 & 0,0343 & & 0,0932 & 36,8529 \\
\hline \multirow{4}{*}{ ○ } & $2-1$ & 10,07 & 6,01 & 9,1339 & 3,1239 & 0,039 & & 0,0902 & 43,2359 \\
\hline & $2-2$ & 9,13 & 5,3 & 7,9214 & 2,6214 & 0,0327 & & 0,0818 & 40,0154 \\
\hline & $2-5$ & 10,07 & 6 & 8,8391 & 2,8391 & 0,0355 & & 0,0902 & 39,294 \\
\hline & $2-6$ & 9,61 & 5,39 & 8,2714 & 2,8814 & 0,036 & & 0,0861 & 41,7885 \\
\hline \multirow{4}{*}{$\begin{array}{l}\circ \\
\infty \\
\infty\end{array}$} & 3-2 & 9,65 & 5,52 & 8,4145 & 2,8945 & 0,0362 & & 0,0865 & 41,8039 \\
\hline & $3-5$ & 10,29 & 6 & 9,0302 & 3,0302 & 0,0378 & & 0,0922 & 41,0413 \\
\hline & $3-6$ & 9,73 & 5,6 & 8,3701 & 2,7701 & 0,0346 & & 0,0872 & 39,6779 \\
\hline & $3-7$ & 10,19 & 5,94 & 9,058 & 3,118 & 0,0389 & & 0,0913 & 42,6459 \\
\hline \multirow{4}{*}{ ৪ } & 4-2 & 9,93 & 6,2 & 8,7582 & 2,5582 & 0,032 & & 0,089 & 35,9048 \\
\hline & $4-3$ & 10,56 & 6,39 & 9,1287 & 2,7387 & 0,0342 & & 0,0946 & 36,1453 \\
\hline & $4-4$ & 10,58 & 6,49 & 9,1645 & 2,6745 & 0,0334 & & 0,0948 & 35,2312 \\
\hline & 4-5 & 10,52 & 6,14 & 9,0236 & 2,8836 & 0,036 & & 0,0943 & 38,2028 \\
\hline \multirow{4}{*}{ 유 } & 5-1 & 10,18 & 6,19 & 8,7636 & 2,5736 & 0,0321 & & 0,0912 & 35,2339 \\
\hline & $5-3$ & 10,04 & 6,12 & 8,3453 & 2,2253 & 0,0278 & & 0,09 & 30,89 \\
\hline & $5-4$ & 9,57 & 5,71 & 8,3419 & 2,6319 & 0,0329 & & 0,0858 & 38,3292 \\
\hline & $5-6$ & 10,05 & 6,09 & 8,6565 & 2,5665 & 0,0321 & & 0,0901 & 35,5915 \\
\hline
\end{tabular}

Obs.: $\quad\left(^{*}\right)$ Dados obtidos experimentalmente

$\left(^{* *}\right)$ Valores calculados 
Apêndice 8: Planilha de Cálculo da Conversão em atmosfera de nitrogênio

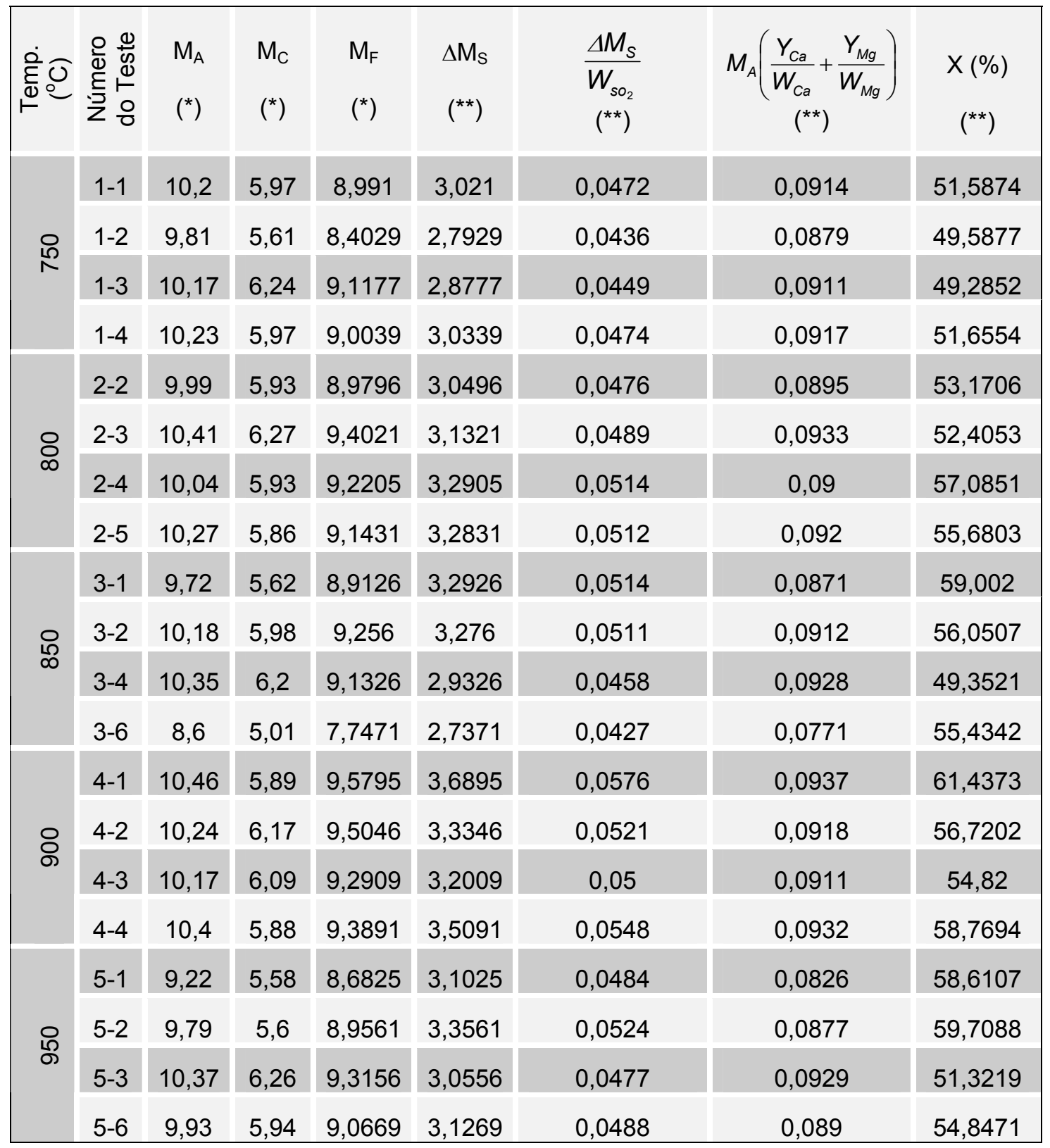

Obs.: $\quad\left(^{*}\right)$ Dados obtidos experimentalmente

$\left.{ }^{* *}\right)$ Valores calculados 
Apêndice 9: Planilha de Cálculo da Efetividade para 1 experimento a $950{ }^{\circ} \mathrm{C}$ em atmosfera de Ar Sintético

\begin{tabular}{|c|c|c|c|c|c|c|}
\hline $\begin{array}{c}\text { Tempo } \\
(\mathrm{s}) \\
\left(^{*}\right)\end{array}$ & $\Delta \mathrm{M}_{\mathrm{S}}\left(^{*}\right)$ & $\frac{d M_{s}}{d t}$ & $\frac{d m}{d t}$ & $\frac{1}{m}$ & $\frac{1}{m} \frac{d m}{d t}$ & $\underset{(* *}{\eta}$ \\
\hline 0 & 6,09877 & 2,68E-04 & 1,34E-04 & 0,27914 & 3,73E-05 & 0,00536 \\
\hline 1 & 6,09902 & 2,69E-04 & 1,34E-04 & 0,27915 & 3,74E-05 & 0,00538 \\
\hline 2 & 6,0993 & 2,74E-04 & 1,37E-04 & 0,27916 & 3,82E-05 & 0,00549 \\
\hline 3 & 6,09958 & 2,82E-04 & 1,41E-04 & 0,27917 & 3,92E-05 & 0,00564 \\
\hline 4 & 6,09987 & 2,92E-04 & 1,46E-04 & 0,27918 & 4,07E-05 & 0,00586 \\
\hline 5 & 6,10015 & 3,02E-04 & 1,51E-04 & 0,27919 & 4,20E-05 & 0,00605 \\
\hline 6 & 6,10047 & 3,27E-04 & 1,63E-04 & 0,2792 & 4,56E-05 & 0,00656 \\
\hline 7 & 6,10079 & 3,54E-04 & 1,76E-04 & 0,27922 & 4,93E-05 & 0,00709 \\
\hline 8 & 6,10118 & 3,67E-04 & 1,83E-04 & 0,27923 & 5,11E-05 & 0,00735 \\
\hline 9 & 6,10156 & 3,72E-04 & 1,85E-04 & 0,27925 & 5,18E-05 & 0,00745 \\
\hline 10 & 6,10192 & $3,55 \mathrm{E}-04$ & 1,77E-04 & 0,27926 & 4,94E-05 & 0,00711 \\
\hline 11 & 6,10228 & $3,44 \mathrm{E}-04$ & $1,72 \mathrm{E}-04$ & 0,27927 & 4,79E-05 & 0,0069 \\
\hline 12 & 6,1026 & $3,50 \mathrm{E}-04$ & 1,75E-04 & 0,27929 & 4,88E-05 & 0,00702 \\
\hline 13 & 6,10294 & $3,72 \mathrm{E}-04$ & 1,85E-04 & 0,2793 & 5,18E-05 & 0,00745 \\
\hline 14 & 6,10334 & 4,17E-04 & $2,08 \mathrm{E}-04$ & 0,27931 & 5,80E-05 & 0,00835 \\
\hline 15 & 6,10376 & 4,78E-04 & $2,38 \mathrm{E}-04$ & 0,27933 & $6,65 \mathrm{E}-05$ & 0,00957 \\
\hline 16 & 6,10427 & 5,71E-04 & $2,85 \mathrm{E}-04$ & 0,27935 & 7,95E-05 & 0,01144 \\
\hline 17 & 6,10487 & 6,88E-04 & $3,43 \mathrm{E}-04$ & 0,27937 & 9,59E-05 & 0,01379 \\
\hline 18 & 6,10564 & 8,06E-04 & $4,02 E-04$ & 0,2794 & $1,12 \mathrm{E}-04$ & 0,01615 \\
\hline 19 & 6,10652 & $9,06 E-04$ & 4,52E-04 & 0,27944 & 1,26E-04 & 0,01816 \\
\hline 20 & 6,10747 & $9,66 \mathrm{E}-04$ & 4,81E-04 & 0,27948 & $1,35 \mathrm{E}-04$ & 0,01936 \\
\hline 21 & 6,10848 & 9,88E-04 & 4,93E-04 & 0,27951 & 1,38E-04 & 0,01982 \\
\hline 22 & 6,10949 & $9,84 \mathrm{E}-04$ & 4,90E-04 & 0,27955 & 1,37E-04 & 0,01973 \\
\hline 23 & 6,11045 & $9,80 \mathrm{E}-04$ & 4,89E-04 & 0,27959 & 1,37E-04 & 0,01966 \\
\hline 24 & 6,11141 & 9,77E-04 & 4,87E-04 & 0,27963 & 1,36E-04 & 0,01959 \\
\hline 25 & 6,11242 & 9,77E-04 & 4,87E-04 & 0,27967 & 1,36E-04 & 0,01961 \\
\hline 26 & 6,11339 & $9,87 E-04$ & 4,92E-04 & 0,27971 & $1,38 \mathrm{E}-04$ & 0,01981 \\
\hline 27 & 6,11435 & 0,00101 & $5,05 E-04$ & 0,27974 & 1,41E-04 & 0,02031 \\
\hline 28 & 6,11538 & 0,00104 & 5,21E-04 & 0,27978 & 1,46E-04 & 0,02097 \\
\hline 29 & 6,11649 & 0,00107 & $5,32 \mathrm{E}-04$ & 0,27983 & 1,49E-04 & 0,02141 \\
\hline 30 & 6,11754 & 0,00106 & $5,30 \mathrm{E}-04$ & 0,27987 & $1,48 \mathrm{E}-04$ & 0,02134 \\
\hline 31 & 6,1186 & 0,00104 & 5,21E-04 & 0,27991 & 1,46E-04 & 0,02097 \\
\hline 32 & 6,11964 & 0,00104 & 5,18E-04 & 0,27995 & $1,45 \mathrm{E}-04$ & 0,02085 \\
\hline 33 & 6,12066 & 0,00103 & 5,16E-04 & 0,27999 & 1,44E-04 & 0,02077 \\
\hline 34 & 6,1217 & 0,00105 & $5,25 \mathrm{E}-04$ & 0,28003 & 1,47E-04 & 0,02117 \\
\hline 35 & 6,12274 & 0,00108 & $5,41 \mathrm{E}-04$ & 0,28007 & 1,51E-04 & 0,02178 \\
\hline 36 & 6,12387 & 0,00112 & 5,58E-04 & 0,28012 & $1,56 \mathrm{E}-04$ & 0,02251 \\
\hline 37 & 6,125 & 0,00116 & 5,77E-04 & 0,28016 & $1,62 E-04$ & 0,02325 \\
\hline 38 & 6,12617 & 0,00117 & 5,85E-04 & 0,28021 & 1,64E-04 & 0,02359 \\
\hline 39 & 6,12737 & 0,0012 & $6,00 \mathrm{E}-04$ & 0,28025 & 1,68E-04 & 0,0242 \\
\hline
\end{tabular}




\begin{tabular}{|c|c|c|c|c|c|c|}
\hline $\begin{array}{c}\text { Tempo } \\
(\mathrm{s}) \\
\left(^{*}\right)\end{array}$ & $\Delta \mathrm{M}_{\mathrm{S}}\left(^{*}\right)$ & $\frac{d M_{S}}{d t}$ & $\frac{d m}{d t}$ & $\frac{1}{m}$ & $\frac{1}{m} \frac{d m}{d t}$ & $\eta_{(* *}$ \\
\hline 40 & 6,12855 & 0,00122 & 6,09E-04 & 0,2803 & 1,71E-04 & 0,02455 \\
\hline 41 & 6,12983 & 0,00126 & $6,27 \mathrm{E}-04$ & 0,28035 & 1,76E-04 & 0,02529 \\
\hline 42 & 6,13105 & 0,0013 & 6,49E-04 & 0,2804 & 1,82E-04 & 0,02618 \\
\hline 43 & 6,13241 & 0,00135 & 6,71E-04 & 0,28045 & 1,88E-04 & 0,02707 \\
\hline 44 & 6,13376 & 0,00142 & 7,09E-04 & 0,2805 & 1,99E-04 & 0,02863 \\
\hline 45 & 6,13519 & 0,00151 & 7,51E-04 & 0,28056 & 2,11E-04 & 0,03033 \\
\hline 46 & 6,13677 & 0,00163 & 8,14E-04 & 0,28062 & 2,28E-04 & 0,03285 \\
\hline 47 & 6,13844 & 0,00178 & 8,87E-04 & 0,28069 & 2,49E-04 & 0,03583 \\
\hline 48 & 6,1403 & 0,00193 & $9,60 \mathrm{E}-04$ & 0,28076 & 2,70E-04 & 0,03878 \\
\hline 49 & 6,14232 & 0,00209 & 0,00104 & 0,28084 & 2,92E-04 & 0,04204 \\
\hline 50 & 6,14445 & 0,00228 & 0,00114 & 0,28092 & $3,20 \mathrm{E}-04$ & 0,046 \\
\hline 51 & 6,14679 & 0,00252 & 0,00126 & 0,28102 & 3,53E-04 & 0,05086 \\
\hline 52 & 6,14947 & 0,00281 & 0,0014 & 0,28112 & 3,93E-04 & 0,05661 \\
\hline 53 & 6,15242 & 0,00312 & 0,00156 & 0,28124 & 4,38E-04 & 0,063 \\
\hline 54 & 6,15567 & 0,00346 & 0,00173 & 0,28137 & 4,86E-04 & 0,0699 \\
\hline 55 & 6,15931 & 0,00386 & 0,00192 & 0,28151 & 5,41E-04 & 0,07791 \\
\hline 56 & 6,16334 & 0,00429 & 0,00214 & 0,28167 & $6,02 \mathrm{E}-04$ & 0,08669 \\
\hline 57 & 6,16787 & 0,00471 & 0,00235 & 0,28185 & $6,62 \mathrm{E}-04$ & 0,09518 \\
\hline 58 & 6,17283 & 0,00513 & 0,00256 & 0,28204 & $7,22 \mathrm{E}-04$ & 0,10387 \\
\hline 59 & 6,1781 & 0,0056 & 0,00279 & 0,28225 & 7,89E-04 & 0,11351 \\
\hline 60 & 6,1839 & 0,00618 & 0,00308 & 0,28248 & 8,71E-04 & 0,12527 \\
\hline 61 & 6,19036 & 0,00686 & 0,00342 & 0,28274 & 9,68E-04 & 0,13923 \\
\hline 62 & 6,1976 & 0,00765 & 0,00382 & 0,28303 & 0,00108 & 0,15545 \\
\hline 63 & 6,20556 & 0,00854 & 0,00426 & 0,28335 & 0,00121 & 0,17354 \\
\hline 64 & 6,21457 & 0,00949 & 0,00473 & 0,28371 & 0,00134 & 0,19317 \\
\hline 65 & 6,22456 & 0,01053 & 0,00525 & 0,28411 & 0,00149 & 0,2147 \\
\hline 66 & 6,23555 & 0,01162 & 0,00579 & 0,28455 & 0,00165 & 0,23716 \\
\hline 67 & 6,24774 & 0,01277 & 0,00637 & 0,28505 & 0,00182 & 0,26117 \\
\hline 68 & 6,26107 & 0,014 & 0,00698 & 0,28559 & 0,00199 & 0,28683 \\
\hline 69 & 6,27565 & 0,01525 & 0,00761 & 0,28618 & 0,00218 & 0,31322 \\
\hline 70 & 6,29158 & 0,01657 & 0,00826 & 0,28683 & 0,00237 & 0,34106 \\
\hline 71 & 6,30875 & 0,01794 & 0,00895 & 0,28754 & 0,00257 & 0,37014 \\
\hline 72 & 6,32738 & 0,01934 & 0,00965 & 0,28831 & 0,00278 & 0,40014 \\
\hline 73 & 6,34746 & 0,02081 & 0,01038 & 0,28915 & 0,003 & 0,43165 \\
\hline 74 & 6,36895 & 0,02229 & 0,01111 & 0,29004 & 0,00322 & 0,46378 \\
\hline 75 & 6,392 & 0,02378 & 0,01186 & 0,29101 & 0,00345 & 0,49656 \\
\hline 76 & 6,41654 & 0,02528 & 0,0126 & 0,29205 & 0,00368 & 0,52963 \\
\hline 77 & 6,44257 & 0,02674 & 0,01333 & 0,29317 & 0,00391 & 0,56246 \\
\hline 78 & 6,47004 & 0,02818 & 0,01405 & 0,29435 & 0,00414 & 0,59518 \\
\hline 79 & 6,49896 & 0,02961 & 0,01477 & 0,2956 & 0,00436 & 0,62803 \\
\hline 80 & 6,52926 & 0,03099 & 0,01545 & 0,29693 & 0,00459 & 0,66019 \\
\hline 81 & 6,56102 & 0,03231 & 0,01611 & 0,29833 & 0,00481 & 0,69154 \\
\hline 82 & 6,59395 & 0,03354 & 0,01673 & 0,2998 & 0,00501 & 0,72154 \\
\hline
\end{tabular}




\begin{tabular}{|c|c|c|c|c|c|c|}
\hline $\begin{array}{c}\text { Tempo } \\
(\mathrm{s}) \\
\left(^{*}\right)\end{array}$ & $\Delta \mathrm{M}_{\mathrm{S}}\left(^{*}\right)$ & $\frac{d M_{S}}{d t}$ & $\frac{d m}{d t}$ & $\frac{1}{m}$ & $\frac{1}{m} \frac{d m}{d t}$ & $\underset{(* *)}{\eta}$ \\
\hline 83 & 6,62815 & 0,03472 & 0,01731 & 0,30134 & 0,00522 & 0,75065 \\
\hline 84 & 6,66342 & 0,03584 & 0,01787 & 0,30295 & 0,00541 & 0,77897 \\
\hline 85 & 6,69988 & 0,03685 & 0,01838 & 0,30462 & 0,0056 & 0,8055 \\
\hline 86 & 6,73728 & 0,03778 & 0,01884 & 0,30636 & 0,00577 & 0,83041 \\
\hline 87 & 6,77549 & 0,03858 & 0,01924 & 0,30816 & 0,00593 & 0,85303 \\
\hline 88 & 6,8145 & 0,03929 & 0,01959 & 0,31002 & 0,00607 & 0,87386 \\
\hline 89 & 6,85417 & 0,03993 & 0,01991 & 0,31194 & 0,00621 & 0,89358 \\
\hline 90 & 6,89437 & 0,04049 & 0,02019 & 0,3139 & 0,00634 & 0,91197 \\
\hline 91 & 6,93519 & 0,04097 & 0,02043 & 0,31592 & 0,00645 & 0,92868 \\
\hline 92 & 6,97646 & 0,04135 & 0,02062 & 0,31798 & 0,00656 & 0,9435 \\
\hline 93 & 7,01798 & 0,04164 & 0,02076 & 0,32009 & 0,00665 & 0,95625 \\
\hline 94 & 7,05974 & 0,04186 & 0,02088 & 0,32224 & 0,00673 & 0,96792 \\
\hline 95 & 7,10173 & 0,04203 & 0,02096 & 0,32443 & 0,0068 & 0,97831 \\
\hline 96 & 7,1439 & 0,0421 & 0,02099 & 0,32666 & 0,00686 & 0,98668 \\
\hline 97 & 7,18605 & 0,04204 & 0,02097 & 0,32891 & 0,0069 & 0,99219 \\
\hline 98 & 7,22808 & 0,04191 & 0,0209 & 0,3312 & 0,00692 & 0,99588 \\
\hline 99 & 7,26986 & 0,04175 & 0,02082 & 0,3335 & 0,00694 & 0,99895 \\
\hline 100 & 7,31154 & 0,04153 & 0,02071 & 0,33583 & 0,00695 & 1,00066 \\
\hline 101 & 7,35306 & 0,04123 & 0,02056 & 0,33818 & 0,00695 & 1 \\
\hline 102 & 7,39414 & 0,04084 & 0,02037 & 0,34054 & 0,00694 & 0,99788 \\
\hline 103 & 7,43472 & 0,04033 & 0,02011 & 0,3429 & 0,0069 & 0,99215 \\
\hline 104 & 7,47492 & 0,03972 & 0,01981 & 0,34527 & 0,00684 & 0,98393 \\
\hline 105 & 7,5143 & 0,039 & 0,01945 & 0,34763 & 0,00676 & 0,97275 \\
\hline 106 & 7,55293 & 0,03815 & 0,01903 & 0,34997 & 0,00666 & 0,95803 \\
\hline 107 & 7,59071 & 0,03725 & 0,01858 & 0,3523 & 0,00654 & 0,94168 \\
\hline 108 & 7,62748 & 0,03625 & 0,01808 & 0,35459 & 0,00641 & 0,92223 \\
\hline 109 & 7,6633 & 0,03515 & 0,01753 & 0,35685 & 0,00625 & 0,89996 \\
\hline 110 & 7,69789 & 0,03402 & 0,01697 & 0,35906 & 0,00609 & 0,87648 \\
\hline 111 & 7,73126 & 0,03285 & 0,01638 & 0,36122 & 0,00592 & 0,85139 \\
\hline 112 & 7,76362 & 0,03166 & 0,01579 & 0,36333 & 0,00574 & 0,82534 \\
\hline 113 & 7,79469 & 0,03041 & 0,01517 & 0,36539 & 0,00554 & 0,79731 \\
\hline 114 & 7,82448 & 0,02909 & 0,01451 & 0,36738 & 0,00533 & 0,76685 \\
\hline 115 & 7,8529 & 0,02774 & 0,01383 & 0,36931 & 0,00511 & 0,73512 \\
\hline 116 & 7,87998 & 0,02638 & 0,01316 & 0,37116 & 0,00488 & 0,70253 \\
\hline 117 & 7,90566 & 0,02502 & 0,01248 & 0,37293 & 0,00465 & 0,66948 \\
\hline 118 & 7,93 & 0,02365 & 0,0118 & 0,37463 & 0,00442 & 0,63579 \\
\hline 119 & 7,95299 & 0,02229 & 0,01111 & 0,37624 & 0,00418 & 0,60166 \\
\hline 120 & 7,97458 & 0,02092 & 0,01043 & 0,37777 & 0,00394 & 0,56701 \\
\hline 121 & 7,99481 & 0,01958 & 0,00977 & 0,37922 & 0,0037 & 0,53284 \\
\hline 122 & 8,01369 & 0,01832 & 0,00913 & 0,38058 & 0,00348 & 0,50019 \\
\hline 123 & 8,03136 & 0,01714 & 0,00854 & 0,38186 & 0,00326 & 0,46949 \\
\hline 124 & 8,0479 & 0,01601 & 0,00799 & 0,38306 & 0,00306 & 0,44012 \\
\hline 125 & 8,06339 & 0,01495 & 0,00746 & 0,3842 & 0,00286 & 0,41217 \\
\hline
\end{tabular}




\begin{tabular}{|c|c|c|c|c|c|c|}
\hline $\begin{array}{c}\text { Tempo } \\
(\mathrm{s}) \\
\left(^{*}\right)\end{array}$ & $\Delta \mathrm{M}_{\mathrm{S}}\left(^{*}\right)$ & $\frac{d M_{S}}{d t}$ & $\frac{d m}{d t}$ & $\frac{1}{m}$ & $\frac{1}{m} \frac{d m}{d t}$ & $\underset{(* *)}{\eta}$ \\
\hline 126 & 8,07774 & 0,01396 & 0,00696 & 0,38526 & 0,00268 & 0,38594 \\
\hline 127 & 8,0912 & 0,01303 & 0,0065 & 0,38626 & 0,00251 & 0,36119 \\
\hline 128 & 8,10381 & 0,01219 & 0,00608 & 0,3872 & 0,00235 & 0,33858 \\
\hline 129 & 8,11552 & 0,01139 & 0,00568 & 0,38807 & 0,0022 & 0,31721 \\
\hline 130 & 8,12652 & 0,01067 & 0,00532 & 0,3889 & 0,00207 & 0,29767 \\
\hline 131 & 8,1368 & 0,01002 & 0,00499 & 0,38968 & 0,00195 & 0,28003 \\
\hline 132 & 8,1465 & 0,00942 & 0,0047 & 0,39042 & 0,00183 & 0,26389 \\
\hline 133 & 8,1556 & 0,00889 & 0,00443 & 0,39111 & 0,00173 & 0,24945 \\
\hline 134 & 8,16422 & 0,0084 & 0,00419 & 0,39177 & 0,00164 & 0,23605 \\
\hline 135 & 8,17239 & 0,00792 & 0,00395 & 0,39239 & 0,00155 & 0,22294 \\
\hline 136 & 8,1801 & 0,00746 & 0,00372 & 0,39299 & 0,00146 & 0,2103 \\
\hline 137 & 8,18726 & 0,00704 & 0,00351 & 0,39354 & 0,00138 & 0,19873 \\
\hline 138 & 8,19408 & 0,00669 & 0,00334 & 0,39407 & 0,00131 & 0,18919 \\
\hline 139 & 8,20059 & 0,0064 & 0,00319 & 0,39457 & 0,00126 & 0,18105 \\
\hline 140 & 8,20689 & 0,00608 & 0,00303 & 0,39506 & 0,0012 & 0,1723 \\
\hline 141 & 8,21283 & 0,00576 & 0,00287 & 0,39552 & 0,00114 & 0,16338 \\
\hline 142 & 8,21835 & 0,00544 & 0,00271 & 0,39595 & 0,00107 & 0,15455 \\
\hline 143 & 8,22365 & 0,00515 & 0,00257 & 0,39637 & 0,00102 & 0,14651 \\
\hline 144 & 8,22868 & 0,00492 & 0,00245 & 0,39676 & $9,74 \mathrm{E}-04$ & 0,14012 \\
\hline 145 & 8,23343 & 0,00472 & 0,00235 & 0,39714 & 9,34E-04 & 0,13441 \\
\hline 146 & 8,23807 & 0,00455 & 0,00227 & 0,3975 & $9,03 E-04$ & 0,12991 \\
\hline 147 & 8,24254 & 0,00443 & 0,00221 & 0,39785 & 8,79E-04 & 0,12654 \\
\hline 148 & 8,2469 & 0,0043 & 0,00214 & 0,3982 & 8,53E-04 & 0,12277 \\
\hline 149 & 8,25118 & 0,00419 & 0,00209 & 0,39854 & 8,32E-04 & 0,11969 \\
\hline 150 & 8,25524 & 0,00408 & 0,00204 & 0,39886 & $8,12 \mathrm{E}-04$ & 0,11679 \\
\hline 151 & 8,2593 & 0,00397 & 0,00198 & 0,39918 & 7,90E-04 & 0,11363 \\
\hline 152 & 8,26325 & 0,00384 & 0,00191 & 0,3995 & $7,65 \mathrm{E}-04$ & 0,11004 \\
\hline 153 & 8,26701 & 0,00368 & 0,00184 & 0,3998 & $7,34 \mathrm{E}-04$ & 0,10564 \\
\hline 154 & 8,27058 & 0,00355 & 0,00177 & 0,40008 & $7,09 \mathrm{E}-04$ & 0,102 \\
\hline 155 & 8,27405 & 0,00344 & 0,00172 & 0,40036 & 6,87E-04 & 0,09886 \\
\hline 156 & 8,2775 & 0,00336 & 0,00167 & 0,40063 & $6,70 \mathrm{E}-04$ & 0,09645 \\
\hline 157 & 8,28076 & 0,00325 & 0,00162 & 0,40089 & $6,50 \mathrm{E}-04$ & 0,09356 \\
\hline 158 & 8,284 & 0,00315 & 0,00157 & 0,40115 & $6,29 E-04$ & 0,09052 \\
\hline 159 & 8,28706 & 0,00307 & 0,00153 & 0,4014 & $6,14 \mathrm{E}-04$ & 0,08838 \\
\hline 160 & 8,29007 & 0,00302 & 0,0015 & 0,40164 & $6,04 \mathrm{E}-04$ & 0,08693 \\
\hline 161 & 8,29307 & 0,003 & 0,00149 & 0,40188 & $6,00 \mathrm{E}-04$ & 0,0864 \\
\hline 162 & 8,29608 & 0,00299 & 0,00149 & 0,40213 & 5,99E-04 & 0,08613 \\
\hline 163 & 8,29904 & 0,00295 & 0,00147 & 0,40236 & 5,92E-04 & 0,08516 \\
\hline 164 & 8,30201 & 0,00289 & 0,00144 & 0,4026 & 5,80 E-04 & 0,08343 \\
\hline 165 & 8,30485 & 0,00281 & 0,0014 & 0,40283 & 5,65E-04 & 0,08136 \\
\hline 166 & 8,30761 & 0,00275 & 0,00137 & 0,40306 & 5,52E-04 & 0,07941 \\
\hline 167 & 8,31031 & 0,00269 & 0,00134 & 0,40328 & 5,41E-04 & 0,0779 \\
\hline 168 & 8,31301 & 0,00267 & 0,00133 & 0,4035 & $5,36 \mathrm{E}-04$ & 0,07717 \\
\hline
\end{tabular}




\begin{tabular}{|c|c|c|c|c|c|c|}
\hline $\begin{array}{c}\text { Tempo } \\
(\mathrm{s}) \\
\left(^{*}\right)\end{array}$ & $\Delta \mathrm{M}_{\mathrm{S}}\left(^{*}\right)$ & $\frac{d M_{s}}{d t}$ & $\frac{d m}{d t}$ & $\frac{1}{m}$ & $\frac{1}{m} \frac{d m}{d t}$ & $\underset{(* *)}{\eta}$ \\
\hline 169 & 8,31561 & 0,00263 & 0,00131 & 0,40371 & 5,30E-04 & 0,07623 \\
\hline 170 & 8,31829 & 0,0026 & 0,0013 & 0,40392 & 5,23E-04 & 0,07527 \\
\hline 171 & 8,32083 & 0,00255 & 0,00127 & 0,40413 & 5,14E-04 & 0,07391 \\
\hline 172 & 8,32339 & 0,00249 & 0,00124 & 0,40434 & 5,01E-04 & 0,07214 \\
\hline 173 & 8,32581 & 0,00244 & 0,00122 & 0,40454 & 4,92E-04 & 0,07082 \\
\hline 174 & 8,32823 & 0,00239 & 0,00119 & 0,40474 & 4,83E-04 & 0,06945 \\
\hline 175 & 8,3306 & 0,00236 & 0,00118 & 0,40493 & 4,77E-04 & 0,06867 \\
\hline 176 & 8,33295 & 0,00234 & 0,00117 & 0,40512 & 4,73E-04 & 0,06804 \\
\hline 177 & 8,33527 & 0,00232 & 0,00116 & 0,40531 & 4,70E-04 & 0,06759 \\
\hline 178 & 8,3376 & 0,00229 & 0,00114 & 0,4055 & 4,63E-04 & 0,06662 \\
\hline 179 & 8,3399 & 0,00224 & 0,00112 & 0,40569 & 4,54E-04 & 0,06528 \\
\hline 180 & 8,34208 & 0,00221 & 0,0011 & 0,40587 & 4,47E-04 & 0,06428 \\
\hline 181 & 8,34425 & 0,00219 & 0,00109 & 0,40605 & 4,43E-04 & 0,06374 \\
\hline 182 & 8,34647 & 0,00218 & 0,00109 & 0,40623 & 4,42E-04 & 0,06359 \\
\hline 183 & 8,34865 & 0,00216 & 0,00108 & 0,40641 & 4,37E-04 & 0,06288 \\
\hline 184 & 8,35079 & 0,00211 & 0,00105 & 0,40659 & 4,28E-04 & 0,06164 \\
\hline 185 & 8,35287 & 0,00208 & 0,00104 & 0,40676 & 4,22E-04 & 0,06074 \\
\hline 186 & 8,35492 & 0,00208 & 0,00104 & 0,40693 & 4,23E-04 & 0,0608 \\
\hline 187 & 8,35699 & 0,00211 & 0,00105 & 0,4071 & $4,28 \mathrm{E}-04$ & 0,06152 \\
\hline 188 & 8,35914 & 0,0021 & 0,00105 & 0,40728 & 4,27E-04 & 0,06151 \\
\hline 189 & 8,36129 & 0,0021 & 0,00105 & 0,40745 & 4,26E-04 & 0,06135 \\
\hline 190 & 8,3633 & 0,00206 & 0,00103 & 0,40762 & 4,19E-04 & 0,06028 \\
\hline 191 & 8,3654 & 0,00203 & 0,00101 & 0,40779 & 4,14E-04 & 0,05953 \\
\hline 192 & 8,36739 & 0,00201 & 0,001 & 0,40796 & 4,09E-04 & 0,05887 \\
\hline 193 & 8,36941 & 0,002 & 9,99E-04 & 0,40813 & 4,08E-04 & 0,05866 \\
\hline 194 & 8,37135 & 0,00202 & 0,00101 & 0,40829 & 4,11E-04 & 0,05908 \\
\hline 195 & 8,37344 & 0,002 & 9,96E-04 & 0,40846 & 4,07E-04 & 0,05856 \\
\hline 196 & 8,37546 & 0,00197 & $9,80 \mathrm{E}-04$ & 0,40863 & $4,00 \mathrm{E}-04$ & 0,05762 \\
\hline 197 & 8,37735 & 0,00192 & 9,59E-04 & 0,40879 & 3,92E-04 & 0,0564 \\
\hline 198 & 8,37922 & 0,00191 & $9,52 \mathrm{E}-04$ & 0,40894 & 3,89E-04 & 0,05601 \\
\hline 199 & 8,38117 & 0,00194 & $9,65 E-04$ & 0,40911 & 3,95E-04 & 0,0568 \\
\hline 200 & 8,38309 & 0,00195 & $9,72 \mathrm{E}-04$ & 0,40927 & 3,98E-04 & 0,05724 \\
\hline
\end{tabular}

Obs.: $\left.\quad{ }^{*}\right)$ Dados obtidos experimentalmente

$\left.{ }^{(* *}\right)$ Valores calculados 
Apêndice 10: Planilha de Cálculo da Efetividade para 1 experimento a $950{ }^{\circ} \mathrm{C}$ em atmosfera de nitrogênio

\begin{tabular}{|c|c|c|c|c|c|c|}
\hline $\begin{array}{c}\text { Tempo } \\
(\mathrm{s}) \\
\left(^{*}\right)\end{array}$ & $\begin{array}{c}\Delta \mathrm{M} \\
\left(^{*}\right)\end{array}$ & $\frac{d M_{S}}{d t}$ & $\begin{array}{c}\frac{d m}{d t} \\
\left({ }^{* *}\right)\end{array}$ & $\frac{1}{m}$ & $\begin{array}{c}\frac{1}{m} \frac{d m}{d t} \\
\left({ }^{* *}\right)\end{array}$ & $\underset{(* *)}{\eta}$ \\
\hline 0 & 5,9412 & $3,939 E-5$ & 2,4547E-5 & 0,28223 & $6,92778 \mathrm{E}-6$ & 5,75397E-4 \\
\hline 1 & 5,94131 & 6,881E-5 & $4,28809 E-5$ & 0,28223 & $1,21023 \mathrm{E}-5$ & 0,00101 \\
\hline 2 & 5,94126 & $1,5116 \mathrm{E}-4$ & 9,41997E-5 & 0,28223 & $2,65858 \mathrm{E}-5$ & 0,00221 \\
\hline 3 & 5,94146 & $2,7289 \mathrm{E}-4$ & $1,70059 \mathrm{E}-4$ & 0,28224 & 4,79972E-5 & 0,00399 \\
\hline 4 & 5,94188 & $4,0069 \mathrm{E}-4$ & $2,49701 \mathrm{E}-4$ & 0,28226 & $7,04805 E-5$ & 0,00585 \\
\hline 5 & 5,94237 & $4,6291 \mathrm{E}-4$ & $2,88476 \mathrm{E}-4$ & 0,28228 & $8,14318 \mathrm{E}-5$ & 0,00676 \\
\hline 6 & 5,94281 & $5,1737 \mathrm{E}-4$ & $3,22414 \mathrm{E}-4$ & 0,28231 & $9,10192 \mathrm{E}-5$ & 0,00756 \\
\hline 7 & 5,94331 & $6,083 \mathrm{E}-4$ & $3,7908 \mathrm{E}-4$ & 0,28233 & $1,07026 \mathrm{E}-4$ & 0,00889 \\
\hline 8 & 5,94399 & $7,4272 \mathrm{E}-4$ & $4,62847 \mathrm{E}-4$ & 0,28236 & $1,30691 \mathrm{E}-4$ & 0,01085 \\
\hline 9 & 5,94482 & $8,8177 \mathrm{E}-4$ & $5,495 E-4$ & 0,2824 & $1,55182 \mathrm{E}-4$ & 0,01289 \\
\hline 10 & 5,94577 & $9,686 \mathrm{E}-4$ & $6,03611 \mathrm{E}-4$ & 0,28245 & $1,70491 \mathrm{E}-4$ & 0,01416 \\
\hline 11 & 5,94683 & 9,984E-4 & $6,22182 \mathrm{E}-4$ & 0,2825 & $1,75769 \mathrm{E}-4$ & 0,0146 \\
\hline 12 & 5,94783 & $9,6526 \mathrm{E}-4$ & $6,01529 \mathrm{E}-4$ & 0,28255 & $1,69965 \mathrm{E}-4$ & 0,01412 \\
\hline 13 & 5,94878 & $8,7652 \mathrm{E}-4$ & $5,46229 \mathrm{E}-4$ & 0,2826 & $1,54365 \mathrm{E}-4$ & 0,01282 \\
\hline 14 & 5,94962 & 7,987E-4 & $4,97733 \mathrm{E}-4$ & 0,28264 & $1,40681 \mathrm{E}-4$ & 0,01168 \\
\hline 15 & 5,95032 & $7,3266 \mathrm{E}-4$ & $4,56578 \mathrm{E}-4$ & 0,28268 & $1,29065 \mathrm{E}-4$ & 0,01072 \\
\hline 16 & 5,95106 & $7,0443 \mathrm{E}-4$ & $4,38986 \mathrm{E}-4$ & 0,28272 & $1,24108 \mathrm{E}-4$ & 0,01031 \\
\hline 17 & 5,95173 & $7,2613 \mathrm{E}-4$ & $4,52509 \mathrm{E}-4$ & 0,28275 & $1,27946 \mathrm{E}-4$ & 0,01063 \\
\hline 18 & 5,95244 & $7,493 \mathrm{E}-4$ & $4,66948 \mathrm{E}-4$ & 0,28278 & $1,32045 \mathrm{E}-4$ & 0,01097 \\
\hline 19 & 5,95326 & $7,5998 \mathrm{E}-4$ & $4,73603 \mathrm{E}-4$ & 0,28282 & $1,33947 \mathrm{E}-4$ & 0,01113 \\
\hline 20 & 5,95404 & $7,5579 \mathrm{E}-4$ & $4,70992 \mathrm{E}-4$ & 0,28286 & $1,33227 \mathrm{E}-4$ & 0,01107 \\
\hline 21 & 5,95473 & $7,3886 \mathrm{E}-4$ & $4,60442 E-4$ & 0,2829 & $1,30258 \mathrm{E}-4$ & 0,01082 \\
\hline 22 & 5,95548 & $7,3843 \mathrm{E}-4$ & $4,60174 \mathrm{E}-4$ & 0,28294 & $1,302 E-4$ & 0,01081 \\
\hline 23 & 5,95623 & $7,7591 \mathrm{E}-4$ & $4,83531 \mathrm{E}-4$ & 0,28297 & $1,36826 \mathrm{E}-4$ & 0,01136 \\
\hline 24 & 5,95698 & $8,1391 \mathrm{E}-4$ & $5,07211 \mathrm{E}-4$ & 0,28301 & $1,43546 \mathrm{E}-4$ & 0,01192 \\
\hline 25 & 5,95786 & $8,6884 \mathrm{E}-4$ & $5,41443 \mathrm{E}-4$ & 0,28305 & $1,53258 \mathrm{E}-4$ & 0,01273 \\
\hline 26 & 5,95874 & $9,3865 \mathrm{E}-4$ & $5,84947 \mathrm{E}-4$ & 0,2831 & 1,65597E-4 & 0,01375 \\
\hline 27 & 5,9597 & 0,001 & $6,25927 \mathrm{E}-4$ & 0,28315 & $1,77229 \mathrm{E}-4$ & 0,01472 \\
\hline 28 & 5,96076 & 0,00108 & $6,73887 \mathrm{E}-4$ & 0,2832 & $1,90844 \mathrm{E}-4$ & 0,01585 \\
\hline 29 & 5,96187 & 0,00116 & $7,22713 \mathrm{E}-4$ & 0,28325 & $2,04712 \mathrm{E}-4$ & 0,017 \\
\hline 30 & 5,96306 & 0,00125 & $7,76225 \mathrm{E}-4$ & 0,28331 & 2,19916E-4 & 0,01827 \\
\hline 31 & 5,96434 & 0,00136 & $8,4594 \mathrm{E}-4$ & 0,28338 & $2,39721 \mathrm{E}-4$ & 0,01991 \\
\hline 32 & 5,96575 & 0,00149 & $9,31434 \mathrm{E}-4$ & 0,28345 & $2,64014 \mathrm{E}-4$ & 0,02193 \\
\hline 33 & 5,96731 & 0,00166 & 0,00103 & 0,28353 & $2,93331 \mathrm{E}-4$ & 0,02436 \\
\hline 34 & 5,96905 & 0,00185 & 0,00116 & 0,28361 & $3,27603 \mathrm{E}-4$ & 0,02721 \\
\hline 35 & 5,971 & 0,00208 & 0,00129 & 0,28371 & $3,6707 \mathrm{E}-4$ & 0,03049 \\
\hline 36 & 5,97317 & 0,00232 & 0,00145 & 0,28382 & $4,10899 \mathrm{E}-4$ & 0,03413 \\
\hline 37 & 5,97563 & 0,0026 & 0,00162 & 0,28394 & $4,60159 \mathrm{E}-4$ & 0,03822 \\
\hline 38 & 5,97834 & 0,00293 & 0,00182 & 0,28408 & $5,18061 \mathrm{E}-4$ & 0,04303 \\
\hline 39 & 5,98141 & 0,00328 & 0,00205 & 0,28424 & $5,81318 \mathrm{E}-4$ & 0,04828 \\
\hline
\end{tabular}




\begin{tabular}{|c|c|c|c|c|c|c|}
\hline $\begin{array}{c}\text { Tempo } \\
(\mathrm{s}) \\
\left(^{*}\right)\end{array}$ & $\begin{array}{c}\Delta \mathrm{M} \\
\left(^{*}\right)\end{array}$ & $\frac{d M_{S}}{d t}$ & $\frac{d m}{d t}$ & $\frac{1}{m}$ & $\frac{1}{m} \frac{d m}{d t}$ & $\eta_{\left({ }^{* *}\right)}$ \\
\hline 40 & 5,98491 & 0,00368 & 0,00229 & 0,28441 & 6,52273E-4 & 0,05418 \\
\hline 41 & 5,98875 & 0,00411 & 0,00256 & 0,28461 & $7,29628 \mathrm{E}-4$ & 0,0606 \\
\hline 42 & 5,99307 & 0,00452 & 0,00282 & 0,28482 & $8,02678 \mathrm{E}-4$ & 0,06667 \\
\hline 43 & 5,9979 & 0,00486 & 0,00303 & 0,28507 & 8,63653E-4 & 0,07173 \\
\hline 44 & 6,00295 & 0,00512 & 0,00319 & 0,28532 & $9,10433 \mathrm{E}-4$ & 0,07562 \\
\hline 45 & 6,00812 & 0,00536 & 0,00334 & 0,28559 & $9,53458 \mathrm{E}-4$ & 0,07919 \\
\hline 46 & 6,01357 & 0,00562 & 0,0035 & 0,28586 & 0,001 & 0,08315 \\
\hline 47 & 6,01938 & 0,0059 & 0,00368 & 0,28616 & 0,00105 & 0,08742 \\
\hline 48 & 6,02542 & 0,0062 & 0,00386 & 0,28647 & 0,00111 & 0,09193 \\
\hline 49 & 6,03171 & 0,00654 & 0,00408 & 0,28679 & 0,00117 & 0,09714 \\
\hline 50 & 6,0384 & 0,00699 & 0,00435 & 0,28713 & 0,00125 & 0,10382 \\
\hline 51 & 6,04561 & 0,00757 & 0,00472 & 0,2875 & 0,00136 & 0,11261 \\
\hline 52 & 6,0534 & 0,00828 & 0,00516 & 0,28791 & 0,00148 & 0,12333 \\
\hline 53 & 6,06204 & 0,00911 & 0,00568 & 0,28835 & 0,00164 & 0,13593 \\
\hline 54 & 6,07157 & 0,01007 & 0,00627 & 0,28885 & 0,00181 & 0,15051 \\
\hline 55 & 6,08206 & 0,01109 & 0,00691 & 0,28939 & 0,002 & 0,1661 \\
\hline 56 & 6,09373 & 0,01216 & 0,00758 & 0,29 & 0,0022 & 0,18256 \\
\hline 57 & 6,10641 & 0,01325 & 0,00826 & 0,29067 & 0,0024 & 0,19936 \\
\hline 58 & 6,1202 & 0,01431 & 0,00892 & 0,2914 & 0,0026 & 0,21584 \\
\hline 59 & 6,13508 & 0,01539 & 0,00959 & 0,29219 & 0,0028 & 0,23278 \\
\hline 60 & 6,15094 & 0,01649 & 0,01028 & 0,29304 & 0,00301 & 0,25013 \\
\hline 61 & 6,168 & 0,01764 & 0,01099 & 0,29395 & 0,00323 & 0,26831 \\
\hline 62 & 6,1862 & 0,01883 & 0,01173 & 0,29493 & 0,00346 & 0,28743 \\
\hline 63 & 6,20562 & 0,02003 & 0,01248 & 0,29599 & 0,0037 & 0,3069 \\
\hline 64 & 6,22628 & 0,02125 & 0,01324 & 0,29712 & 0,00394 & 0,32684 \\
\hline 65 & 6,24813 & 0,02249 & 0,01402 & 0,29833 & 0,00418 & 0,34734 \\
\hline 66 & 6,27121 & 0,02378 & 0,01482 & 0,29962 & 0,00444 & 0,36872 \\
\hline 67 & 6,29563 & 0,02509 & 0,01563 & 0,30099 & 0,00471 & 0,39083 \\
\hline 68 & 6,32141 & 0,02642 & 0,01647 & 0,30245 & 0,00498 & 0,41365 \\
\hline 69 & 6,34847 & 0,02777 & 0,01731 & 0,304 & 0,00526 & 0,43694 \\
\hline 70 & 6,37691 & 0,02912 & 0,01815 & 0,30565 & 0,00555 & 0,46072 \\
\hline 71 & 6,40672 & 0,03052 & 0,01902 & 0,30739 & 0,00585 & 0,48555 \\
\hline 72 & 6,43789 & 0,03191 & 0,01988 & 0,30924 & 0,00615 & 0,51071 \\
\hline 73 & 6,47056 & 0,03332 & 0,02076 & 0,3112 & 0,00646 & 0,53664 \\
\hline 74 & 6,50453 & 0,03475 & 0,02166 & 0,31326 & 0,00678 & 0,56352 \\
\hline 75 & 6,53998 & 0,03619 & 0,02255 & 0,31545 & 0,00711 & 0,59092 \\
\hline 76 & 6,57696 & 0,03763 & 0,02345 & 0,31775 & 0,00745 & 0,61883 \\
\hline 77 & 6,61531 & 0,03896 & 0,02428 & 0,32019 & 0,00777 & 0,64559 \\
\hline 78 & 6,655 & 0,04012 & 0,025 & 0,32274 & 0,00807 & 0,67021 \\
\hline 79 & 6,69574 & 0,0411 & 0,02561 & 0,32541 & 0,00833 & 0,69217 \\
\hline 80 & 6,73735 & 0,04192 & 0,02613 & 0,32818 & 0,00857 & 0,71213 \\
\hline 81 & 6,77962 & 0,04268 & 0,0266 & 0,33104 & 0,0088 & 0,73124 \\
\hline 82 & 6,82268 & 0,04341 & 0,02705 & 0,33401 & 0,00904 & 0,75043 \\
\hline
\end{tabular}




\begin{tabular}{|c|c|c|c|c|c|c|}
\hline $\begin{array}{c}\text { Tempo } \\
(\mathrm{s}) \\
\left(^{*}\right)\end{array}$ & $\begin{array}{l}\Delta \mathrm{M} \\
\left(^{*}\right)\end{array}$ & $\frac{d M_{S}}{d t}$ & $\frac{d m}{d t}$ & $\frac{1}{m}$ & $\frac{1}{m} \frac{d m}{d t}$ & $\eta_{\left({ }^{* *}\right)}$ \\
\hline 83 & 6,86646 & 0,04415 & 0,02751 & 0,33708 & 0,00927 & 0,77027 \\
\hline 84 & 6,91097 & 0,0449 & 0,02798 & 0,34026 & 0,00952 & 0,79071 \\
\hline 85 & 6,95622 & 0,04568 & 0,02847 & 0,34356 & 0,00978 & 0,81224 \\
\hline 86 & 7,00228 & 0,04648 & 0,02897 & 0,34698 & 0,01005 & 0,83481 \\
\hline 87 & 7,04919 & 0,04729 & 0,02947 & 0,35053 & 0,01033 & 0,85804 \\
\hline 88 & 7,0969 & 0,04807 & 0,02996 & 0,35423 & 0,01061 & 0,88131 \\
\hline 89 & 7,14538 & 0,04874 & 0,03037 & 0,35806 & 0,01087 & 0,90324 \\
\hline 90 & 7,19453 & 0,04926 & 0,0307 & 0,36203 & 0,01111 & 0,92309 \\
\hline 91 & 7,24406 & 0,04964 & 0,03093 & 0,36612 & 0,01133 & 0,94063 \\
\hline 92 & 7,29387 & 0,04985 & 0,03107 & 0,37033 & 0,0115 & 0,95556 \\
\hline 93 & 7,34389 & 0,04992 & 0,03111 & 0,37465 & 0,01166 & 0,96809 \\
\hline 94 & 7,39388 & 0,04985 & 0,03107 & 0,37908 & 0,01178 & 0,97817 \\
\hline 95 & 7,44367 & 0,04964 & 0,03094 & 0,38359 & 0,01187 & 0,98564 \\
\hline 96 & 7,49325 & 0,04934 & 0,03075 & 0,38819 & 0,01194 & 0,99138 \\
\hline 97 & 7,54243 & 0,04895 & 0,0305 & 0,39286 & 0,01198 & 0,99534 \\
\hline 98 & 7,59121 & 0,04849 & 0,03022 & 0,39761 & 0,01202 & 0,99795 \\
\hline 99 & 7,63944 & 0,048 & 0,02991 & 0,40242 & 0,01204 & 0,99977 \\
\hline 100 & 7,6872 & 0,04743 & 0,02956 & 0,4073 & 0,01204 & 0,99996 \\
\hline 101 & 7,73442 & 0,0468 & 0,02916 & 0,41224 & 0,01202 & 0,99848 \\
\hline 102 & 7,78088 & 0,04607 & 0,02871 & 0,41722 & 0,01198 & 0,99496 \\
\hline 103 & 7,82658 & 0,0453 & 0,02823 & 0,42224 & 0,01192 & 0,9899 \\
\hline 104 & 7,8715 & 0,04448 & 0,02772 & 0,42729 & 0,01184 & 0,98368 \\
\hline 105 & 7,91559 & 0,0436 & 0,02717 & 0,43236 & 0,01175 & 0,97581 \\
\hline 106 & 7,95877 & 0,04265 & 0,02658 & 0,43745 & 0,01163 & 0,96578 \\
\hline 107 & 8,00097 & 0,04162 & 0,02594 & 0,44254 & 0,01148 & 0,95344 \\
\hline 108 & 8,04208 & 0,04052 & 0,02525 & 0,44762 & 0,0113 & 0,93869 \\
\hline 109 & 8,08206 & 0,03936 & 0,02453 & 0,45267 & 0,0111 & 0,92212 \\
\hline 110 & 8,1208 & 0,03816 & 0,02378 & 0,45767 & 0,01088 & 0,904 \\
\hline 111 & 8,15839 & 0,03693 & 0,02302 & 0,46263 & 0,01065 & 0,88437 \\
\hline 112 & 8,19472 & 0,03565 & 0,02222 & 0,46753 & 0,01039 & 0,86276 \\
\hline 113 & 8,22976 & 0,03434 & 0,0214 & 0,47235 & 0,01011 & 0,83954 \\
\hline 114 & 8,26338 & 0,03299 & 0,02056 & 0,47707 & 0,00981 & 0,81469 \\
\hline 115 & 8,29576 & 0,0316 & 0,01969 & 0,48171 & 0,00949 & 0,7878 \\
\hline 116 & 8,32669 & 0,03015 & 0,01879 & 0,48622 & 0,00914 & 0,75878 \\
\hline 117 & 8,35609 & 0,02866 & 0,01786 & 0,49059 & 0,00876 & 0,72767 \\
\hline 118 & 8,38397 & 0,02723 & 0,01697 & 0,49481 & 0,0084 & 0,69749 \\
\hline 119 & 8,41041 & 0,02593 & 0,01616 & 0,49887 & 0,00806 & 0,66965 \\
\hline 120 & 8,43571 & 0,02479 & 0,01545 & 0,50283 & 0,00777 & 0,64523 \\
\hline 121 & 8,45989 & 0,02375 & 0,0148 & 0,50667 & 0,0075 & 0,62273 \\
\hline 122 & 8,48318 & 0,02273 & 0,01417 & 0,51042 & 0,00723 & 0,60053 \\
\hline 123 & 8,5054 & 0,02171 & 0,01353 & 0,51406 & 0,00695 & 0,5776 \\
\hline 124 & 8,52661 & 0,02066 & 0,01287 & 0,51757 & 0,00666 & 0,55345 \\
\hline 125 & 8,54672 & 0,01961 & 0,01222 & 0,52095 & 0,00637 & 0,52869 \\
\hline
\end{tabular}




\begin{tabular}{|c|c|c|c|c|c|c|}
\hline $\begin{array}{c}\text { Tempo } \\
(\mathrm{s}) \\
\left(^{*}\right)\end{array}$ & $\begin{array}{c}\Delta \mathrm{M} \\
\left(^{*}\right)\end{array}$ & $\frac{d M_{S}}{d t}$ & $\frac{d m}{d t}$ & $\frac{1}{m}$ & $\frac{1}{m} \frac{d m}{d t}$ & $\eta_{\left({ }^{* *}\right)}$ \\
\hline 126 & 8,56582 & 0,01854 & 0,01155 & 0,5242 & 0,00605 & 0,5029 \\
\hline 127 & 8,58383 & 0,0175 & 0,0109 & 0,5273 & 0,00575 & 0,47751 \\
\hline 128 & 8,60073 & 0,01647 & 0,01026 & 0,53025 & 0,00544 & 0,45206 \\
\hline 129 & 8,61675 & 0,01547 & 0,00964 & 0,53307 & 0,00514 & 0,42678 \\
\hline 130 & 8,63172 & 0,01451 & 0,00905 & 0,53573 & 0,00485 & 0,40248 \\
\hline 131 & 8,64568 & 0,01362 & 0,00848 & 0,53824 & 0,00457 & 0,37931 \\
\hline 132 & 8,65884 & 0,01278 & 0,00796 & 0,54063 & 0,00431 & 0,35764 \\
\hline 133 & 8,67126 & 0,01201 & 0,00749 & 0,5429 & 0,00406 & 0,33761 \\
\hline 134 & 8,68283 & 0,01131 & 0,00705 & 0,54504 & 0,00384 & 0,31917 \\
\hline 135 & 8,69375 & 0,01067 & 0,00665 & 0,54707 & 0,00364 & 0,30215 \\
\hline 136 & 8,70416 & 0,0101 & 0,00629 & 0,54901 & 0,00345 & 0,28689 \\
\hline 137 & 8,71395 & 0,00954 & 0,00595 & 0,55086 & 0,00328 & 0,27202 \\
\hline 138 & 8,72321 & 0,00901 & 0,00561 & 0,55261 & 0,0031 & 0,25763 \\
\hline 139 & 8,73193 & 0,0085 & 0,0053 & 0,55428 & 0,00294 & 0,24385 \\
\hline 140 & 8,74021 & 0,008 & 0,00499 & 0,55587 & 0,00277 & 0,2303 \\
\hline 141 & 8,74795 & 0,00756 & 0,00471 & 0,55736 & 0,00262 & 0,21798 \\
\hline 142 & 8,75522 & 0,00716 & 0,00446 & 0,55877 & 0,00249 & 0,20697 \\
\hline 143 & 8,7622 & 0,0068 & 0,00424 & 0,56014 & 0,00237 & 0,19725 \\
\hline 144 & 8,76886 & 0,00646 & 0,00403 & 0,56144 & 0,00226 & 0,18783 \\
\hline 145 & 8,77515 & 0,00614 & 0,00382 & 0,56268 & 0,00215 & 0,17873 \\
\hline 146 & 8,78107 & 0,00582 & 0,00363 & 0,56385 & 0,00205 & 0,16992 \\
\hline 147 & 8,78679 & 0,00555 & 0,00346 & 0,56498 & 0,00195 & 0,1623 \\
\hline 148 & 8,79216 & 0,00531 & 0,00331 & 0,56605 & 0,00187 & 0,15559 \\
\hline 149 & 8,79736 & 0,00511 & 0,00318 & 0,56709 & 0,00181 & 0,14999 \\
\hline 150 & 8,80234 & 0,00495 & 0,00308 & 0,56809 & 0,00175 & 0,14554 \\
\hline 151 & 8,80724 & 0,00479 & 0,00298 & 0,56908 & 0,0017 & 0,14099 \\
\hline 152 & 8,81196 & 0,00462 & 0,00288 & 0,57004 & 0,00164 & 0,13642 \\
\hline 153 & 8,81648 & 0,00446 & 0,00278 & 0,57095 & 0,00159 & 0,13168 \\
\hline 154 & 8,82084 & 0,00429 & 0,00267 & 0,57184 & 0,00153 & 0,12704 \\
\hline 155 & 8,82508 & 0,00414 & 0,00258 & 0,57271 & 0,00148 & 0,12263 \\
\hline 156 & 8,82912 & 0,00399 & 0,00249 & 0,57353 & 0,00143 & 0,1184 \\
\hline 157 & 8,83302 & 0,00385 & 0,0024 & 0,57433 & 0,00138 & 0,11455 \\
\hline 158 & 8,83681 & 0,00374 & 0,00233 & 0,57511 & 0,00134 & 0,11146 \\
\hline 159 & 8,8405 & 0,00362 & 0,00226 & 0,57588 & 0,0013 & 0,10796 \\
\hline 160 & 8,8441 & 0,0035 & 0,00218 & 0,57662 & 0,00126 & 0,10448 \\
\hline 161 & 8,84749 & 0,00337 & 0,0021 & 0,57732 & 0,00121 & 0,10062 \\
\hline 162 & 8,85082 & 0,00326 & 0,00203 & 0,57802 & 0,00117 & 0,09754 \\
\hline 163 & 8,85398 & 0,00316 & 0,00197 & 0,57867 & 0,00114 & 0,09478 \\
\hline 164 & 8,85716 & 0,00304 & 0,00189 & 0,57934 & 0,0011 & 0,09107 \\
\hline 165 & 8,86014 & 0,00291 & 0,00181 & 0,57996 & 0,00105 & 0,08724 \\
\hline 166 & 8,86292 & 0,00278 & 0,00173 & 0,58055 & 0,001 & 0,08344 \\
\hline 167 & 8,86563 & 0,0027 & 0,00168 & 0,58112 & $9,77238 \mathrm{E}-4$ & 0,08117 \\
\hline 168 & 8,8683 & 0,00261 & 0,00163 & 0,58168 & $9,47692 \mathrm{E}-4$ & 0,07871 \\
\hline
\end{tabular}




\begin{tabular}{|c|c|c|c|c|c|c|}
\hline $\begin{array}{c}\text { Tempo } \\
(\mathrm{s}) \\
\left(^{*}\right)\end{array}$ & $\begin{array}{l}\Delta \mathrm{M} \\
\left(^{*}\right)\end{array}$ & $\frac{d M_{S}}{d t}$ & $\frac{d m}{d t}$ & $\frac{1}{m}$ & $\frac{1}{m} \frac{d m}{d t}$ & $\underset{\left({ }^{* *}\right)}{\eta}$ \\
\hline 169 & 8,87095 & 0,00252 & 0,00157 & 0,58224 & $9,15731 \mathrm{E}-4$ & 0,07606 \\
\hline 170 & 8,87333 & 0,00244 & 0,00152 & 0,58274 & $8,85078 \mathrm{E}-4$ & 0,07351 \\
\hline 171 & 8,87573 & 0,00235 & 0,00147 & 0,58325 & $8,55517 \mathrm{E}-4$ & 0,07106 \\
\hline 172 & 8,8781 & 0,00228 & 0,00142 & 0,58375 & $8,30826 \mathrm{E}-4$ & 0,06901 \\
\hline 173 & 8,88034 & 0,00222 & 0,00139 & 0,58423 & $8,09211 \mathrm{E}-4$ & 0,06721 \\
\hline 174 & 8,88245 & 0,00217 & 0,00135 & 0,58468 & 7,89787E-4 & 0,0656 \\
\hline 175 & 8,88466 & 0,0021 & 0,00131 & 0,58515 & $7,65282 \mathrm{E}-4$ & 0,06356 \\
\hline 176 & 8,88677 & 0,00203 & 0,00127 & 0,5856 & $7,41785 \mathrm{E}-4$ & 0,06161 \\
\hline 177 & 8,88867 & 0,00192 & 0,0012 & 0,58601 & $7,02633 \mathrm{E}-4$ & 0,05836 \\
\hline 178 & 8,89061 & 0,00184 & 0,00114 & 0,58642 & $6,70789 \mathrm{E}-4$ & 0,05571 \\
\hline 179 & 8,89237 & 0,00179 & 0,00112 & 0,5868 & $6,5434 \mathrm{E}-4$ & 0,05435 \\
\hline 180 & 8,8941 & 0,00174 & 0,00109 & 0,58717 & $6,37411 \mathrm{E}-4$ & 0,05294 \\
\hline 181 & 8,89587 & 0,00173 & 0,00108 & 0,58755 & $6,31959 \mathrm{E}-4$ & 0,05249 \\
\hline 182 & 8,89757 & 0,0017 & 0,00106 & 0,58792 & $6,22986 \mathrm{E}-4$ & 0,05174 \\
\hline 183 & 8,89926 & 0,00167 & 0,00104 & 0,58828 & $6,11382 \mathrm{E}-4$ & 0,05078 \\
\hline 184 & 8,90091 & 0,00165 & 0,00103 & 0,58864 & $6,0444 \mathrm{E}-4$ & 0,0502 \\
\hline 185 & 8,90254 & 0,00163 & 0,00101 & 0,58899 & $5,97171 \mathrm{E}-4$ & 0,0496 \\
\hline 186 & 8,90417 & 0,00161 & 0,001 & 0,58934 & 5,91957E-4 & 0,04917 \\
\hline 187 & 8,90577 & 0,00161 & 0,001 & 0,58969 & $5,9024 \mathrm{E}-4$ & 0,04902 \\
\hline 188 & 8,90735 & 0,00159 & $9,91664 \mathrm{E}-4$ & 0,59003 & $5,85112 \mathrm{E}-4$ & 0,0486 \\
\hline 189 & 8,90898 & 0,00157 & $9,76452 \mathrm{E}-4$ & 0,59038 & $5,76482 \mathrm{E}-4$ & 0,04788 \\
\hline 190 & 8,91052 & 0,00153 & $9,51313 \mathrm{E}-4$ & 0,59072 & $5,61958 \mathrm{E}-4$ & 0,04667 \\
\hline 191 & 8,91202 & 0,00148 & $9,19812 \mathrm{E}-4$ & 0,59105 & $5,4365 \mathrm{E}-4$ & 0,04515 \\
\hline 192 & 8,91346 & 0,00145 & $9,01983 \mathrm{E}-4$ & 0,59136 & $5,33396 \mathrm{E}-4$ & 0,0443 \\
\hline 193 & 8,91488 & 0,00144 & $8,94617 \mathrm{E}-4$ & 0,59167 & $5,29318 \mathrm{E}-4$ & 0,04396 \\
\hline 194 & 8,91632 & 0,00143 & $8,89382 \mathrm{E}-4$ & 0,59198 & $5,26499 \mathrm{E}-4$ & 0,04373 \\
\hline 195 & 8,91777 & 0,00144 & $8,94436 \mathrm{E}-4$ & 0,5923 & $5,29774 \mathrm{E}-4$ & 0,044 \\
\hline 196 & 8,91916 & 0,00143 & $8,90809 \mathrm{E}-4$ & 0,5926 & $5,27896 \mathrm{E}-4$ & 0,04385 \\
\hline 197 & 8,92064 & 0,00138 & $8,62523 \mathrm{E}-4$ & 0,59293 & $5,11414 \mathrm{E}-4$ & 0,04248 \\
\hline 198 & 8,92203 & 0,00132 & $8,21275 \mathrm{E}-4$ & 0,59323 & 4,87207E-4 & 0,04047 \\
\hline 199 & 8,92325 & 0,0012 & $7,50313 \mathrm{E}-4$ & 0,5935 & $4,45311 \mathrm{E}-4$ & 0,03699 \\
\hline 200 & 8,92444 & 0,0011 & $6,86961 \mathrm{E}-4$ & 0,59376 & 4,07892E-4 & 0,03388 \\
\hline
\end{tabular}

Obs.: $\left.\quad{ }^{*}\right)$ Dados obtidos experimentalmente

$\left.{ }^{(* *}\right)$ Valores calculados 